\title{
OPTICAL PROPERTIES OF TURBID COASTAL WATER AND THEIR REMOTE SENSING RETRIEVALS BASED ON RADIATIVE TRANSFER APPROACHES
}





\title{
OPTICAL PROPERTIES OF TURBID COASTAL WATER AND THEIR REMOTE SENSING RETRIEVALS BASED ON RADIATIVE TRANSFER APPROACHES
}

\author{
DISSERTATION
}

to obtain

the degree of doctor at the University of Twente, on the authority of the rector magnificus, prof.dr. T.T.M. Palstra

on account of the decision of the Doctorate Board, to be publicly defended

on Friday March 29, 2019 at 14.45 hrs

by

Xiaolong $\mathrm{Yu}$

Born on January 2, 1990

In Lu'an, Anhui, China 
This thesis has been approved by:

Prof.dr.ing. W. Verhoef, supervisor

dr.ir. S. Salama, co-supervisor

Prof.dr. F. Shen, co-supervisor

ITC dissertation number 346

ITC, P.O. Box 217, 7500 AE Enschede, The Netherlands

ISBN 978-90-365-4738-3

DOI 10.3990/1.9789036547383

Cover designed by Job Duim

Printed by ITC Printing Department

Copyright (C) 2019 by Xiaolong Yu

- 1 C Faculty OF gEO-INFORMATION SCIENCE AND EARTH OBSERVATION 
Graduation committee

\section{Chairman/Secretary}

Prof.dr.ir. A. Veldkamp

\section{Supervisor}

Prof.dr.ing. W. Verhoef

\section{Co-supervisors}

Dr.ir. S. Salama

Prof.dr. F. Shen

\section{Members}

Prof.dr. D. van der Wal

Dr.ir. C. Mannaerts

Prof.dr. Z. Lee

Prof.dr. T. Kutser

Dr. D. Doxaran

Dr. D. Simis
University of Twente

University of Twente

East China Normal University

University of Twente

University of Twente

University of Massachusetts, Boston

University of Tartu

Villefrance Oceanographic Laboratory, France

Plymouth Marine Laboratory, UK 



\section{Summary}

Radiative transfer theory describes how light, regarding its spectral radiance, travels and varies along any specific path at a specified point in the water, and ties together the water apparent optical properties (AOPs) and inherent optical properties (IOPs) through the radiative transfer equations (RTEs). In this study, the author used the analytical 2SeaColor model, which is based on the approximate solution of RTEs using two-stream approach, to retrieve IOPs, diffuse attenuation coefficient $\left(K_{d}\right.$, in $\left.\mathrm{m}^{-1}\right)$, and the concentration of suspended particulate matter $\left(C_{\mathrm{SPM}}\right.$, in $\left.\mathrm{mg} / \mathrm{L}\right)$ in the turbid Yangtze estuary. The application of 2 SeaColor to the GOCI geostationary sensors has enabled a better understanding of the diurnal cycle of suspended sediment in the study area. The known linear relationship between $C_{\mathrm{SPM}}$ and particulate backscattering coefficient $\left(b_{b p}\right.$, in $\left.\mathrm{m}^{-1}\right)$, was investigated, using 2SeaColor retrievals and field measurements. Although the validity of the linear relationship was confirmed for relatively clear waters, the author showed that in turbid waters, nonlinearity governs the relationship between $C_{\mathrm{SPM}}$ and $b_{b p}$. The two respective relationships between $C_{\mathrm{SPM}}$ and $b_{b p}$ for relatively clear and turbid waters were further integrated using a sigmoid function to retrieve wide-range $C_{\mathrm{SPM}}$ without the need for a switching scheme. Apart from SPM, colored dissolved organic matter (CDOM) also significantly reduces light transparency and contributes to the complexity of the optical properties in the Yangtze estuary. Thereby, the author has also investigated the seasonal variability of CDOM absorption properties. Finally, the author proposed a locally calibrated model to estimate the concentration of dissolved organic carbon (DOC). The summary of the major results obtained from this dissertation is briefly described in the following.

The thesis is structured in six chapters, of which the first chapter describes the background of ocean color remote sensing in optically complex waters and the second chapter explains the physical principals of the 2 SeaColor model. In Chapter 3, the author first proposed improved IOPs parameterizations to the analytical 2SeaColor model to account for the complex optical properties in the Yangtze estuary. The improved 2SeaColor model was later employed to derive the diffuse attenuation coefficient $\left(K_{d}\right.$, in $\left.\mathrm{m}^{-1}\right)$ from remote sensing reflectance $\left(R_{r s}\right.$, in $\left.\mathrm{sr}^{-1}\right)$. Retrievals from the improved model were then validated with three in-situ datasets and compared with an empirical (the Zhang model) and a semianalytical model (the Lee model). Statistics from the validation results show that the 2 SeaColor model provides the best estimates of $K_{d}$ for the full range of 
observations, with the largest determination coefficient $\left(R^{2}=0.935\right)$ and the smallest root mean squared error $\left(\mathrm{RMSE}=0.078 \mathrm{~m}^{-1}\right)$. For clear waters, where $K_{d}(490)<0.2 \mathrm{~m}^{-1}$, the Zhang model provides the most accurate $K_{d}$ estimations, but results from the Lee model and the 2 SeaColor are comparable. For turbid waters, where $K_{d}(490)>0.2 \mathrm{~m}^{-1}$, the 2 SeaColor model is found to be more accurate, with an RMSE of $0.186 \mathrm{~m}^{-1}$, compared to RMSEs of $0.279 \mathrm{~m}^{-1}$ and 0.388 $\mathrm{m}^{-1}$ for the Zhang model and the Lee model, respectively. The improved 2SeaColor model is finally applied to the GOCI (Geostationary Ocean Color Imager) level 2 product to produce $K_{d}$ maps over the Yangtze estuary, resulting in a reasonable distribution and expected range of $K_{d}$ for the Yangtze estuary, while the Zhang model and the Lee model show the potential of underestimation and overestimation, respectively. The consistently stable and accurate $K_{d}$ estimates in both clear and turbid waters show great potentials of the 2SeaColor model for estimating $K_{d}$ over optically complex waters.

In Chapter 4, the author proposed a novel model to quantitatively estimate the concentration of SPM $\left(C_{\mathrm{SPM}}\right.$, in $\left.\mathrm{mg} / \mathrm{L}\right)$ from remotely sensed particulate backscattering $\left(b_{b p}\right.$, in $\left.\mathrm{m}^{-1}\right) . b_{b p}$ of both clear and turbid waters were first retrieved by the improved 2 SeaColor model, and then the relationships between $b_{b p}$ and $C_{\text {SPM }}$ were calibrated for a wide-range of $C_{\text {SPM }}$ from 0.4 to $2068.8 \mathrm{mg} / \mathrm{L}$. Calibration results show that $b_{b p}$ and $C_{\mathrm{SPM}}$ are linearly correlated for relatively clear waters, but their relationship becomes significantly curved for turbid water. To avoid the discontinuity issue resulted from the two respective $b_{b p}-C_{\mathrm{SPM}}$ relationships for clear and turbid waters, an index of $b_{b p}\left(S_{\text {index }}\right)$ was introduced based on a sigmoid function to retrieve $C_{\mathrm{SPM}}$. The $S_{\text {index }}-C_{\mathrm{SPM}}$ model was calibrated using a calibration (Cal) dataset and then validated with the validation (Val) dataset. Validation results show that the $S_{\text {index }}-C_{\mathrm{SPM}}$ model has overall better retrieval accuracy $(\mathrm{rMAD}=33.4 \%)$ compared with the re-calibrated $\mathrm{He}$ model $(\mathrm{rMAD}=185.2 \%)$ and the GOCI SPM model $(\mathrm{rMAD}=50.2 \%)$. For extremely turbid waters, these three models show comparable performance with rMAD of $15.29 \%, 12.72 \%$, and $17.22 \%$ for the $S_{\text {index }}-C_{\mathrm{SPM}}$ model, the GOCI SPM model, and the $H e$ model, respectively. The $S_{\text {index }}-C_{\mathrm{SPM}}$ model, without tuning the empirical constants, was also applied to an independent SeaSWIR dataset collected from the estuaries of Europe and Argentina with measured $C_{\text {SPM }}$ up to $1400 \mathrm{mg} / \mathrm{L}$. Validation results show a very promising retrieval accuracy with rMAD of $30.3 \%$ without tuning the empirical coefficients, indicating the potential good transferability of the $S_{\text {index }}-C_{\mathrm{SPM}}$ model among global turbid coastal waters. Further, the three models were implemented on the GOCI image acquired 
at 02:16 UTC, March $8^{\text {th }}$ of 2013 to generate the SPM mapping products for the Yangtze estuary, where discontinues are observed for the switching-based GOCI SPM model at the front of the turbid plume, while the $S_{\text {index }}-C_{\mathrm{SPM}}$ model produced a smooth and realistic SPM mapping product. At last, the $S_{\text {index }}-C_{\mathrm{SPM}}$ model was applied to 8 GOCI images acquired on March $8^{\text {th }}$ of 2013 to investigate the diurnal variation of $C_{\mathrm{SPM}}$, and the comparison with tide information shows that the predicted $C_{\mathrm{SPM}}$ can be well explained by hydrologic processes, which further enhanced our confidence in the reliability and repeatability of the $S_{\text {index }}-C_{\mathrm{SPM}}$ model.

In Chapter 5, the author investigated the seasonal variability of CDOM absorption properties and its relationship between salinity and dissolved organic carbon (DOC). The CDOM absorption coefficient at $355 \mathrm{~nm}\left(a_{g}(355)\right)$ was found to be inversely correlated with salinity, with Pearson's coefficients $r$ of -0.901 and 0.826 for summer and winter observations, respectively. Analysis results of the relationships between salinity and CDOM optical properties (i.e., absorption coefficient and spectral slope) suggested that terrigenous inputs dominated CDOM sources in the Yangtze estuary, but the proportion of terrigenous CDOM declined with increasing salinity. Resuspension of bottom sediments could be an important source of CDOM in the winter. We further developed an empirical model to estimate DOC concentration from $a_{g}$ (355) and spectral slope $S_{275-295}$ using the calibration dataset by non-linear regression. The developed model was validated with the validation dataset, resulting in an acceptable error with a determination coefficient $\left(R^{2}\right)$ of 0.746 , a root mean squared error (RMSE) of $20.99 \mu \mathrm{mol} / \mathrm{L}$ and a mean relative absolute error (rMAD) of $14.46 \%$. This empirical model could be potentially adopted in retrieving DOC concentration using ocean color remote sensing over the Yangtze estuarine and coastal waters. 


\section{Samenvatting}

De theorie van stralingsoverdracht beschrijft hoe licht, in eenheden van spectrale radiantie, zich voortplant and varieert over elke specifieke weg in het water, en verbindt de schijnbare optische eigenschappen (apparent optical properties of AOP's) van water met de inherente optische eigenschappen (inherent optical properties of IOP's) via de vergelijkingen voor stralingstransport. In deze studie heeft de auteur het analytische model 2SeaColor gebruikt, dat is gebaseerd op een vereenvoudigde oplossing van de stralingstransportvergelijkingen met de tweestromen benadering, om IOP's and concentraties van opgeloste deeltjes $\left(C_{\mathrm{SPM}}\right.$, in $\left.\mathrm{mg} / \mathrm{L}\right)$ te bepalen in het zeer troebele Yangtze estuarium. De toepassing van 2SeaColor op de sensoren van de GOCI geostationaire satelliet heeft een beter begrip mogelijk gemaakt van de dagelijkse cyclus in het zwevend sediment in het studiegebied. Het bekende lineaire verband tussen $C_{\mathrm{SPM}}$ en de deeltjes backscattercoëfficiënt $\left(b_{b p}\right.$, in $\left.\mathrm{m}^{-1}\right)$ is onderzocht door middel van 2SeaColor bepalingen en veldmetingen. Hoewel de geldigheid van dit lineaire verband werd bevestigd voor relatief heldere wateren, toont de auteur aan dat in troebel water het verband gekenmerkt wordt door niet-lineariteit. De twee respectievelijke verbanden tussen $C_{\mathrm{SPM}}$ en $b_{b p}$ voor relatief heldere en troebele wateren zijn verder geïntegreerd met een sigmoide functie om $C_{\mathrm{SPM}}$ over een breed bereik te kunnen bepalen zonder gebruik te maken van een schakelmechanisme. Naast SPM, reduceren ook gekleurde opgeloste stoffen (colored dissolved organic matter, of CDOM) de transparantie voor licht en dragen deze bij aan de complexiteit van de optische eigenschappen in het Yangtze estuarium. Daarom heeft de auteur ook de seizoensafhankelijke variabiliteit in absorptie-eigenschappen van deze stoffen in het Yangtze estuarium onderzocht. Tenslotte formuleerde de auteur een lokaal geijkt model om de concentratie van opgeloste organische koolstof (dissolved organic carbon, of DOC) te schatten. Een overzicht van de voornaamste resultaten verkregen in deze dissertatie wordt hieronder beschreven.

De dissertatie is gestructureerd in zes hoofdstukken, waarvan het eerste hoofdstuk de achtergronden beschrijft van ocean color remote sensing in optisch complexe wateren en het tweede hoofdstuk de fysische principes verklaart van het 2SeaColor model. In Hoofdstuk 3 stelt de auteur eerst verbeterde IOP parametrisaties voor in het analytische 2 SeaColor model teneinde rekening te kunnen houden met de complexe optische eigenschappen in het Yangtze estuarium. Het verbeterde 2SeaColor model werd later ingezet om de diffuse uitdovingscoëfficiënt $\left(K_{d}\right.$, in $\left.\mathrm{m}^{-1}\right)$ af te leiden uit de remote sensing reflectie $\left(R_{r s}\right.$, 
in $\left.\mathrm{sr}^{-1}\right)$. Bepalingen met het verbeterde model zijn vervolgens gevalideerd met drie in-situ datasets en vergeleken met een empirisch model (het Zhang model) en met een semi-analytisch model (het Lee model). De statistiek van de validatieresultaten laat zien dat het 2 SeaColor model de beste schattingen geeft van $K_{d}$ over het gehele bereik van de waarnemingen, met de hoogste determinatiecoëfficiënt $\left(R^{2}=0.935\right)$ en de kleinste root mean squared error $\left(\right.$ RMSE $\left.=0.078 \mathrm{~m}^{-1}\right)$. Voor heldere wateren, met $K_{d}(490)<0.2 \mathrm{~m}^{-1}$, geeft het Zhang model de nauwkeurigste $K_{d}$ schattingen, maar de resultaten van het Lee model en 2SeaColor zijn redelijk vergelijkbaar. Voor troebel water, waar $K_{d}$ (490) $>0.2 \mathrm{~m}^{-1}$, werd gevonden dat 2SeaColor nauwkeuriger is, met een RMSE van $0.186 \mathrm{~m}^{-1}$, vergeleken met RMSE's van $0.279 \mathrm{~m}^{-1}$ en $0.388 \mathrm{~m}^{-1}$ voor respectievelijk het Zhang model en het Lee model. Het verbeterde 2SeaColor model is uiteindelijk toegepast op het GOCI (Geostationary Ocean Color Imager) level 2 product om $K_{d}$ kaarten te maken van het Yangtze estuarium, wat resulteerde in een redelijke verdeling en een verwacht bereik van $K_{d}$ voor dit gebied, terwijl het Zhang model en het Lee model respectievelijk onderschatting en overschatting kunnen laten zien. De consequent stabiele en nauwkeurige $K_{d}$ schattingen in zowel helder als troebel water tonen een groot potentieel van het 2SeaColor model voor het schatten van $K_{d}$ in optisch complexe wateren.

In Hoofdstuk 4 introduceert de auteur een nieuw model voor het kwantitatief schatten van de concentratie van SPM $\left(C_{\mathrm{SPM}}\right.$, in $\left.\mathrm{mg} / \mathrm{L}\right)$ uit de met remote sensing bepaalde deeltjes backscatter coëfficiënt $\left(b_{b p}\right.$, in $\left.\mathrm{m}^{-1}\right)$. De $b_{b p}$ van zowel heldere als troebele wateren zijn eerst bepaald met het verbeterde 2SeaColor model, en vervolgens zijn de verbanden tussen $b_{b p}$ en $C_{\mathrm{SPM}}$ geijkt over een breed bereik van $C_{\mathrm{SPM}}$ van 0.4 tot $2068.8 \mathrm{mg} / \mathrm{L}$. Calibratieresultaten laten zien dat $b_{b p}$ en $C_{\mathrm{SPM}}$ lineair zijn gecorreleerd voor relatief heldere wateren, maar het verband wordt sterk kromlijnig voor troebel water. Om discontinuïteit als gevolg van de twee respectievelijke $b_{b p}-C_{\mathrm{SPM}}$ verbanden voor helder en troebel water te vermijden is een index van $b_{b p}\left(S_{\text {index }}\right)$ geïntroduceerd die is gebaseerd op een sigmoidefunctie om $C_{\mathrm{SPM}}$ te bepalen. Het $S_{\text {index }}-C_{\mathrm{SPM}}$ model is gecalibreerd met een Cal dataset en vervolgens gevalideerd met een Val dataset. Validatieresultaten laten zien dat het $S_{\text {index }}-C_{\mathrm{SPM}}$ model over het geheel een betere schattingsnauwkeurigheid heeft (relative mean absolute deviation $\mathrm{rMAD}=33.4 \%$ ) vergeleken met het gehercalibreerde He model ( $\mathrm{rMAD}=185.2 \%$ ) en het GOCI SPM model (rMAD $=50.2 \%$ ). Voor extreem troebele wateren laten deze drie modellen vergelijkbare prestaties zien, met respectievelijk een rMAD van $15.29 \%, 12.72 \%$, en $17.22 \%$ voor het $S_{\text {index }}-C_{\text {SPM }}$ model, het GOCI SPM model, en het He model. Het $S_{\text {index }}$ 
$C_{\text {SPM }}$ model, zonder aanpassingen aan de empirische coëfficiënten, is ook toegepast op een totaal onafhankelijke SeaSWIR dataset verzameld in estuaria in Europa en Argentinië met gemeten $C_{\mathrm{SPM}}$ tot $1400 \mathrm{mg} / \mathrm{L}$. De validatieresultaten tonen een veelbelovende schattingsnauwkeurigheid met een rMAD van $30.3 \%$ zonder bijstelling van de empirische coëfficiënten, wat wijst op een goede overdraagbaarheid van het $S_{\text {index }}-C_{\mathrm{SPM}}$ model naar de troebele kustwateren wereldwijd. Verder zijn de drie modellen toegepast op een GOCI beeld opgenomen om 2:26 uur UTC op 8 maart 2013 om SPM kaartproducten te genereren voor het Yangtze estuarium, waar discontinuïteiten worden waargenomen met het geschakelde GOCI SPM model bij het front van een troebele pluim, terwijl het $S_{\text {index }}-C_{\mathrm{SPM}}$ model een geleidelijk en realistisch SPM kaartproduct genereerde. Tenslotte is het $S_{\text {index }}-C_{\mathrm{SPM}}$ model toegepast op acht GOCI beelden, ook opgenomen op 8 maart 2013, om de dagelijkse variaties in $C_{\mathrm{SPM}}$ te onderzoeken, en de vergelijking met getijde-informatie laat zien dat de voorspelde $C_{\mathrm{SPM}}$ goed kan worden verklaard door hydrologische processen, hetgeen ons vertrouwen in de betrouwbaarheid en de herhaalbaarheid van het $S_{\text {index }}-C_{\mathrm{SPM}}$ verder versterkte.

In Hoofdstuk 5 heeft de auteur de seizoensafhankelijke variabiliteit in de absorptie-eigenschappen van CDOM onderzocht en de relaties hiervan met zoutgehalte en opgeloste organische koolstof (DOC). Voor de CDOM absorptiecoëfficiënt bij $355 \mathrm{~nm}\left(a_{g}(355)\right)$ werd gevonden dat deze negatief gecorreleerd was aan het zoutgehalte, met Pearson coëfficiënten $r$ van -0.901 en -0.826 voor waarnemingen in respectievelijk de zomer en winter. Resultaten van de analyse van de relaties tussen zoutgehalte en CDOM optische eigenschappen (d.w.z. de absorptiecoëfficiënt en de spectrale helling) suggereren dat CDOM bronnen worden gedomineerd door materiaal van terrigene oorsprong in het Yangtze estuarium, maar het aandeel van terrigeen CDOM nam af met toenemend zoutgehalte. Hersuspensie van bodemsedimenten zou een belangrijke bron van CDOM in de winter kunnen zijn. We hebben verder een empirisch model ontwikkeld om de DOC concentratie te schatten uit $a_{g}(355)$ en de spectrale helling $S_{275-295}$ door gebruik te maken van de calibratie dataset via niet-lineaire regressie. Het ontwikkelde model is gevalideerd met de validatie dataset, wat resulteerde in een acceptabele fout met een determinatiecoëfficiënt $\left(R^{2}\right)$ van 0.746 , een RMSE van $20.99 \mu \mathrm{mol} / \mathrm{L}$ en een rMAD van $14.46 \%$. Dit empirische model zou potentieel geadopteerd kunnen worden voor het schatten van DOC concentraties met ocean color remote sensing boven het Yangtze estuarium en de nabije kustwateren. 


\section{Acknowledgments}

I could never complete this thesis without the help and supports from my families, supervisors, friends, and many others, who had made invaluable contributions, directly and indirectly, to this Ph.D. research. To all of them, I would like to express my sincere gratitudes.

My first and foremost thank you goes to my promoter Prof. dr. Wouter Verhoef for his invitation, which made my Ph.D. journey possible in the Netherlands. I feel so fortunate and greatly honored to have him as my promoter. He introduced me into the field of radiative transfer theory and his constant encouragement and great patience inspired me to devote myself to this field, which become the fundamental basis of this Ph.D. research. His highly learned knowledge and valuable insights got me through all the problems and challenges in my Ph.D. research. What I appreciate most is that he is always supportive whenever I had a question or request. I doubt that I can get to this point without his unstinting guidance and immense support.

I am sincerely grateful to my co-supervisor Dr. ir. Mhd. Suhyb Salama for his professional supervision and guidance. To me, he is more than a supervisor; he is also a friend who shares with me not only knowledge but also the experiences of both work and life. He has always been supportive and helpful whenever I got stuck in the research. I do appreciate all the effort he had made to make my life and research easy. Knowledge is not the only thing I learned from him, one of the most important qualities I learned is to do scientific research with passion, dedication and rigorous attitude, which helped me overcome all the obstacles that emerged in my research. I believe this quality, as well as other qualities in him, will continue to cultivate my scientific thinking and shape my research career.

I am eternally grateful to Prof. dr. Fang Shen who has been my supervisor since 2010 in East China Normal University. Words are not enough to express my gratitude. It was her encouragement and trust that made me determined to apply for the fellowship from the China Scholarship Council to support this Ph.D. research. I would like to thank her for having faith in me all the time and always encouraging me to exploit my potential and achieve more. I appreciate all the opportunities she offered that allowed me to develop myself in both personal quality and academic study. She has put considerable time and effort into supervising me through my postgraduate study and Ph.D. study, for which I will 
be forever in debt to her. I am also appreciated for her generosity in providing all the in-situ data for this Ph.D. research, which makes this thesis possible.

Special thanks to Prof. dr. Zhongbo. Su (Bob) for his excellent management of the department and providing a comfortable academic environment where I can focus only on my research. Many thanks to E.L. Butt - Castro (Tina), J. de Koning (Anke), Loes Colenbrander and other staff and faculty members for their administrative assistance and support during my stay in ITC. I also would like to express earnest gratitude to my officemates and colleagues, $\mathrm{Xu}$, Behnaz, Isabel, Novi, Shaoning, Peiqi, Junping, Binbin, Chengliang, Qiang, Bagher, Moiteela, Jan and many others, for the wonderful talks and discussions we had. I am glad that we have the Ph.D. workshop where Ph.D. students can exchange ideas. The interesting reports and presentations from them broadened my perspective and renewed my understanding of different research aspects regarding the lifefundamental element, water.

I am also grateful that there is a lovely and supportive Chinese community in Enschede, where I can always find assistance when I needed it. Many thanks to Xu Yuan, Binbin, Chengliang, Donghai, Hong Zhao, Jing Liu, Junping, Lianyu, Mandy, Peiqi, Ruosha, Shaoning, Wen Bai, Xiaojing, Xiaoling, Xi Zhu, Xuelong, Yifang, Yijian, Ying Huang, Youwen and many others for the help and support. It is my pleasure to be one of the communities and thanks for the parties, trips, and activities we had together, those beautiful memories will never fade away.

I acknowledge the fellowship from the China Scholarship Council that financially support my stay in the Netherlands. Without support from CSC, I could never be able to complete this thesis.

At last, to my parents, grandparents, and sisters, thanks for holding my back and always supporting me on every decision I made. We had very tough days when I was a child, and it was their unconditional love, and unwavering support got me through. I am grateful to have them all by my side when I finally get the Ph.D. degree after two decades of hard study. Thanks for always being proud of me, which motivated me to work harder and be a better person. This thesis is dedicated to my family.

"All endings are new beginnings." 
At the time I complete this thesis, I do realize it is just the beginning of a new chapter of my life and career. There will undoubtedly be more challenges ahead, but thanks to my families, supervisors, and friends, I am well prepared now.

For Mom (ChuanXia Zhang) and Dad (Yu Zhang) 


\section{Contents}

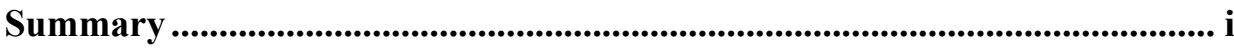

Samenvatting ........................................................................................................

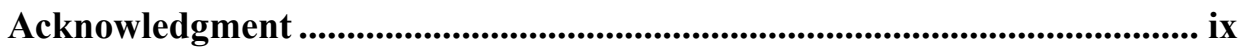

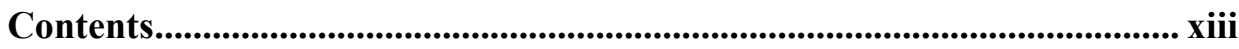

Lists of abbreviations and symbols ...................................................... xvii

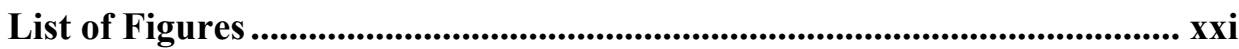

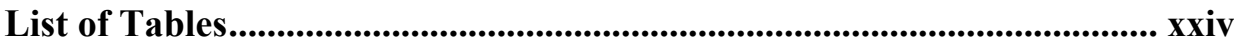

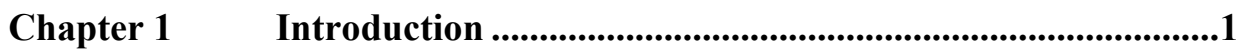

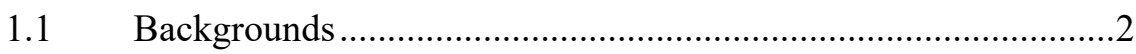

1.1.1 Development of the atmospheric correction algorithm ............4

1.1.2 Retrieval of IOPs and the concentrations of in-water

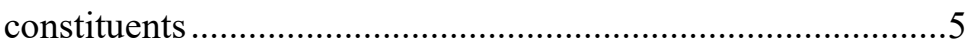

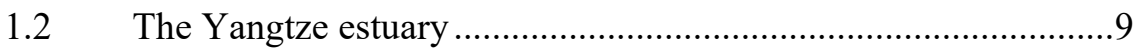

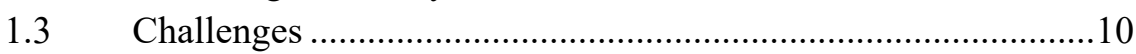

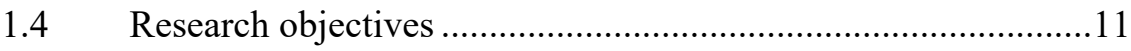

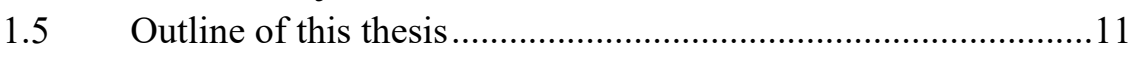

Chapter 2 Principal Basics and Methods ................................................13

$2.1 \quad$ Radiative transfer in the water.................................................. 14

2.2 The 2SeaColor model ................................................................15

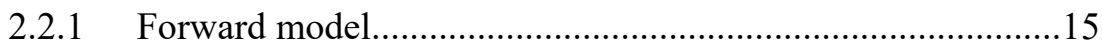

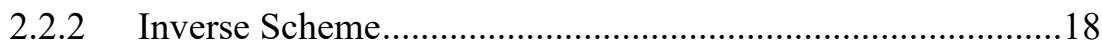

2.3 Models sensitivities to SPM concentration ................................20

Chapter 3 Retrieval of the diffuse attenuation coefficient using the

2SeaColor model: A case study in the Yangtze Estuary .................................23

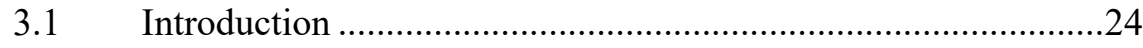

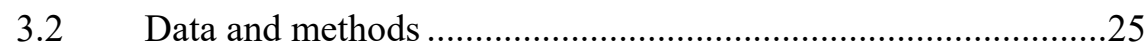

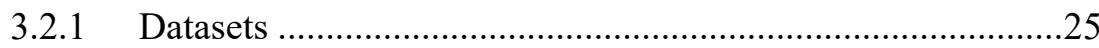

3.2.2 GOCI images and atmospheric correction.............................29

3.2.3 The 2SeaColor model ........................................................... 31

3.2.4 The Zhang model and the Lee model ......................................31

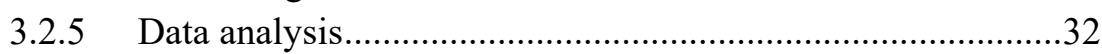

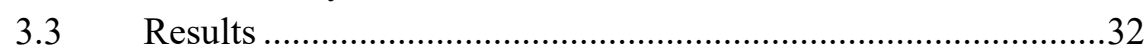

3.3.1 Improvement on the parameterizations .................................32

3.3.2 Validation and inter-comparison for $\mathrm{K}_{\mathrm{d}}$ retrieval models........33

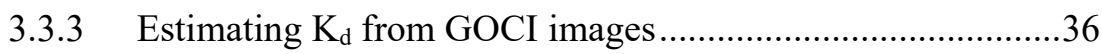

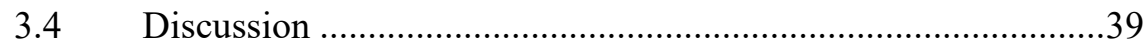




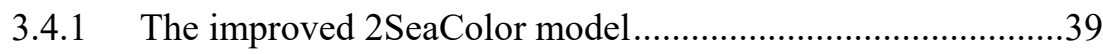

3.4.2 Assessments of $\mathrm{K}_{\mathrm{d}}$ retrieval models..........................................41

3.4.3 Variation of $\mathrm{K}_{\mathrm{d}}$ maps in Yangtze Estuary ................................42

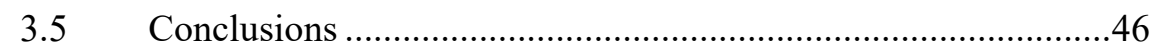

Chapter 4 Retrieval of wide-range suspended particulate matter concentration from remotely sensed particulate backscattering coefficients ..............................................................47

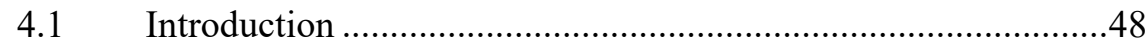

4.2 Data and methods ................................................................49

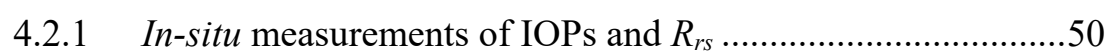

4.2.2 Field sampling and Lab measurements .................................52

4.2.3 Atmospheric correction of GOCI images ................................53

4.2.4 Retrieval models for SPM concentration................................56

4.2.5 Scattering correction for particulate absorption measured by

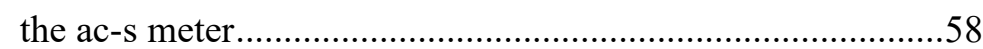

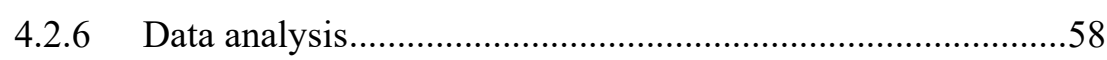

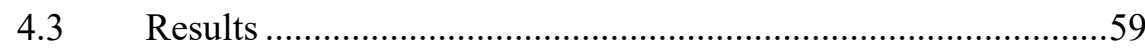

4.3.1 Quality assurance of in-situ measured IOPs............................59

4.3.2 Validation of retrieved IOPs by the 2SeaColor model ...........61

4.3.3 $\mathrm{Cal} / \mathrm{Val}$ of the SPM retrieval model ......................................62

4.3.4 Mapping SPM concentrations in the Yangtze estuary.............65

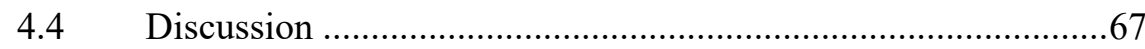

4.4.1 Uncertainties in the atmospheric correction algorithm...........67

4.4.2 The proposed $S_{\text {index }}-C_{\mathrm{SPM}}$ model..........................................68

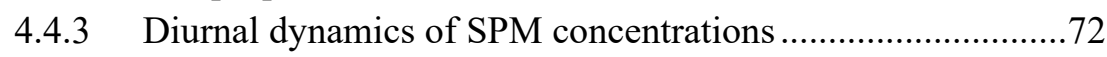

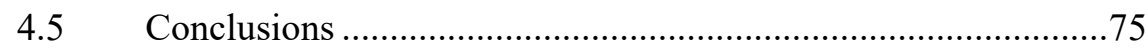

Chapter 5 Light absorption properties of CDOM in the Yangtze estuarine and coastal waters: an alternative approach for DOC

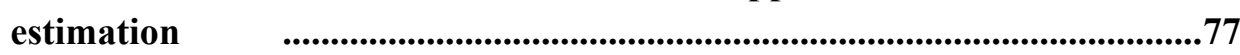

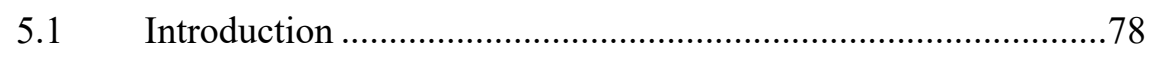

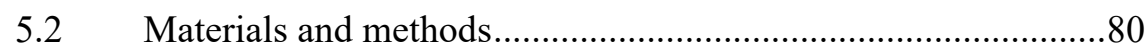

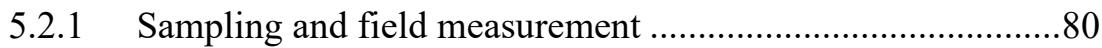

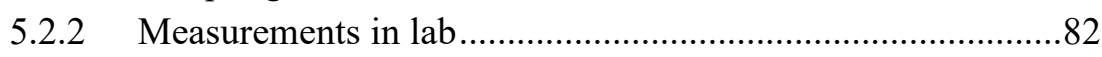

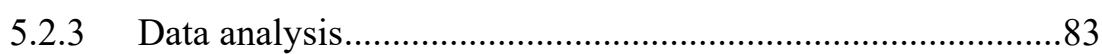

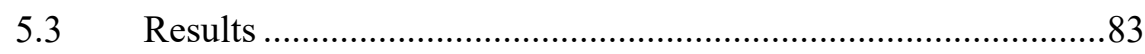

5.3.1 CDOM light absorption and its spatial-temporal distribution 83

5.3.2 CDOM absorption coefficient and salinity............................86

5.3.3 Spectral slope of CDOM absorption and salinity ...................87 


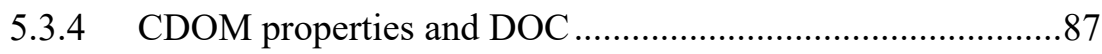

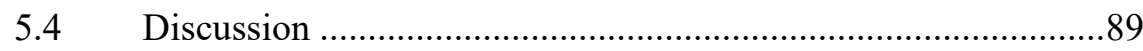

5.4.1 CDOM optical properties among world's estuarine and coastal

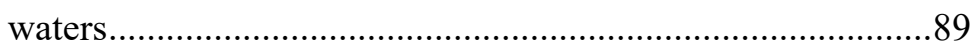

5.4.2 Spatial-temporal variation of CDOM in the Yangtze estuary 91

5.4.3 Implications: CDOM sources ..............................................92

5.4.4 Implications: DOC source and estimation..............................94

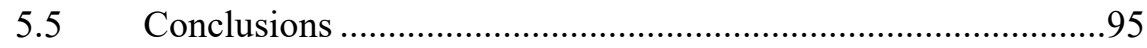

Chapter 6 Synthesis ......................................................................99

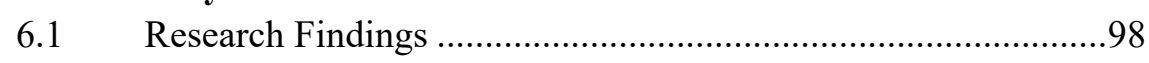

6.2 Sustainable Development Goals.............................................100

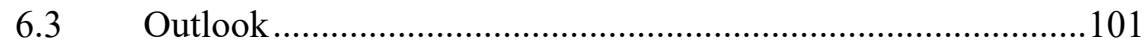

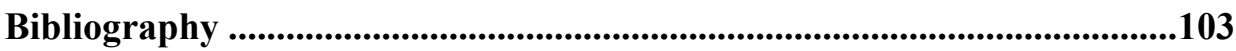

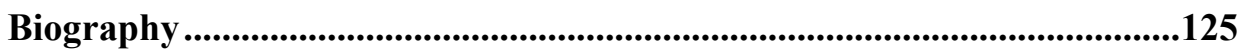




\section{Lists of abbreviations and symbols}

Abbreviations

$\mathrm{AC}$

AOPs

$\mathrm{CDM}$

CDOM

Chl-a

COASTLOOC

CZCS

DOC

DOM

F100

F25

GDPS

GOCI

HyperSAS

IOCCG

IOPs

K-M

LUTs

MERIS

MODIS

NASA

NAP

NIR

$\mathrm{NN}$

NOMAD

OLCI

POC

PSU

QIOPs

QSSA

rMAD

RMSE

RTE
Atmospheric correction

Apparent Optical Properties

Combination of CDOM and NAP

Colored Dissolved Organic Matter

Chlorophyll a

Coastal Surveillance through Observation of Ocean

Color

Coastal Zone Color Scanner

Dissolved Organic Carbon

Dissolved Organic Matter

Percentage of observations with relative error $<100 \%$

Percentage of observations with relative error $<25 \%$

GOCI Data Processing System

Geostationary Ocean Color Imager

Hyperspectral Surface Acquisition System

International Ocean Colour Coordinating Group

Inherent Optical Properties

Kubelka-Munk Model

Lookup Tables for parameters estimated by MODTRAN

Medium Resolution Imaging Spectroradiometer

Moderate Resolution Imaging Spectroradiometer

The National Aeronautics and Space Administration

Non-algal particles

Near-infrared band

Neural Network

NASA Bio-Optical Marine Algorithm Data set

Ocean Land Colour Instrument

Particulate Organic Carbon

Practical Salinity Unit

Quasi-Inherent Optical Properties

Quasi-Single-scattering Approximation

Relative Mean Absolute Difference

Root Mean Squared Error

Radiative Transfer Equation 
SeaWiFS

SDGs

SPM

SSA

SRF

SZA

TOA

UTC

\section{Symbols}

$a$

$a_{d g}$

$a_{g}$

$a_{g}^{*}(355)$

$a_{N A P}$

$a_{N A P}^{*}$

$a_{p}$

$a_{\varphi}$

$b$

$b_{b}$

$b_{b p}$

$b_{b w}$

$b_{f}$

$b_{p}{ }^{*}$

$b_{w}$

$c$

$C_{S P M}$

[DOC]

$E^{-}$

$E^{+}$

$E_{d}$

$E_{\mathrm{s}}$

$F_{0}$

$J$

$k$

$K_{d}$
Sea-Viewing Wide Field of View Sensor

Sustainable Development Goals

Suspended Particulate Matter

Single-scattering Approximation

Spectral Response Function

Solar Zenith Angle

Top of the atmosphere

Coordinated Universal Time

Total absorption coefficient, $\mathrm{m}^{-1}$

Combined absorption coefficients of CDOM and NAP, $\mathrm{m}^{-}$

1

Absorption coefficient of CDOM, $\mathrm{m}^{-1}$

DOC normalized $a_{g}$ at $355 \mathrm{~nm}, \mathrm{~m}^{-1} \mu \mathrm{mol}^{-1} \mathrm{~L}$

Absorption coefficient of NAP, $\mathrm{m}^{-1}$

Specific-absorption coefficient of NAP, $\mathrm{m}^{2} \mathrm{mg}^{-1}$

Absorption coefficient of total particles, $\mathrm{m}^{-1}$,

Absorption coefficient of phytoplankton pigment, $\mathrm{m}^{-1}$

Total scattering coefficient, $\mathrm{m}^{-1}$

Total backscattering coefficient, $\mathrm{m}^{-1}$

Backscattering coefficient of NAP, $\mathrm{m}^{-1}$

Backscattering coefficient of pure water, $\mathrm{m}^{-1}$

Total forward scattering coefficient, $\mathrm{m}^{-1}$

Specific-scattering coefficient of total particles, $\mathrm{m}^{2} \mathrm{mg}^{-1}$

Scattering coefficient of pure water, $\mathrm{m}^{-1}$

Total attenuation coefficient, $\mathrm{m}^{-1}$

SPM concentration, $\mathrm{mg} / \mathrm{L}$

The concentration of DOC, $\mu \mathrm{mol} / \mathrm{L}$

Diffuse downward irradiance, $\mathrm{W} \mathrm{m}^{-2} \mathrm{~nm}^{-1}$

Diffuse upward irradiance, $\mathrm{W} \mathrm{m}^{-2} \mathrm{~nm}^{-1}$

Total downward planar irradiance, $\mathrm{W} \mathrm{m}^{-2} \mathrm{~nm}^{-1}$

Solar irradiance, $\mathrm{W} \mathrm{m}^{-2} \mathrm{~nm}^{-1}$

Extraterrestrial solar irradiance, $\mathrm{W} \mathrm{m}^{-2} \mathrm{~nm}^{-1}$

Jacobian matrix

Extinction coefficient, $\mathrm{m}^{-1}$

Diffuse attenuation coefficient, $\mathrm{m}^{-1}$ 


\begin{tabular}{|c|c|}
\hline$L_{i}$ & Sky radiance, $\mathrm{W} \mathrm{sr}^{-1} \mathrm{~m}^{-2} \mathrm{~nm}^{-1}$ \\
\hline$L_{t}$ & Sea-surface radiance, $\mathrm{W} \mathrm{sr}^{-1} \mathrm{~m}^{-2} \mathrm{~nm}^{-1}$ \\
\hline$L_{T O A}$ & Total radiance received at the TOA, $\mathrm{W} \mathrm{sr} \mathrm{m}^{-2} \mathrm{~nm}^{-1}$ \\
\hline$L_{w}$ & Water-leaving radiance, $\mathrm{W} \mathrm{sr}{ }^{-1} \mathrm{~m}^{-2} \mathrm{~nm}^{-1}$ \\
\hline$n_{w}$ & Refraction index of water \\
\hline$Q$ & $\begin{array}{l}\text { Ratio of upwelling irradiance to upwelling radiance just } \\
\text { beneath the surface }\end{array}$ \\
\hline$R$ & Irradiance reflectance \\
\hline$r_{\infty}$ & Bi-hemispherical infinite reflectance \\
\hline$R^{2}$ & Determination coefficient \\
\hline$\rho_{n w}$ & Normalized water-leaving reflectance \\
\hline$R_{\mathrm{rs}}$ & Above-surface remote sensing reflectance, $\mathrm{sr}^{-1}$ \\
\hline$r_{\mathrm{rs}}$ & Below-surface remote sensing reflectance, $\mathrm{sr}^{-1}$ \\
\hline$r_{s d}^{\infty}$ & Directional-hemispherical infinite reflectance \\
\hline$S_{\text {index }}$ & An index of bbp based on a sigmoid function \\
\hline$S_{275-295}$ & Spectral slope of $a_{g}(\lambda)$ between 275 and $295 \mathrm{~nm}, \mathrm{~nm}^{-1}$ \\
\hline$S_{440}$ & $\begin{array}{l}\text { Spectral slope of } a_{g}(\lambda) \text { calculated using } 440 \mathrm{~nm} \text { as } \\
\text { reference, } \mathrm{nm}^{-1}\end{array}$ \\
\hline$S_{\mathrm{CDOM}}$ & Spectral slope of $a_{g}(\lambda), \mathrm{nm}^{-1}$ \\
\hline$S_{\mathrm{NAP}}$ & Spectral slope of $a_{N A P}(\lambda), \mathrm{nm}^{-1}$ \\
\hline$\theta s^{\prime}$ & Under-water zenith angle, degree \\
\hline$\theta s$ & Above-water solar zenith angle, degree \\
\hline$u$ & $=b_{b} /\left(a+b_{b}\right)$ \\
\hline$\mu_{w}$ & Cosine of under-water zenith angle \\
\hline$x$ & $=b_{b} / a$ \\
\hline$Y$ & The power-law exponent of $b_{b p}(\lambda), \mathrm{nm}-1$ \\
\hline$\eta$ & $\begin{array}{l}\text { Forward-backward asymmetry parameter for scattering } \\
\text { coefficient }\end{array}$ \\
\hline$z$ & Depth, zero at surface and decrease in downward direction \\
\hline
\end{tabular}




\section{List of Figures}

Figure 2.1. Light pathways in the atmosphere and water in coastal regions

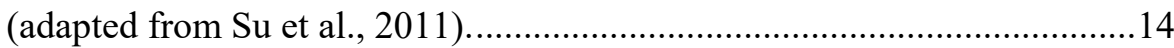

Figure 2.2. Model sensitivities to SPM concentrations at different reference wavelengths (' 0 ' and ' 60 ' for the Duntley model refer to the under-water solar zenith angle).....

Figure 3.1. Location of the field data sets. (a) The NOMAD, (b) the COASTLOOC and (c) the Yangtze dataset (solid circles are matchups sites within $1 \mathrm{~h}$ of GOCI capturing images) .26

Figure 3.2. Percentage distribution of solar zenith angle (SZA) in the three in-situ datasets.

Figure 3.3. Field measured spectra of $R_{\mathrm{rs}}(\lambda)$ and $K_{\mathrm{d}}(\lambda)$ of the Yangtze dataset.

Figure 3.4. Comparison between the original 2SeaColor model and the 2SeaColor model with improved parameterizations for (a) IOCCG dataset and (b) Yangtze dataset.

Figure 3.5. Known versus derived $K_{d}(490)$ for (a) Zhang model, (b) Lee model and (c) 2SeaColor model, applied to all three data sets. The insets with smaller markers show the results for low $K_{d}(490)$ observations where known $K_{d}(490) \leqslant 0.2 \mathrm{~m}-1$. .34

Figure 3.6 Comparisons between field-measured $R_{r s}$ and GOCI $R_{r s}$ product for six matchups at each GOCI bands except band $865 \mathrm{~nm}$...................................36

Figure 3.7. $K_{d}$ derived from atmospherically corrected GOCI image using the 2SeaColor model. Four wavelengths are shown: (a) 440nm, (b) 490nm, (c) $550 \mathrm{~nm}$ and (d) $640 \mathrm{~nm}$. .38

Figure 3.8. Validation of 2SeaColor-derived total absorption and backscattering coefficient at $490 \mathrm{~nm}, a(490)$ and $b_{b}(490)$, using matched observations in the NOMAD and COASTLOOC datasets. Note the difference in scales for $a(490)$ in both cases.

Figure 3.9. $K_{d}$ maps derived from the GOCI level 2 product (L2P) at wavelength $490 \mathrm{~nm}$ using (a) Zhang model, (b) Lee model and (c) 2SeaColor model. The image was captured at 02:16 UTC, 8 March 2013 and ' $X$ ' marks are matchup sites.

Figure 3.10. Comparison between field-measured $K_{d}(490)$ and GOCI-derived $K_{d}$ (490) using the Zhang model, the Lee model and the 2SeaColor model for the six matchups. 
Figure 4.1. Location of the sampling stations for the two cruises in (a) March 2013 and (b) February 2011. The color image in (a) (composited by GOCI bands at $680 \mathrm{~nm}, 555 \mathrm{~nm}$, and $443 \mathrm{~nm}$ ) was acquired at 01:16 UTC on March $8^{\text {th }}, 2013$. The black pins in (a) indicate the stations with GOCI match-ups and the blue pins in (a) are the hydrologic stations.....................................50

Figure 4.2. Spectra of field-measured $\mathrm{R}_{\mathrm{rs}}$ during the two cruises........................51

Figure 4.3. Validation of $R_{r s}$ product of the GOCI standard AC against matched in-situ measurements for GOCI 8 wavebands. .........................................54

Figure 4.4. $R_{r s}$ mapping products of GOCI standard AC over the Yangtze estuary for the image acquired on 02:16 UTC, March 8 of 2013 ..............................55

Figure 4.5. Comparison between laboratory and field measured absorption coefficients (uncorrected and corrected results by the three methods) at 440 $\mathrm{nm}(\mathrm{a})$ and $650 \mathrm{~nm}$ (b)

.59

Figure 4.6 Cross-comparison between field-measured $b_{b}$ by the ECO-VSF and ECO-bb9 for the surface data. . .61

Figure 4.7. Validation of retrieved IOPs by the 2 SeaColor model for (a) total absorption coefficient at $440 \mathrm{~nm}$, and (b) total backscattering coefficient at $532 \mathrm{~nm}$ 62

Figure 4.8. Relationship between $b_{b p}(555)$ and $C_{\text {SPM }}$. The red circles mark samples with $C_{\mathrm{SPM}}$ less than $100 \mathrm{mg} / \mathrm{L}$, while the black markers represent samples with $C_{\mathrm{SPM}}>100 \mathrm{mg} / \mathrm{L}$

Figure 4.9. Calibration and validation of the $S_{\text {index }}-C_{\mathrm{SPM}}$ model using the $\mathrm{Cal}$ and Val datasets

Figure 4.10. Validation results of the three $C_{S P M}$ retrieval models using the Val dataset.

Figure 4.11. SPM Maps over the Yangtze estuary produced by (a) our proposed model, (b) the He model, and (c) the GOCI SPM model. The GOCI image was acquired at 02:16 UTC, March $8^{\text {th }}, 2013$.

Figure 4.12. Validation of retrieved SPM for GOCI match-ups by the GOCI standard model, the He model, and our proposed model. .67

Figure 4.13. Retrieval of $C_{\mathrm{SPM}}$ for the SeaSWIR dataset using the $b_{b p}-C_{\mathrm{SPM}}$ (Eq. (4.13) and Eq. (4.14)) and the $S_{\text {index }}-C_{\mathrm{SPM}}$ (Eq. (4.16)) relationships calibrated in this study. . .71

Figure 4.14. Diurnal variations of SPM concentrations in the Yangtze estuary on March 8th, 2013. The black circles in (a) represent the locations of the hydrologic stations. . .73

Figure 4.15. Diurnal dynamics of CSPM (the right ordinate axis) at three hydrometric stations corresponding to the variations of the tidal level (the left 
ordinate axis). Figs. a, b, and c are corresponding to the stations labeled St. 1, St.2, and St. 3 in Figure 4.1a, respectively.

Figure 5.1. Location of sampling stations in the Yangtze estuarine and coastal waters. Samples were collected from five cruises in summer (July 2011, July 2012 and August 2013) and winter (February and March of 2012). .81

Figure 5.2. CDOM absorption spectra of all measurements. The two blue spectra represent samples with maximum and minimum absorption coefficients, while the red spectrum is the mean absorption coefficient of all samples...82

Figure 5.3. Spatial distribution of surface over the Yangtze estuarine and coastal region. Data is collected from five cruises in July of 2011 (a), February (b), March (c), July (d) of 2012 and August of 2013 (e)

Figure 5.4. Vertical distribution of $a_{g}(355)$ along geographic longitude increasing in July 2011. Figs. $4 \mathrm{a}-4 \mathrm{f}$ are corresponding to the six axial transects in Fig. 3 a from the bottom up. . .85

Figure 5.5. Relationships between salinity and $a_{g}(355)$. All CDOM measurements are divided into (a) two subsets for samples collected in winter and summer and (b) three subsets according to the salinity with two thresholds at 20 and 32 PSU . .86

Figure 5.6. Scatter plots between salinity and $S_{275-295}$ (a) and $S_{\mathrm{R}}$ (b). All observations are divided into three subsets using thresholds of salinity at 20 PSU and 32 PSU.

Figure 5.7. Calibration and validation for DOC estimation model using the Cal and Val datasets. (a) A non-linear relationship (black line) is used to fit $a_{g}$ (355)/DOC and $S_{275-295}$ using the Cal dataset. A reference relationship from (Fichot and Benner 2012) is also provided (dash line). (b) Validation of the developed model using the Val dataset. .88

Figure 5.8. The trends of the spectral slopes $\left(S_{275-295}\right.$ and $\left.S_{350-400}\right)$ and the slope ratio $S_{\mathrm{R}}$ to the increasing salinity. .93 


\section{List of Tables}

Table 3-1. Introduction of the GOCI 8 spectral bands and their primary application.

Table 3-2. Statistical results of three $K_{\mathrm{d}}$ retrieval models with respect to observations divided into two subsets with a threshold of $K_{\mathrm{d}}(490)=0.2 \mathrm{~m}$

Table 4-1. Statistic results of scattering corrected ac-s measured absorptions by the three methods compared with laboratory measurements at 440 and 650 nm.

Table 4-2. Statistical data of the three SPM retrieval models that support Figure 4.10. . .65

Table 5-1. Comparisons of CDOM absorption $a_{g}(355), S_{440}$ and salinity among different estuarine and coastal waters. .90 
Chapter 1 Introduction 


\subsection{Background}

The propagation of light in natural waters is determined by how photons travel and change energy with depth in a water body. The properties of water that affect the light penetration are defined as the optical properties, which are conveniently divided into two mutually exclusive classes: the inherent optical properties (IOPs) and the apparent optical properties (AOPs) (Mobley, 1994). Inherent optical properties are those properties that depend only upon the medium, such as the absorption and scattering coefficients. IOPs of natural waters are determined by the optically significant constituents in the form of dissolved and particulate matter, which are essentially attributable to four components based upon the similarity in their optical properties: pure water, colored dissolved organic matter (CDOM), non-algae particles (NAP) and phytoplankton pigment (Chlorophyll). Apparent optical properties, on the other hand, depend on both the medium (the IOPs) and the geometric (directional) structure of the ambient light field, such as various reflectance (Kirk, 1994; Mobley, 1994). Two of the most important AOPs in ocean color remote sensing is the normalized water-leaving radiance $\left(n L_{w}\right.$, in $\left.\mathrm{W} \cdot \mathrm{sr}^{-1} \cdot \mathrm{m}^{-2} \cdot \mathrm{nm}^{-1}\right)$ and the remote sensing reflectance $\left(R_{r s}\right.$, in $\left.\mathrm{sr}^{-1}\right)$. Note that $R_{r s}$ is the ratio of $n L_{w}$ to the extra-terrestrial solar irradiance $\left(F_{0}\right.$, in $\left.\mathrm{W} \cdot \mathrm{m}^{-2} \cdot \mathrm{nm}^{-1}\right)$ (Gordon and Wang, 1994a). Theoretically, the composition of in-water constituents determines how much light is absorbed and scattered at a specific wavelength and thus affects the magnitude and shape of the spectral distribution of radiance that leaving from the water surface, such as $n L_{w}$. Reversely, with proper inversion, IOPs and the concentrations of in-water constituents can be derived from $n L_{w}$ or $R_{r s}$ measurements (Carder et al., 1999; Garver and Siegel, 1997; Hoge and Lyon, 1996; Lee et al., 2007; Lee et al., 2002; Lee et al., 2009; Maritorena et al., 2002; Salama and Verhoef, 2015; Werdell et al., 2013).

Traditional investigation of optical properties and their retrievals from AOPs is mainly based on discrete sampling, which is time-consuming and shows less success in interpreting the variations of optical properties at large spatialtemporal scales. Since the launch of Coastal Zone Color Scanner (CZCS) in 1978, researches on water optical properties have been seen great leap forward (IOCCG, $2000,2006)$. The followed ocean color satellites, with greatly improved spatial and temporal resolutions and enhance radiometric measurements, allows simultaneous observation of the optical properties and interpretation of in-water constituents with much advanced accuracy. Among these satellites are the SeaViewing Wide Field of View Sensor (SeaWiFS, launched in 1999), the Moderate 
Resolution Imaging Spectroradiometer (MODIS, launched in 2002), the Medium Resolution Imaging Spectroradiometer (MERIS, launched in 2002), the Geostationary Ocean Color Imager (GOCI, launched in 2010), the Visible Infrared Imaging Radiometer Suite (VIIRS, launched in 2012), the Ocean and Land Colour Instrument (OLCI, launched in 2016) and et cetera. However, as optical properties of natural waters have been reported with great temporal and spatial variabilities among rivers, lakes, coastal waters, and Open Ocean, it is still a challengeable task to obtain accurate products of IOPs and in-water constituents from remote sensing imagery.

The variabilities of optical properties among global waters are closely related to the concentration of dissolved and particulate substances, such as the CDOM, Chl-a, suspended sediments. Further, the in-water constitutes could also have strong relationships with biogeochemical parameters, such as the strong correlations between CDOM and the dissolved organic carbon (DOC), and between SPM and the particulate organic carbon (POC) (Asmala et al., 2012; Ferrari, 2000; Fichot and Benner, 2011, 2012; Matsuoka et al., 2012a; RochelleNewall et al., 2014; Spencer et al., 2007). Therefore, remotely sensed optical properties could further be employed to retrieve biogeochemical parameters. Comparing to conventional investigation methods, e.g., discrete sampling, remote sensing of biogeochemical parameters provides synoptic coverage at large temporal-spatial scales allowing thereby a synoptic view of the aquatic system, and therefore represents a compelling alternative (Doerffer and Fischer, 1994; Gregg et al., 2017; Joshi et al., 2017; Kirk, 1994; Lee et al., 1999; Longhurst and Harrison, 1989; Mobley, 1994; Sathyendranath et al., 1989).

The fundamental task for remote sensing of the water optical properties, also referred to as ocean color, is to retrieve accurate products, including both the IOPs and the associated concentrations of in-water constituents, from airborne or spaceborne radiometric measurements. Ocean color remote sensing from satellite imagery includes two critical steps. The first step is to remove the atmosphere's contributions from the airborne or spaceborne measurements to obtain reliable $n L_{w}$ or $R_{r s}$. This procedure is the so-called "atmospheric correction" (Gordon and Wang, 1994a). The second step is to quantitatively derive the optical properties and the concentrations of the water constituents from the water-leaving radiance or the $R_{r s}$. This step employs the "inverse algorithm" to retrieve IOPs and the inwater constituents from AOPs. However, due to the variability in the optical properties among different waters, numerous algorithms for atmospheric correction and IOPs retrieval have been developed (IOCCG, 2000, 2006). 


\subsubsection{Development of the atmospheric correction algorithm}

About $90 \%$ of the radiance seen by a satellite at the top of the atmosphere (TOA) is contributed by the atmosphere (including aerosols, water vapor, and clouds), and about $10 \%$ from the background signal from the ocean (Huot et al., 2001; Morel, 1980). In order to obtain target IOPs signals from satellite sensors, satellite imagery must be corrected to remove the radiance contributions from the atmosphere. Atmospheric effects are mainly attributed to multiple scattering by air molecules (Rayleigh scattering) and aerosols only, and the interaction term between molecular and aerosol scattering (Gordon and Wang, 1994b).

An effective method to remove the atmosphere's contribution from the total radiance received at TOA $\left(L_{T O A}\right)$ was proposed by Gordon and Wang (1994b), where the assumption was made that sea-water absorbs all the light in the red and near-infrared (NIR) region of the spectrum in clear ocean waters. This atmospheric correction scheme is referred to as GW94 and this assumption is well known as the black-pixel assumption. The GW94 allows an accurate estimation of the atmosphere's contribution for SeaWiFS products and can be easily adapted to other satellite products, especially for open ocean waters. However, the blackpixel assumption does not work well for optically complex waters, mostly in coastal regions and inland waters, because the non-negligible water-leaving radiance in the NIR will lead to an overestimation of the atmospheric radiance in the whole visible spectrum (IOCCG, 2000; Ruddick et al., 2000; Salama and Shen, 2010a; Siegel et al., 2000). To account for the complex optical properties, many algorithms have been developed to extend the GW94 model to process the atmospheric correction for the coastal waters (Bailey et al., 2010; Kuchinke et al., 2009; Ruddick et al., 2000; Stumpf et al., 2003).

For productive waters or turbid coastal waters, satellite-derived $R_{r s}$ from the NIR atmospheric correction can be significantly underestimated and can even become negative in the blue bands (Wang et al., 2012). An improved scheme was proposed to remove the atmospheric effects for MODIS ocean colour products by using shortwave infrared (SWIR) bands, where the water can still be considered as black for turbid waters due to the strong absorption of water at SWIR bands. This algorithm is hereafter denoted as the SWIR atmospheric correction (Wang, 2007; Wang and Shi, 2005; Wang et al., 2009b; Wang et al., 2007). Furthermore, the SWIR atmospheric correction was proved to be more effective and flexible for turbid coastal waters compared with the NIR atmospheric correction, mainly because it can avoid masking out some of the 
turbid water pixels as cloud pixels (Wang and Shi, 2006). However, the applicability of the SWIR atmospheric correction could be limited for many ocean color satellite sensors due to lacking the SWIR bands, such as the MERIS, OLCI, and GOCI. Alternative atmospheric correction algorithms were developed to optimize the atmospheric and oceanic signals at the NIR bands and then extrapolate to the visible bands by the neural network (NN) inversion method, which worked well for MERIS products over optically complex waters (Brajard et al., 2012; Schroeder et al., 2007).

For extremely turbid waters, a practical model for atmospheric correction based on radiative transfer theory was developed using MODTRAN simulations (Adler-Golden et al., 1999; Berk et al., 1999; Verhoef and Bach, 2003). With the assumption of a hypothetical homogeneous Lambertian surface of the water, a lookup table (LUT) can be generated from MODTRAN simulations for various atmospheric conditions (visibility and aerosol type) and viewing geometries and then applied to solve the inversion problem. Atmospherically corrected $R_{r s}$ from MERIS based on the MODTRAN simulation was found to be promising when validated with matched in-situ measurements in the extremely turbid coastal waters in the Yangtze estuary (Shen et al., 2010b). Similar to the assumption of black water at NIR band in clear ocean waters, water-leaving radiance at ultraviolet (UV) wavelengths could be neglected compared with longer wavelengths in extremely turbid coastal waters due to strong scattering by the particles in the atmosphere and strong absorption by CDOM in the water (He et al., 2013; He et al., 2012). The implementation of the UV atmospheric correction on MODIS and GOCI images shows great improvements in the accuracy of satellite-derive $R_{r s}$ with respect to the NIR and SWIR atmospheric correction (Wang and Shi, 2007). The UV atmospheric correction is also found more promising than the standard atmospheric correction approach of GOCI (Ahn et al., 2012) over the Yangtze estuary and the Hangzhou Bay (He et al., 2013; He et al., 2012).

\subsubsection{Retrieval of IOPs and the concentrations of in-water constituents}

While the atmospherically corrected spectra $\left(n L_{w}\right.$ or $\left.R_{r s}\right)$ are of some interests in themselves, their main significance remains in that they can be used to remotely interpret the optical properties of the water body, such as the inherent optical properties. The two fundamental IOPs are the absorption coefficient $\left(a(\lambda)\right.$, in $\mathrm{m}^{-}$ ${ }^{1}$ ) and volume scattering function $\left(\beta(\lambda)\right.$, in $\left.\mathrm{m}^{-1} \cdot \mathrm{sr}^{-1}\right)$, which describe how light is 
absorbed and scattered in the water. The scattering coefficient $\left(b(\lambda)\right.$, in $\left.\mathrm{m}^{-1}\right)$ and the backscattering coefficients $\left(b_{b}(\lambda)\right.$, in $\left.\mathrm{m}^{-1}\right)$ can be derived from the volume scattering function by integrating the $\beta(\lambda)$ over all scattering angles and over only the backward scattering angles, respectively. Another ecologically essential IOP, or Quasi-IOP as some scholars may define, is the diffuse attenuation coefficient $\left(K_{d}\right.$, in $\left.\mathrm{m}^{-1}\right)$, which describes the penetration of incident solar radiation in the water column. Many efforts have been made to remotely retrieve IOPs, $K_{d}$, and the concentrations of in-water constituents, such as chlorophyll-a, CDOM, and suspended particulate matter (SPM), from earth observation data since the launch of CZCS in 1978. Numerous inverse algorithms have been developed, which can be inclusively classified into three types, i.e., the empirical approach, the theoretical approach, and the semi-analytical approach that employs both empirical relationships and analytical solutions.

\subsubsection{Empirical approach}

Empirical models are mostly employed in the retrievals of the concentration of optically active compositions (e.g., Chl- $a$ and SPM). It is not possible to analytically estimate the concentrations of Chl- $a$ or SPM because their relationships with inherent optical properties are dependent on the physical characteristics of the particles, such as the types, composition, grain size, and et cetera. Developing an empirical model requires a priori established relationships between remotely measured reflectance, at a specific wavelength or combination of two or more wavelengths, and the concentrations of in-water constituents determined from in-situ measurements. Chl- $a$ is one of the first in-water constituents that has been retrieved from remotely sensed data. Empirical models have been traditionally developed to retrieve Chl- $a$ concentration using the bluegreen band ratio of the $n L_{w}$ or $R_{r s}$ in the optically clear waters and using two-band and three-band algorithms for optically complex waters (Dall'Olmo et al., 2003; Gitelson, 1992; Gordon et al., 1983; Le et al., 2013; Le et al., 2009; O'Reilly et al., 1998; Shen et al., 2010c). Empirical models have also been extensively employed to retrieve the concentrations of CDOM and suspended sediments in coastal waters (D'Sa et al., 2007; Doerffer and Fischer, 1994; Liu et al., 2014; Loisel et al., 2014; Siswanto et al., 2011; Zhang et al., 2010). Other biogeochemical parameters, such as dissolved organic carbon (DOC), through its relationship with CDOM absorption properties, can also be empirically retrieved from earth observation data (Cao et al., 2018; Zhao and Song, 2018). $K_{d}$, as a QIOP, has also been empirically related to reflectance measurements for both 
clear waters and optically complex waters (Austin and Petzold, 1981; Mueller, 2000; Werdell and Bailey, 2005; Zhang and Fell, 2007).

However, it is worthy to point out that the empirical models, although they are simple and easy to implement, have a major drawback regarding the model transferability. The empirical coefficients derived from statistical regression are highly dependent on the calibration dataset, and therefore only appropriate for waters with optical properties similar to those used in the model development. For example, most empirical models have satisfying performance in optically simple waters, usually referred to as the Case 1 water (Morel and Prieur, 1977), where absorption by Chl- $a$, apart from pure water, dominates the inherent optical properties. However, the performance of these models degrades noticeably when applied to optically complex waters, where strong absorptions by CDOM and NAP exist at the blue bands and the scattering from NAP cannot be negligible, without re-calibrating the empirical coefficients (Carder et al., 1989; Gitelson et al., 2007; Gons, 1999).

\subsubsection{Semi-analytical methods}

To account for the relatively large and independent variations of Chl- $a$, CDOM, and NAP in optically complex waters, apart from the empirical models, semianalytical and analytical models have been proposed. Analytical models are based on theoretical modelling of the underwater light field, such as the radiative transfer equations (RTEs) (Mobley, 1994). Due to the complexity of the shape of the volume scattering function and variations in the environmental factors that affect the light field in natural waters, exact analytical solutions of the RTEs exist only for a few idealized and unphysical situations such as no scattering. However, it is possible to arrive at approximate analytical solutions relating the AOPs and IOPs with proper assumptions and restrictive conditions, such as the singlescattering approximation (SSA) (Gordon, 1973).

Gordon and Morel (1983) proposed one of the most widely used analytical model based on simplified solutions of the RTEs, where the remote sensing reflectance just beneath the surface $\left(r_{\mathrm{rs}}\right.$, in $\left.\mathrm{sr}^{-1}\right)$ can be theoretically linked to inherent optical properties, namely the ratio of total backscattering coefficient $\left(b_{b}\right)$ to the sum of total absorption and backscattering coefficients $\left(a+b_{b}\right)$. The ratio is hereafter referred to as $u(\lambda)$ (Gordon et al., 1988). The conversion of $r_{\mathrm{rs}}$ to the above-surface remote sensing reflectance $\left(R_{\mathrm{rs}}\right)$ was also given as a function of the Fresnel surface reflectance (Gordon et al., 1988). With the proposed relationship between 
$R_{\mathrm{rs}}$ and $u(\lambda)$, knowledge of the absorption coefficient will enable the retrieval of backscattering or vice versa.

Many semi-analytical algorithms were developed on the basis of Gordon's equations with $u(\lambda)$ first being derived from $R_{\mathrm{rs}}$, and then decomposed (or inverted) $u(\lambda)$ into IOPs of different components with proper empirical approach or iterative approach, including mainly the spectral optimization, spectral deconvolution, and bulk inversion (Hoge and Lyon, 1996; Werdell et al., 2013). Among these semi-analytical models are the Carder's algorithm for MODIS (Carder et al., 1999), the QAA algorithm (Lee et al., 2007; Lee et al., 2002; Lee et al., 2009) and the GSM algorithm (Garver and Siegel, 1997; Maritorena et al., 2002). Many other efforts have been made using neural network algorithms (Buckton et al., 1999; Doerffer and Schiller, 2007; Schiller and Doerffer, 1999) or nonlinear optimization (Doxaran et al., 2006; Salama et al., 2009; Salinas et al., 2007) to obtain the optimal solutions of the Gordon's equations to retrieve IOPs. It is worthy to note that the absorption coefficients by CDOM and NAP share similar spectral features and are difficult to be derived directly from the semi-analytical algorithms. CDOM and NAP absorption coefficients are usually treated as a combined parameter (CDM). Derived CDM from semi-analytical algorithms are further partitioned into individual absorption of CDOM and NAP using empirical models (Dong et al., 2013; Lee et al., 2002). With retrieved total absorption and backscattering coefficients, $K_{d}$ can be then remotely retrieved (Doron et al., 2007; Lee et al., 2005a; Lee et al., 2005b; Morel and Loisel, 1998; Wang et al., 2009a).

For the retrieval of SPM concentrations, semi-analytical models have also been proposed based on radiative transfer (Doxaran et al., 2006; Shen and Verhoef, 2010; Shen et al., 2014; Volpe et al., 2011). In some other models, SPM concentrations are inverted from remotely retrieved IOPs with the assumption of a constant specific absorption or scattering coefficient, which is the ratio of $a$ or $b$ to SPM concentration. However, the relationship between IOPs and SPM could be highly dependent on the type, grain size, and composition of suspended particles. Therefore, the assumption of constant specific IOPs results in larger uncertainties when applied to a new region of interest and pre-determining the specific IOPs from locally calibrated data is necessary to improve model accuracy (Binding et al., 2005; Doxaran et al., 2006).

Semi-analytical models can retrieve IOPs for both optically simple and complex waters with satisfying accuracy. Compared with empirical models, although the 
retrieval accuracy from semi-analytical models could be sometimes worse than for locally calibrated empirical models, semi-analytical models can be applied to different types of water without a priori calibrations on the empirical coefficients (IOCCG, 2006).

\subsubsection{Analytical models}

As mentioned in Section 1.1.2.2, most of the semi-analytical models adopted Gordon's solution of RTEs, while little has been done to improve the forward model for radiative transfer in water. Kubelka and Munk (1931) proposed a generic two-stream solution of the RTEs for turbid media, which has been validated for extremely turbid waters with very promising estimation of SPM concentration (Ambarwulan et al., 2012; Shen et al., 2010b). Duntley (1942) also introduced an approximate solution of the RTEs based on a two-stream approach that considers both direct and diffuse incident radiation. The Duntley model was later incorporated with an inverse scheme to analytically retrieve IOPs and $K_{d}$, namely, the 2SeaColor model (Salama and Verhoef, 2015). The 2SeaColor model includes the solution of the Duntley equation as the forward model and an inversion scheme using spectral optimization. Yu et al. (2016) revised the 2SeaColor model with improved IOPs parameterizations, which produced more accurate and reasonable estimations of the IOPs and $K_{d}$ for the Yangtze estuary.

In this dissertation, the author first employed the 2SeaColor model for the retrieval of IOPs and $K_{d}$, then utilized locally calibrated models to estimate SPM concentration from derived particulate backscattering coefficient and derive DOC concentration from CDOM absorption coefficients, respectively. Empirical and semi-analytical models from other publications were also adopted in this study for model inter-comparison.

\subsection{The Yangtze estuary}

The Yangtze River is third largest in length, fifth largest in water discharge, and fourth largest in sediment load, after the Amazon, Zaire and Orinoco, with average annual water and sediment discharge into the estuary up to $8.96 \times 10^{11} \mathrm{~m}^{3}$ and $3.9 \times 10^{11} \mathrm{~kg}$ from 1950 to 2010 , respectively. It originates from Geladaindong Peak on the Tibetan Plateau and runs into the East China Sea at Shanghai city. The rich water and sediments discharges make the Yangtze estuary one of the world's most turbid estuaries. The estuary, mainly the inshore area and the river mouth, is affected by a strong semidiurnal tide where tidal amplitudes are average between 4.5 and $5.0 \mathrm{~m}$ (Huang, 1992). The Yangtze delta area is the most 
populous and economically developed region in China, which accounts for more than $20 \%$ of China's Gross Domestic Product.

The Yangtze estuary, same as world's major estuaries, functions as the exchange hub of the marine ecosystem and land ecosystem where massive material exchanges between land and ocean. The material exchanges, especially the change of carbon as dissolve substance, promote the global carbon cycle and maintain the sustainability of the environment. Besides, the estuary ecosystem is heavily affected by human activities and very sensitive to global climate change. Therefore, monitoring in the optical properties of the Yangtze estuary could be of great scientific, economic, and social benefits. Furthermore, optical measurements can provide insights into the aquatic ecosystem, such as the health status of the water body, biological productivity, sediment load, pollutants, bathymetry, and carbon stocks et cetera. (Doerffer and Fischer, 1994; Gregg et al., 2017; Joshi et al., 2017; Kirk, 1994; Lee et al., 1999; Longhurst and Harrison, 1989; Mobley, 1994; Sathyendranath et al., 1989).

\subsection{Challenges}

Water optical properties in the Yangtze estuary are frequently changed due to seasonal riverine discharges, tidal currents, and wind-driven resuspensions of bottom sediments, fresh and salt water mixing, resulting in one of the world's most optically-complex regions. For turbid waters, one of the challenges for ocean color remote sensing is the scarcity of "ground-true" data for model validation, which is because current commercial instruments for IOPs measurements, such as Wet Labs ac-s meter and bb9 meter, are prone to saturate in high turbidity environments. The other challenges is that due to the large variation of the IOPs and concentrations of in-water constituents, most semianalytical models have been less successful in retrieving IOPs or $K_{d}$ (IOCCG, 2000, 2006; Salama et al., 2011; Wang et al., 2017; Zibordi et al., 2009), which is mainly attributed to the strong backscattering by the suspended particles. Therefore, developed models for the retrieval of SPM and Chl-a concentrations in the Yangtze estuary are all empirical or semi-analytical based (Shen et al., 2010b; Shen et al., 2010c; Shen et al., 2013; Sokoletsky et al., 2014). Studies based on radiative transfer approach, on the other hand, are hardly discussed in published literature. Despite the lack of in-situ measured IOPs for model validation, the comparison between analytical model and semi-analytical models could still provide compelling insights into the models' performance in turbid waters, which will be discussed in this dissertation. 
SPM concentration was reported to be less than $1 \mathrm{mg} / \mathrm{L}$ in the offshore waters of the Yangtze estuary and beyond $5000 \mathrm{mg} / \mathrm{L}$ in the Hangzhou Bay (He et al., 2013). Due to the large variation of SPM concentration in the Yangtze estuary, the currently proposed SPM models have to include a switching scheme to account for the less turbid and extremely turbid waters (Shen et al., 2010b; Shen et al., 2013), which in return results in discontinuity issue with derived SPM. To avoid the discontinuity issue and produce reasonable and realistic mapping products of SPM, dedicated efforts are required to improve the SPM retrieval models.

\section{$1.4 \quad$ Research objectives}

The Yangtze estuary is rich in both particulate and dissolved substances that originate from terrestrial sources discharged from the Yangtze River. The particulate substance, i.e., SPM, is mainly due to land erosion in the river basin while the dissolved substance, i.e., CDOM, is related to agriculture activities. The abundance of SPM and CDOM, both significantly restrict light penetration in water, make the optical properties of the Yangtze estuary much more complex than the majority of the world's estuaries. Thereby, investigating the optical properties of the Yangtze estuary is of great interest for IOP retrieval models' development and evaluation in optically-complex waters.

The main objective of this dissertation is to investigate the optical properties in the Yangtze estuary and develop fairly accurate models to retrieve both the optical properties and the concentrations of water constituents. The main objective can be fulfilled by the three sub-objectives described below.

1) Improve the analytical $2 \mathrm{SeaColor}$ model to enhance its accuracy in the Yangtze estuary in retrieving inherent optical properties and diffuse attenuation coefficient.

2) Explore the relationship between particulate backscattering properties and SPM concentration in the Yangtze estuary and develop a novel model to retrieve the wide-range SPM concentration.

3) Investigate the seasonal variability of CDOM absorption properties in the Yangtze estuary and propose a regionally applicable model for the estimation of dissolved organic carbon concentration from CDOM.

\subsection{Outline of this thesis}

This thesis consists of six chapters. First two chapters are the general introduction and detailed description of the analytical 2 SeaColor model, followed by three 
core chapters and a last chapter of synthesis. Each core chapter addresses one of the sub-objectives mentioned above and has been prepared as a standalone research paper that has been published in or submitted to the peer-reviewed journal. The six chapters are arranged as follows:

Chapter 1 describes the background of ocean color remote sensing and some state-of-art developments of models in optically-complex water that remotely retrieve inherent optical properties and the concentrations of in-water constituents.

Chapter 2 introduces the general concept of radiative transfer theory and provide a comprehensive description of the two-steam radiative transfer model, i.e., the 2SeaColor model, which includes both the original 2SeaColor model and its updated version with improved parametrizations.

Chapter 3 describes the retrieval of the diffuse attenuation coefficient $\left(K_{d}\right)$ in the Yangtze estuary using the 2SeaColor model with improved parameterization and compares the model's performance with empirical and semi-analytical $K_{d}$ retrieval models.

In Chapter 4 , the derived particulate backscattering coefficient $\left(b_{b p}\right)$ from the 2SeaColor model is used to quantitatively estimate the concentration of suspended particulate matter $\left(C_{S P M}\right)$. The proposed model utilizes a $b_{b p}$ index based on sigmoid function to accurately retrieve wide-range $C_{S P M}$ between 0.4 and $2000 \mathrm{mg} / \mathrm{L}$ without the need for a switching scheme.

Chapter 5 presents the seasonal variability of the light absorption properties of colored dissolved organic matter (CDOM) in the Yangtze estuary and the robust relationship between dissolved organic carbon and CDOM absorption properties, includes the absorption coefficient and the spectral slope of the absorption coefficient.

Chapter 6 is a Synthesis of the results obtained in this dissertation. It includes the main conclusions of Chapter 3, 4, and 5 and recommendations for future efforts in ocean color remote sensing in turbid coastal waters. 
Chapter 2 Principal Basics and Methods 


\subsection{Radiative transfer in the water}

Light can be described by various physical and mathematical quantities in terms of the radiance. The radiative transfer theory explains how radiance varies with distance along any specific path at a specified point in the medium (Mobley, 1994). The radiative transfer theory is widely used to explain different kinds of science questions, among them is the radiative transfer in atmosphere and water. Figure illustrates how light propagates and interacts with the medium within the atmosphere and water in the coastal environment. For remote sensing applications, the atmospheric correction algorithm focuses on the light propagation between just above the water surface and TOA and utilizes the radiative transfer equations (RTE) for the atmosphere, while retrieval model of inherent optical properties targets at the light transfer inside the water column.

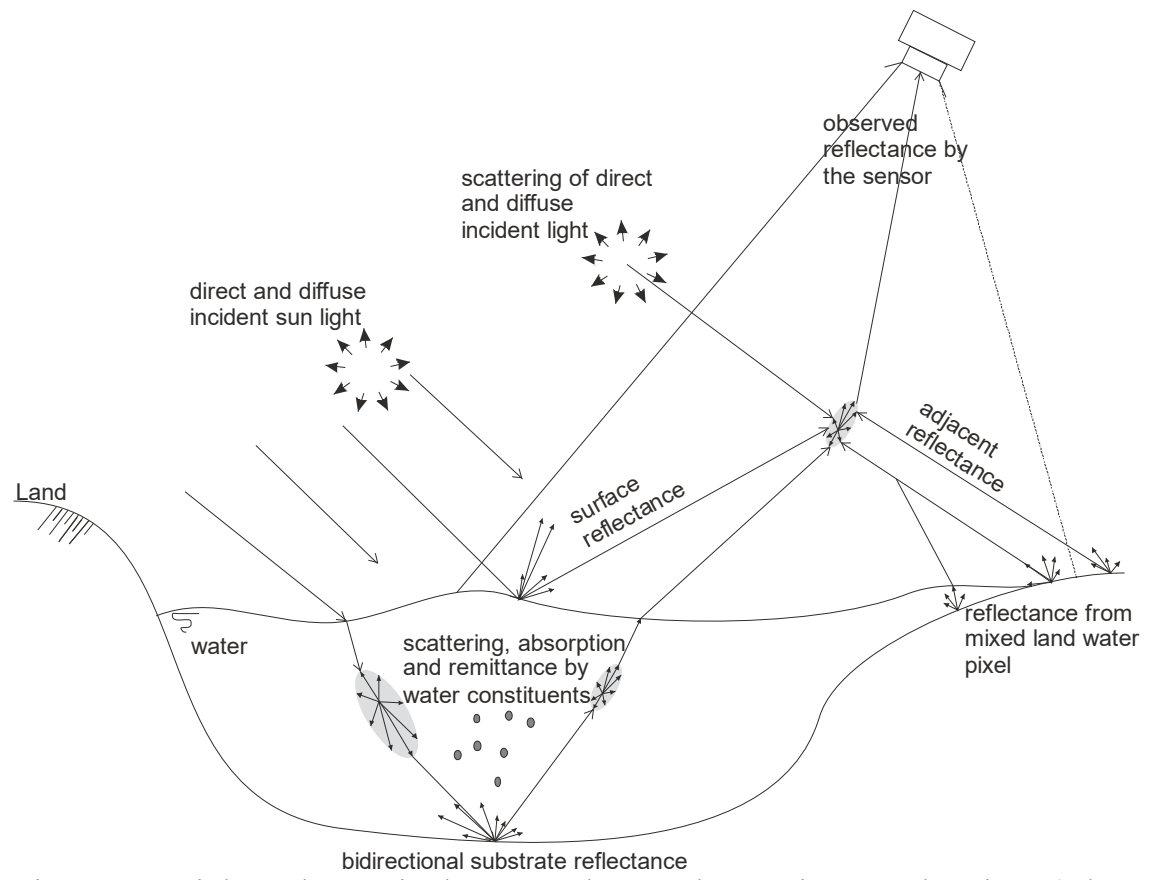

Figure 2.1. Light pathways in the atmosphere and water in coastal regions (adapted from Su et al., 2011).

The radiative transfer equation, commonly called the RTE, expresses the conservation of energy written for a collimated beam of radiance traveling through an absorbing, scattering and emitting medium. Therefore, radiative transfer equations can tie together the radiance and the IOPs, which provide the theoretical framework for the optical oceanography and ocean-color remote sensing. A useful expression can be derived from the RTEs to relate the IOPs to 
the average cosine and the vertical attenuation coefficient for net downward irradiance. With IOPs and boundary conditions go into the equations, radiance can be predicted. However, solutions of RTEs must be done numerically except for a few trivial cases such as non-scattering media, which can be hardly found in natural waters.

Due to the complexity of the shape of the volume scattering function and variations in the environmental factors that affect the light field in natural waters, retrieval of optical properties from exact analytical solutions of the RTEs is not possible for natural waters, as the conditions and boundaries for RTEs are hard to be exactly quantified. However, with pre-assumed boundary conditions, the equations arising from the RTE theory can be solved with simplified solutions. One of these approximate solutions is the single-scattering approximation (SSA). This solution is developed by assuming that the water is homogeneous, the sea surface is level, the sun is a point source in a black sky, there are no internal sources, and only single-scattering of photons is considered (Gordon and Wang, 1994b). The SSA is generally accepted and validated in optical simple waters, where numerous models, analytical and semi-analytical, were developed for the retrieval of IOPs (Gordon et al., 1988; Gordon and Morel, 1983; Lee et al., 1999; Lee et al., 2002). The other approximate solution of RTEs is based on the twostream approach in which direct and diffuse incident radiation is considered with the assumption of water as an optically deep medium (Duntley, 1942). Salama and Verhoef (2015) later developed the 2SeaColor model that includes the solution of the Duntley equation and an inversion scheme using spectral optimization for the retrieval of IOPs. In this dissertation, the author focuses on the improvements of the 2SeaColor model and its application of retrieving IOPs in turbid coastal waters.

\subsection{The 2SeaColor model}

\subsubsection{Forward model}

Optical properties of water are usually described by means of the absorption coefficient $a(\lambda)$ and the backscattering coefficient $b_{b}(\lambda)$ (wavelength dependency are omitted in this Section for brevity). Radiative transfer inside the water column can be described by the Duntley equations as follows (adapted from Duntley (1942)):

$$
\frac{d E_{s}}{d z}=k E_{s}
$$




$$
\begin{aligned}
& \frac{d E^{-}}{d z}=-s^{\prime} E_{s}+\alpha E^{-}-\sigma E^{+} \\
& \frac{d E^{+}}{d z}=s E_{s}+\sigma E^{-}-\alpha E^{+}
\end{aligned}
$$

where $E_{S}$ is the direct solar flux, and $E^{-}, E^{+}$are the diffuse downward and upward fluxes, $z$ is supposed to increase in an upward direction and to be zero at the top, $k$ is the extinction coefficient for direct sunlight and can be calculated by total absorption $(a)$ and scattering coefficient $(b)$,

$$
k=\frac{a+b}{\cos \theta_{s}}
$$

where $\theta_{s}$ ' is the under-water zenith angle, and can be found with Snell's law from above-water solar zenith angle $\left(\theta_{s}\right), \theta_{s}{ }^{\prime}=\arcsin \left(\sin \theta_{s} / n_{w}\right)$, and $n_{w}$ is the refraction index of water, which is about 1.33 .

The $s$ and $s$ ' in system (2.1) are the backscattering and forward scattering coefficients for direct sunlight and given by,

$$
s=\frac{b_{b}}{\cos \theta_{s}^{\prime}}
$$

and

$$
s^{\prime}=\frac{b_{f}}{\cos \theta_{s}^{\prime}}
$$

where $b_{b}$ and $b_{f}$ are scattering coefficients in the backward and forward direction. Total scattering is then given by $b=b_{b}+b_{f}=(1+\eta) b_{b}$, and the $\eta$ is the forward-backward asymmetry parameter.

The $\alpha$ and $\sigma$ in system (2.1) are the attenuation coefficient and diffuse backward scattering coefficient and are given by $\alpha=2\left(a+b_{b}\right)$ and $\sigma=2 b_{b}$. The eigenvalue $m$ is defined as $m=\sqrt{\alpha^{2}-\sigma^{2}}$.

For the solutions to the diffuse fluxes in system (2.1), the total downward planar irradiance of diffuse and direct light is given by,

$$
E_{d}(z)=E^{-}(z)+E_{S}(0) e^{k z}
$$

The diffuse upward irradiance is expressed as,

$$
E^{+}(z)=r_{\infty} E^{-}(z)+r_{s d}^{\infty} E_{S}(z)
$$


where $r_{\infty}$ is the bi-hemispherical reflectance for the semi-infinite medium and $r_{s d}^{\infty}$ is the directional-hemispherical reflectance of the semi-infinite medium.

The downwelling attenuation coefficient of diffuse and direct light is the analytical differentiation of the downwelling irradiance with depth,

$$
K_{d}=\frac{1}{E_{d}} \frac{d E_{d}}{d z}
$$

The downward diffuse irradiance is derived as:

$$
E^{-}(z)=E^{-}(0) e^{m z}+\left(s^{\prime}+\sigma r_{s d}^{\infty}\right) E_{s}(0) J_{1}(k, z)
$$

with,

$$
J_{1}(k, z)= \begin{cases}\frac{e^{m z}-e^{k z}}{k-m} & (k \neq m) \\ -z e^{k z} & (k=m)\end{cases}
$$

The term $r_{\infty}$ can be written as,

$$
\begin{gathered}
r_{\infty}=\frac{\sigma}{\alpha+m}=\frac{2 b_{b}}{2\left(a+b_{b}\right)+\sqrt{4\left(a+b_{b}\right)^{2}-4 b_{b}{ }^{2}}} \\
=\frac{b_{b}}{a+b_{b}+\sqrt{a\left(a+2 b_{b}\right)}}
\end{gathered}
$$

The term $r_{s d}^{\infty}$ is given by,

$$
r_{s d}^{\infty}=\frac{s+s^{\prime} r_{\infty}}{k+m}
$$

Substitution of water inherent optical properties under the assumption $\eta=1$ gives,

$$
r_{s d}^{\infty}=\frac{\left(1+r_{\infty}\right) b_{b} / \mu_{w}}{\left(a+2 b_{b}\right) / \mu_{w}+m}
$$

where $\mu_{w}=\cos \theta_{s}^{\prime}$. Similarly, we can further write,

$$
\begin{array}{r}
r_{s d}^{\infty}=\frac{\sqrt{a+2 b_{b}}\left(\sqrt{a+2 b_{b}}-\sqrt{a}\right)}{\left.\left(a+2 b_{b}\right)+2 \mu_{w} \sqrt{a\left(a+2 b_{b}\right.}\right)} \\
=\frac{\sqrt{1+2 b_{b} / a}-1}{\sqrt{a+2 b_{b} / a}+2 \mu_{w}}
\end{array}
$$

By introducing the ratio $x=b_{b} / a$ into Eq. (2.10) and Eq. (2.13), one can finally write,

$$
r_{\infty}=\frac{x}{1+x+\sqrt{1+2 x}}
$$




$$
r_{s d}^{\infty}=\frac{\sqrt{1+2 x}-1}{\sqrt{1+2 x}+2 \mu_{w}}
$$

In order to obtain remote sensing reflectance $\left(R_{r s}\right)$ from the forward model, we first combine Eq. (2.5) and Eq. (2.6) to calculate the irradiance reflectance just beneath the surface as,

$$
R=\frac{E^{+}(0)}{E_{d}(0)}=\frac{r_{\infty} E^{-}(z)+r_{s d}^{\infty} E_{S}(z)}{E_{d}(0)}
$$

The $R$ is later translated to $R_{r s}$ following Mobley (1994),

$$
R_{r s}=\frac{0.52 R}{Q-1.7 R}
$$

where $Q$ is the ratio of the water upwelling irradiance to upwelling radiance just beneath the surface. $Q$ is approximate to 3.25 for clear sky condition (Morel and Gentili, 1993; Lee and Carder et al., 1998).

\subsubsection{Inverse Scheme}

Remote sensing reflectance is fundamentally a measure of inherent optical properties, i.e., the bulk absorption coefficient and backscattering coefficient, and therefore can be inverted from known $a$ and $b_{b}$. Following Eq. (2.14) and Eq. (2.15), the inherent optical properties $x\left(=b_{b} / a\right)$ can be linked with the 2SeaColor model predicted reflectance results $r_{\infty}$ and $r_{s d}^{\infty}$. However, $r_{\infty}$ holds only for diffuse incident radiation, and under sunny conditions, it is better to use $r_{s d}^{\infty}$ as a basis for estimation of water optical properties. Therefore, $r_{s d}^{\infty}$ in Eq. (2.15) can be inverted to yield the inherent optical properties $x$ by,

$$
x=\frac{r_{s d}^{\infty}\left(1+2 \mu_{w}\right)\left[1+r_{s d}^{\infty}\left(\mu_{w}-0.5\right)\right]}{\left(1-r_{s d}^{\infty}\right)^{2}}
$$

The $r_{s d}^{\infty}$ can be approximated by $\mathrm{Q} r_{r s}$, where $\mathrm{Q}$ is approximate to 3.25 for clear sky condition (Morel and Gentili, 1993; Lee and Carder et al., 1998) and $r_{r s}$ is the remote sensing reflectance just beneath the surface. Further, an empirical relationship is given to convert $r_{r s}$ to $R_{r s}$ (Lee et al., 2002),

$$
r_{r s}=\frac{R_{r s}}{0.52+1.7 R_{r s}}
$$

Note that the bulk absorption and backscattering coefficients can be parameterized as the total of optical properties by different water constituents, which gives,

$$
a(\lambda)=a_{w}(\lambda)+a_{\varphi}(\lambda)+a_{g}(\lambda)+a_{N A P}(\lambda)
$$

and 


$$
b_{b}(\lambda)=b_{b w}(\lambda)+b_{b p}(\lambda)
$$

where the subscripts $w, \varphi, g$, and $N A P$ in Eq. (2.20) represent pure water, phytoplankton pigment, CDOM, and NAP, respectively. $b_{b w}$ and $b_{b p}$ are referred to as the backscattering coefficients of pure water and NAP, with the assumption that backscattering coefficients of CDOM and phytoplankton pigment are negligible. Absorption and backscattering coefficients of pure water are adopted from (Mobley, 1994; Morel, 1974; Smith and Baker, 1981).

In the original 2SeaColor model, water molecules are assumed to be the only contributor to absorption in the near-infrared (NIR) band (Salama and Verhoef, 2015). Therefore, $b_{b}$ at the NIR bands can be first estimated from the ratio $x$ and the pure water absorption coefficient $\left(a_{w}\right)$. Then $b_{b}$ (NIR) can be extrapolated to shorter wavelengths by,

$$
b_{b p}(\lambda)=b_{b p}\left(\lambda_{0}\right)\left(\frac{\lambda_{0}}{\lambda}\right)^{Y}
$$

where $\lambda_{0}$ is the reference wavelength and $Y$ is the power law exponent for the particle backscattering coefficient. Further, total absorption coefficient $a(\lambda)$ is derived from $b_{b}(\lambda)$ and the ratio $x(\lambda)$.

The parameterizations of the $a(\lambda)$ and $b_{b}(\lambda)$ were later improved to account for optically complex waters where residual absorptions by NAP cannot be neglected in NIR bands (Yu et al., 2016). As implemented in Salama and Shen (2010b), absorption and backscattering coefficients of water constituents are parameterized by (Bricaud et al., 1981; Lee et al., 1998; Sathyendranath et al., 2001),

$$
\begin{aligned}
a_{\varphi}(\lambda)= & \left(a_{0}(\lambda)+a_{1}(\lambda) \ln \left[a_{\varphi}(440)\right]\right) a_{\varphi}(440) \\
& a_{d g}(\lambda)=a_{d g}\left(\lambda_{0}\right) e^{-s\left(\lambda-\lambda_{0}\right)}
\end{aligned}
$$

with $a_{0}$ and $a_{1}$ given in Lee et al. (1998). The subscript $d g$ stands for the combination of CDOM and NAP, and $S$ is the spectral slope of the combined absorption coefficient.

For remote sensing applications, we proceed firstly by inverting the measured spectra of $R_{r s}$ or satellite $R_{r s}$ products into inherent optical properties. From Eq. (2.18) to Eq. (2.24), one can simulate $R_{r s}$ for given $a_{\varphi}(440), a_{d g}\left(\lambda_{0}\right), b_{b p}\left(\lambda_{0}\right)$, $S$, and $Y$. Therefore, the five unknowns can be retrieved from measured $R_{r s}$ spectra as long as $R_{r s}$ data has more than 5 spectral bands. In this study, initial values of $a_{\varphi}(440), a_{d g}\left(\lambda_{0}\right), b_{b p}\left(\lambda_{0}\right)$ and $Y$ are estimated from band-ratios of measured 
$R_{r s}$ (Lee et al., 1999). $S$ is set to $0.015 \mathrm{~nm}^{-1}$ (Lee et al., 2007; Lee et al., 2002). A spectral optimization program using nonlinear curve fitting (lsqcurvefit in Matlab $\left.{ }^{\circledR}\right)$ was applied to compute the sum of squared differences between the model-simulated $R_{r s}$ curve and the field measured $R_{r s}$ curve and iterates until the minimum is reached, at which point the values of $a_{\varphi}(440), a_{d g}\left(\lambda_{0}\right), b_{b p}\left(\lambda_{0}\right)$ and $Y$ are considered to be retrieved. These unknowns can further be used to estimate the spectral absorption and backscattering coefficient of water constituents according to Eq. (2.20) to Eq. (2.24). The $K_{d}$ is meanwhile calculated from the derived $a(\lambda)$ and $b_{b p}(\lambda)$ according to the analytical forward model described in Section 2.2.1.

\subsection{Models sensitivities to SPM concentration}

The reason that most IOPs retrieval models show less success in optical-complex waters, especially in turbid waters, lies mainly in the limitations of the radiative transfer equation used in these models. In this section, we evaluate the sensitivities of a couple of well-known IOPs retrieval models to increasing SPM concentrations. These models are,

(1) the QAA (Lee et al., 2002)

$$
r_{r s}=\sum_{i=1}^{2} g_{i}\left(\frac{b_{b}}{b_{b}+a}\right)^{i}
$$

where $g_{1}=0.0895$ and $g_{2}=0.1247$.

(2) The GSM model (Garver and Siegel, 1997; Maritorena et al., 2002),

$$
R_{r s}=\frac{t^{2}}{n_{w}^{2}} \sum_{i=1}^{2} g_{i}\left(\frac{b_{b}}{b_{b}+a}\right)^{i}
$$

where $t$ is sea-air transmission factor and $n_{w}$ is the index of refraction of the water. $g_{1}=0.0949$ and $g_{2}=0.0794$.

(3) The Kubelka-Munk model (Kubelka and Munk, 1931),

$$
r_{r s}(\lambda)=\frac{\sqrt{1+2 x}-1}{\sqrt{1+2 x}+1}
$$

where $x=b_{b} / a$ and the model is referred to as the K-M model for brevity.

(4) The Duntley model, which is expressed in Eq. (2.15). 
To understand how SPM concentration can affect these models, we made some assumptions that first only water absorbed in these models and thus $a$ equals $a_{w}$ over the whole spectral range. Second, the backscattering coefficients of CDOM and chlorophyll are negligible in the turbid water, which gives $b_{b}$ as a total of $b_{b w}$ and $b_{b p}$. Moreover, $b_{b p}$ is assumed to be linearly related to the SPM concentration $\left(C_{S P M}\right)$ and at a reference wavelength. Then we define,

$$
x \equiv \frac{b_{b}}{a}=\frac{b_{b w}+b_{b p}}{a_{w}} \rightarrow b_{b p}=a_{w} \times x-b_{b w}=f \times C_{S P M}
$$

where $f$ is the empirical coefficient of the linear relationship between $C_{S P M}$ and $b_{b p}$.

Based on the above assumptions and Eq. (2.28), the variation of under-water irradiance reflectance predicted by these four models with increasing SPM concentration is presented in Figure 2.2. Note that the assumptions may not hold in natural waters, especially in optically-complex waters, but the simplification of the IOPs could still provide some insights into how different models respond to increasing water turbidity.
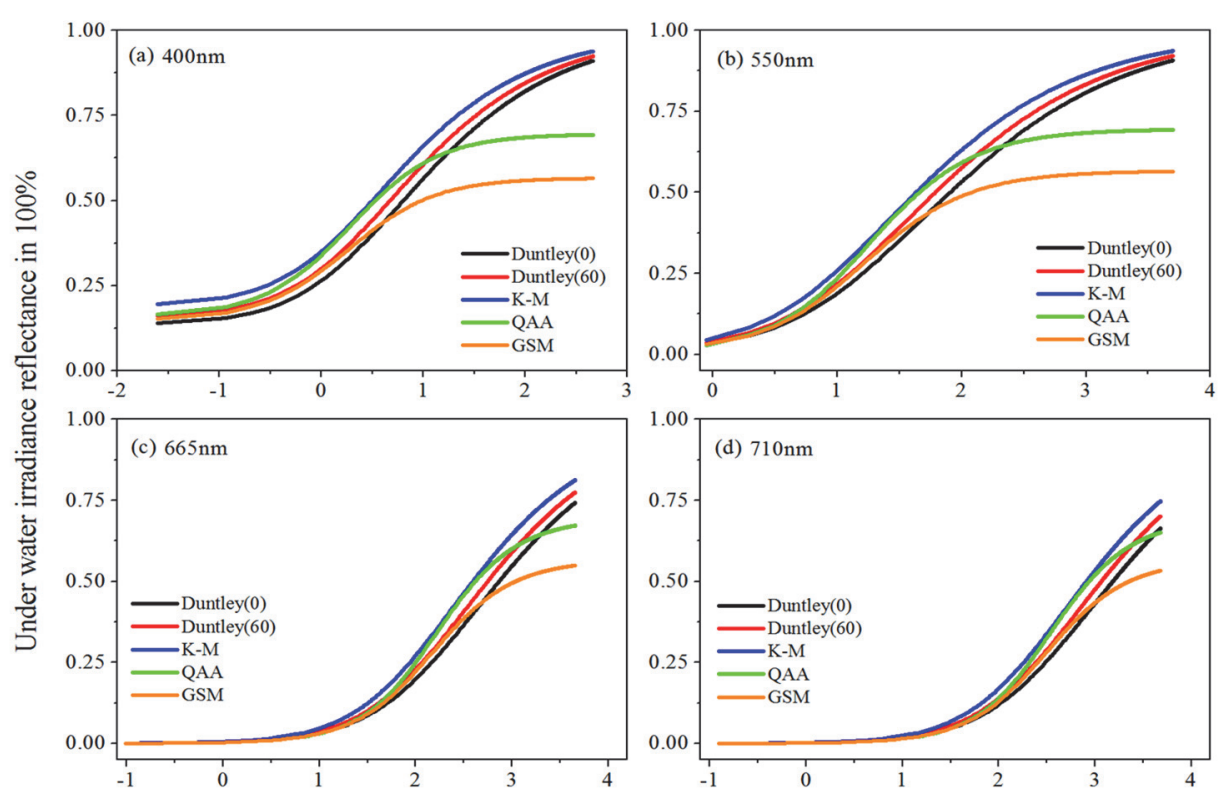

SPM concentration $\mathrm{mg} / \mathrm{L}(\log 10$ scale)

Figure 2.2. Model sensitivities to SPM concentrations at different reference wavelengths (' 0 ' and ' 60 'for the Duntley model refer to the under-water solar zenith angle). 
As shown in Figure 2.2, under-water irradiance reflectance predicted by the four IOPs demonstrate different trends with the increasing of $C_{S P M}$. The predictions of QAA and GSM model present a similar pattern, as both of them employ the quadratic relationship and their major difference lies in the coefficients of the quadratic equations. These two models present an earlier saturation of the underwater irradiance reflectance compared with the K-M model and the Duntley model, which indicates they will be less sensitive to very high $C_{S P M}$. Therefore, using the K-M model or Duntley model could be more suitable to formulate the relationship between IOPs and reflectance in optically-complex waters. As expressed in Eq. (2.15) and Eq. (2.27), the prediction from the Duntley model would be equal to the K-M model when the $\mu_{w}$ in Eq. (2.15) equals 0.5, which corresponds to an under-water zenith angle of $60^{\circ}$. However, this assumption can never happen for sunlight under water since the maximum angle of refraction is $48.6^{\circ}$. Thus, the results of the K-M model may lead to an overestimation in the calculation of under-water irradiance reflectance. It is worthy to note that results in Figure 2.2 also indicate that the saturation effects could shift from blue bands to longer wavelengths with increasing SPM, which is also confirmed from above water measured $R_{r s}$ (Knaeps et al., 2012; Knaeps et al., 2015; Luo et al., 2018; Shen et al., 2010b). 


\section{Chapter 3 Retrieval of the diffuse attenuation coefficient using the 2SeaColor model: A case study in the Yangtze Estuary*}

* This Chapter is based on:

Yu, X., Salama, M.S., Shen, F., \& Verhoef, W. (2016a). Retrieval of the diffuse attenuation coefficient from GOCI images using the 2SeaColor model: A case study in the Yangtze Estuary. Remote Sensing of Environment, 175, 109-119 


\subsection{Introduction}

The diffuse attenuation coefficient $\left(K_{d}\right.$, in $\left.\mathrm{m}^{-1}\right)$ is an important optical property of water bodies that describes the penetration of incident solar radiation in the water column. $K_{d}$ is classified as a quasi-inherent optical property (QIOP), since it depends on both the optically active water constituents and the distribution of the ambient light field (Kirk, 1984, 1991; Mobley, 1994; Smith and Baker, 1978).

Based on the fact that $90 \%$ of the diffusely reflected light from a water body comes from a surface layer of water within a depth of $1 / K_{d} \mathrm{~m}$, the diffuse attenuation coefficient shows potential effects on the functioning of ecological processes and biogeochemical cycles in oceanic and coastal ecosystems. Previous researches have shown that $K_{d}$ can be an effective indicator of turbidity in water and sediment transportation and resuspension (Kirk, 1994; Majozi et al., 2014; Zhang et al., 2006). Meanwhile, $K_{d}$ is a key parameter in studies such as heat transfer in the upper water layer (Stramska and Zuzewicz, 2013; Wu et al., 2007), phytoplankton photosynthesis and photobleaching (Loiselle et al., 2009; McClain et al., 1996), and the estimation of primary production in natural waters (Bergamino et al., 2010; Lee et al., 2011).

Algorithms for the remote retrieval of $K_{d}$ have been developed for clear waters (Austin and Petzold, 1981; Mueller, 2000), but they always generate huge errors in turbid waters due to the complexity in optical properties and limitations in the algorithms (IOCCG, 2000, 2006; Salama et al., 2011; Zibordi et al., 2009). To retrieve $K_{d}$ in optically complex waters, several methods were adopted. The empirical models were developed by statistical fitting based on in-situ measurements (Werdell and Bailey, 2005; Zhang and Fell, 2007). The semianalytic models usually calculated the $K_{d}$ from remotely retrieved inherent optical properties (IOPs) of water constituents (Doron et al., 2007; Lee et al., 2005a; Lee et al., 2005b; Morel and Loisel, 1998; Wang et al., 2009a).

Additionally, Salama and Verhoef (2015) developed the analytical 2SeaColor model to estimate $K_{d}$ at different spectral bands and depths, based on the solution of the radiative transfer equation using the two-stream approximation. The twostream approximation was previously adopted in the retrieval of suspended matter (Ambarwulan et al., 2012; Shen et al., 2010b). However, the assumption in the original 2SeaColor model that only water molecules contribute to the total absorption in the near-infrared (NIR) bands may not work for highly turbid waters, which leads to large uncertainties for observations from turbid waters. Therefore, 
an improvement in the 2 SeaColor model is strongly desired for $K_{d}$ estimation over turbid waters.

The objective of this study is to improve the 2SeaColor model and validate the respective performance of the $2 \mathrm{SeaColor}$ model and other empirical and semianalytical models. We first improve the parameterizations in the inversion scheme of the 2 SeaColor model. Then the 2SeaColor model is validated with three in-situ datasets and compared with empirical and semi-analytic models. At last, we produce $K_{d}$ maps over the Yangtze Estuary by implementing the 2SeaColor model on the level 2 product (L2P) of the Geostationary Ocean Color Imager (GOCI).

\subsection{Data and methods}

\subsubsection{Datasets}

Three in-situ datasets are employed in this study for model validation and intercomparison, which are collected from a variety of waters covering from Open Ocean to coastal regions. They are the NOMAD (NASA Bio-Optical Marine Algorithm Data set) (Werdell and Bailey, 2005), the COASTLOOC (Coastal Surveillance through Observation of Ocean Color) (Babin et al., 2003) and insitu measurements in Yangtze estuarine and coastal water, hereafter denoted as the Yangtze dataset. Figure 3.1 presents the locations of the in-situ observations of these three datasets. Solar zenith angle (SZA, in degree) of each observation is calculated according to location (latitude and longitude and time zone), date and time $(\mathrm{C}++$ code is available at $\mathrm{http} / / \mathrm{www} . \mathrm{psa} . e s / \mathrm{sdg} / \mathrm{sunpos} . \mathrm{htm})$. The percentage distribution of SZA for each dataset is presented in Figure 3.2. 

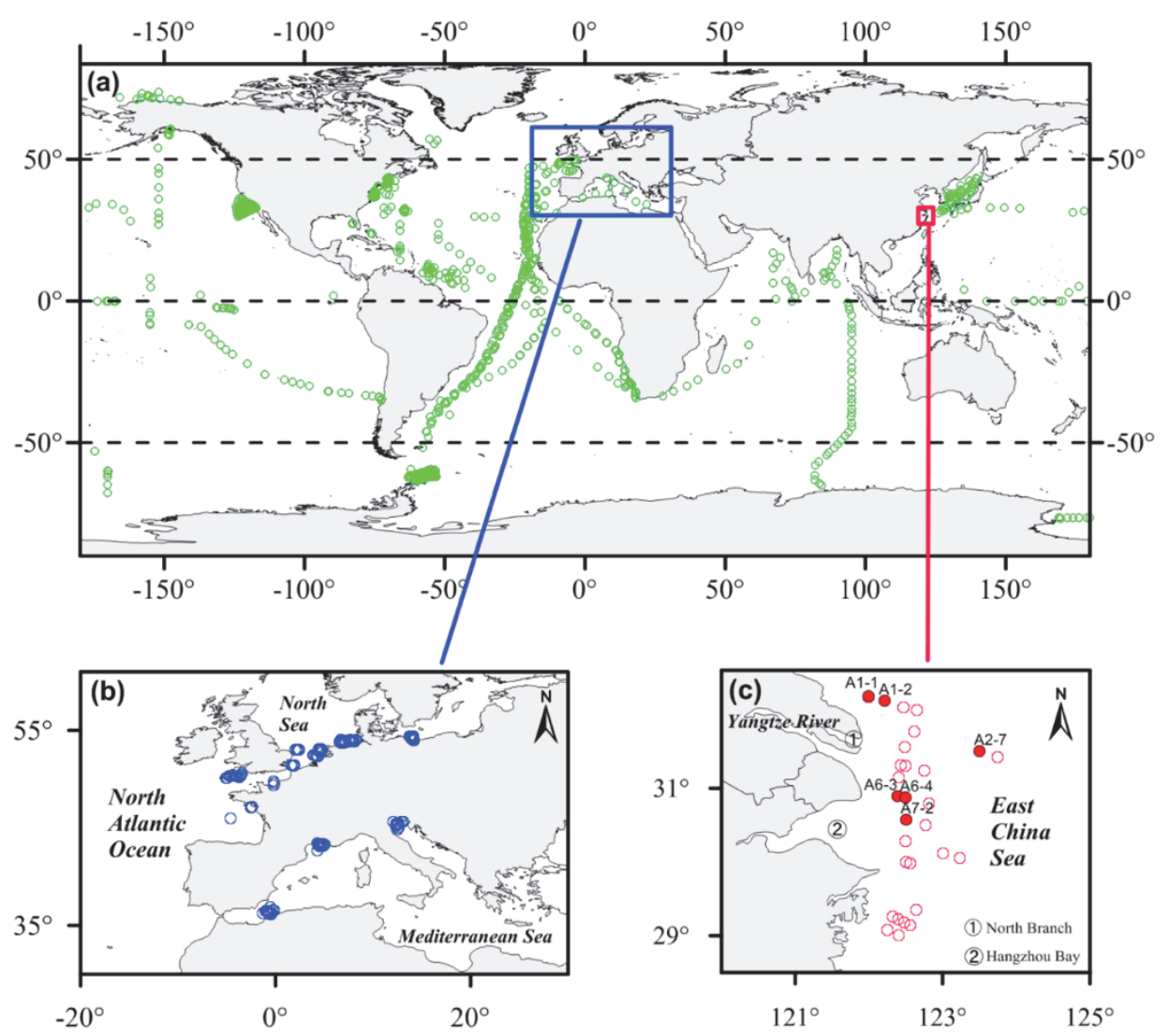

Figure 3.1. Location of the field data sets. (a) The NOMAD, (b) the COASTLOOC and (c) the Yangtze dataset (solid circles are matchups sites within 1h of GOCI capturing images). 


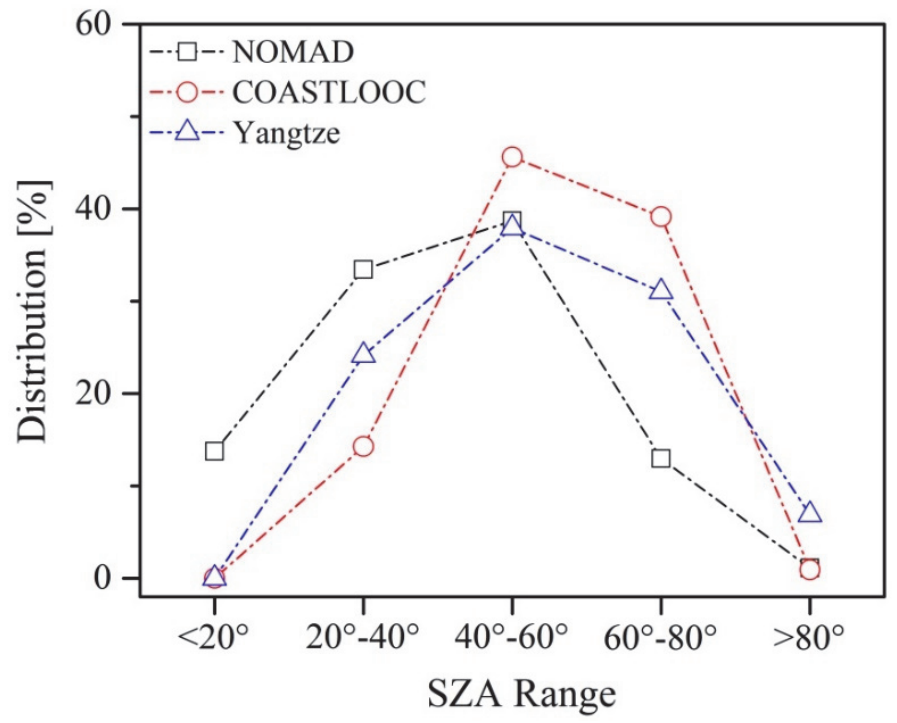

Figure 3.2. Percentage distribution of solar zenith angle (SZA) in the three in-situ datasets.

\subsubsection{NOMAD dataset}

The NOMAD dataset (Werdell and Bailey, 2005) contains 4459 observations of bio-optical parameters collected worldwide from Open Ocean to coastal waters. Observations were selected where the upwelling water radiance $\left(L_{w}\right)$ and the spectral downwelling irradiance $\left(E_{s}\right)$ in the bands at $411,443,489,510,555$, and $665 \mathrm{~nm}$ are all valid, as well as the diffuse attenuation coefficient at 443 and 489 $\mathrm{nm}$. As a result, 1518 concomitant observations were selected (sampled sites are shown in Figure 3.1a). The diffuse attenuation coefficient at $489 \mathrm{~nm}, K_{d}(489)$, of the selected observations ranges from $0.0085 \mathrm{~m}^{-1}$ to $0.9113 \mathrm{~m}^{-1}$ with an average value of $0.0852 \mathrm{~m}^{-1}$ and a standard deviation of $0.105 \mathrm{~m}^{-1}$. Remote sensing reflectance $\left(R_{r s}\right)$ is calculated as the ratio of upwelling water radiance $L_{w}$ to the downwelling irradiance $E_{s}$, and $K_{d}(489)$ is considered equivalent to $K_{d}(490)$ for model validation and inter-comparison in this study.

\subsubsection{COASTLOOC dataset}

The COASTLOOC dataset (Babin et al., 2003) consists of 422 observations of bio-optical parameters collected from European coastal waters. The irradiance reflectance just below the sea surface $R\left(0^{-}\right)$is available in the COASTLOOC data set instead of $R_{r s}$. Therefore, the $R\left(0^{-}\right)$was converted to $R_{r s}$ using the formulation used in Zhang and Fell (2007) where $R_{r s}=0.133 R\left(0^{-}\right)$. It is worthy to mention that this formulation uses a constant value for the upwelling irradiance-to- 
radiance ratio $(Q=4)$, which will generate uncertainties to the calculated $R_{r s}$. However, the effect of the $Q$ value on the derived $K_{d}$ is limited when the ratio of $R_{r s}$ or the spectral optimization technique is used, which will cancel out much of the dependencies. The COASTLOOC dataset was also filtered and 217 concomitant observations were selected where $R_{r s}$ and $K_{d}$ in the bands at 411, 443, $489,510,555,665$ and $705 \mathrm{~nm}$ are all valid, as well as the solar zenith angle $\theta_{s}$ (sampled sites are shown in Figure 3.1b). The $K_{d}(490)$ of the selected observations ranges from $0.025 \mathrm{~m}^{-1}$ to $2.976 \mathrm{~m}^{-1}$ with an average value of 0.490 $\mathrm{m}^{-1}$ and a standard deviation of $0.487 \mathrm{~m}^{-1}$.

\subsubsection{Yangtze dataset}

The Yangtze dataset was collected during a cruise campaign in the Yangtze estuarine and coastal water from $4^{\text {th }}$ to $19^{\text {th }}$ of March 2013. This dataset consists of 29 measurements of $R_{r s}$ and $K_{d}$ (sampled sites are shown in Figure 3.1c). Radiometric measurements were recorded by the Hyperspectral Surface Acquisition System (HyperSAS, Satlantic Inc., Canada), consisting of the seasurface radiance $\left(L_{t}\right)$, sky radiance $\left(L_{i}\right)$ and solar irradiance $\left(E_{s}\right)$ from 350 to 858 $\mathrm{nm}$ in 136 spectral channels. Details about sensors mounting and observation geometries can be found in Shen et al. (2014). $R_{r s}$ was calculated by Mobley (1999),

$$
R_{r s}=\frac{L_{w}}{E_{S}}=\frac{L_{t}-\rho L_{i}}{E_{S}}
$$

where $\rho$ is the sea surface reflectance factor which is a function of solar zenith angle and surface roughness. The Ruddick-Hojerslev model (RHM) (Ruddick et al., 2006) is adopted here to compute the $\rho$ (See Table 6 in Sokoletsky and Shen (2014)).

Vertical profiles of underwater downwelling planar irradiance, $E_{d}(\lambda, z)$, were recorded by the Hyperspectral Ocean Color Radiometer (HyperOCR, Satlantic Inc., Canada), which provides 136 channels of factory calibrated optical data from 350 to $858 \mathrm{~nm} . K_{d}$ is calculated as the absolute slope of a linear regression fitting between $\ln \left[E_{d}(\lambda, z)\right]$ and depth $z$ (Darecki and Stramski, 2004; Kirk, 1994). For the calculation of $K_{d}$ in the surface layer, $E_{d}(\lambda)$ between 0.6 and $2 \mathrm{~m}$ with a $0.1 \mathrm{~m}$ interval are used in the linear regression, and results with determination coefficients larger than 0.99 are accepted. Field measured $R_{r s}$ and $K_{d}$ are presented in Figure 3.3. The $K_{d}$ spectrum is smoothed using the adjacentaveraging method (explanation at http://www.originlab.com/doc/Origin- 
Help/Smooth-Algorithm). $K_{d}(490)$ in the Yangtze data set ranges from 0.179 $\mathrm{m}^{-1}$ to $3.462 \mathrm{~m}^{-1}$ with an average value of $1.229 \mathrm{~m}^{-1}$ and a standard deviation of $0.968 \mathrm{~m}^{-1}$.
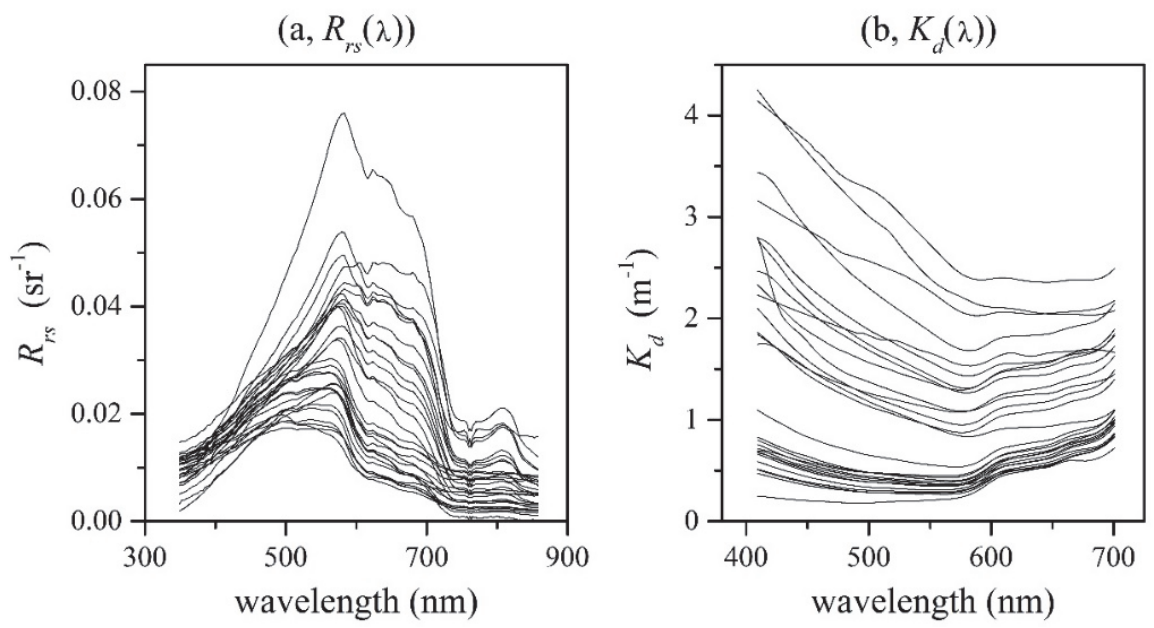

Figure 3.3. Field measured spectra of $R_{\mathrm{rs}}(\lambda)$ and $K_{\mathrm{d}}(\lambda)$ of the Yangtze dataset.

\subsubsection{GOCI images and atmospheric correction}

GOCI (2010 - present) is a geostationary-orbiting ocean color instrument with a spatial resolution of $500 \mathrm{~m}$. It acquires data in eight spectral bands (six visible and two NIR), and eight images are available for the Yangtze Estuary during daytime from 00:15 to 07:45 UTC (Ryu et al., 2012). Table 3-1 briefly introduces the spectral band, bandwidth, and the primary applications for the eight GOCI bands which are centered at $412,443,490,555,660,680,745$, and $865 \mathrm{~nm}$, respectively. A maximum of three images is free for download before the year 2014 from the official website (http://hero911.dothost.co.kr/list_GOCI.php?dir=/GOCI/1.0), while all images are free to access since 2014. 
Table 3-1. Introduction of the GOCI 8 spectral bands and their primary application.

\begin{tabular}{|c|c|c|c|}
\hline Band & $\begin{array}{c}\text { Central } \\
\text { Wavelengths } \\
\text { (nm) }\end{array}$ & $\begin{array}{l}\text { Bandwidth } \\
\quad(\mathrm{nm})\end{array}$ & Primary Application \\
\hline 1 & 412 & 20 & Yellow substance and turbidity \\
\hline 2 & 443 & 20 & Chlorophyll absorption maximum \\
\hline 3 & 490 & 20 & Chlorophyll and other pigments \\
\hline 4 & 555 & 20 & Turbidity, suspended sediment \\
\hline 5 & 660 & 20 & $\begin{array}{l}\text { Baseline of fluorescence signal, } \\
\text { Chlorophyll, suspended sediment }\end{array}$ \\
\hline 6 & 680 & 10 & $\begin{array}{l}\text { Atmospheric correction and } \\
\text { fluorescence signal }\end{array}$ \\
\hline 7 & 745 & 20 & $\begin{array}{l}\text { Atmospheric correction and baseline of } \\
\text { fluorescence signal }\end{array}$ \\
\hline 8 & 865 & 40 & $\begin{array}{l}\text { Aerosol optical thickness, vegetation, } \\
\text { water vapor reference over the ocean }\end{array}$ \\
\hline
\end{tabular}

Six in-situ measurements were sampled within $1 \mathrm{~h}$ of GOCI overpass and selected as matchups in this study. A match-up set is the pair of a 3-by-3 satellite pixel box and an in-situ site matching in location and sampling time. The average value of the 3-by-3-pixel box is used as the matched value of $R_{r s}$ and $K_{d}$. The matched images were acquired on 03:04 UTC and 04:16 UTC of March $4^{\text {th }}$ (the matchups sites are A1-1 and A1-2 in Figure 3.1c), 02:16 UTC of March $5^{\text {th }}$ (A2-7 in Figure 3.1), 02:16 UTC of March $8^{\text {th }}$ (A6-3 and A6-4 in Figure 3.1c) and 04:16 UTC of March $9^{\text {th }}($ A7-2 in Figure 3.1c).

In this study, we corrected the GOCI image using the standard atmospheric correction algorithm (Ahn et al., 2012) which is implemented in GDPS (GOCI Data Processing System) version 1.3. This algorithm is theoretically based on the SeaWiFS method (Gordon and Wang, 1994b) with modifications for turbid waters where the black pixel assumption is invalid (Goyens et al., 2013; Hu et al., 2000; Salama et al., 2004; Salama and Shen, 2010a; Wang and Shi, 2007; Wang et al., 2009b). To improve the accuracy of retrieved water-leaving reflectance in turbid waters, GDPS version 1.3 adopts method of (Hu et al., 2000) to select the nearest non-turbid pixels for deducing NIR water leaving reflectance in turbid waters, and uses the NIR $R_{r s}$ empirical relationship of (Ruddick et al., 2000) for constraining the AC. A brief algorithm description of GDPS version 1.3 can be found at http://222.236.46.37/GDPS/ATBD master_v9.pdf. The GOCI level 2 product (L2P) from GDPS including remote sensing reflectance $\left(R_{r s}\right)$, which is used in this study to produce maps of diffuse attenuation coefficient. 


\subsubsection{The 2SeaColor model}

The 2SeaColor model is based on the solution of the two-stream radiative transfer equations including direct sunlight, as described in Duntley $(1942,1963)$. Both the analytical forward model and the inversion scheme are provided in detail in Salama and Verhoef (2015). To analytically derive $K_{d}$ from $R_{r s}$, the first step is to derive the total absorption coefficient $(a)$ and backscattering coefficient $\left(b_{b}\right)$ from $R_{r s}$ in the inversion scheme using spectral optimization, after which $K_{d}$ is calculated from the derived IOPs using the analytical forward model. Descriptions of the analytical forward model and the inverse scheme are included in Section 2.2.1 and Section 2.2.2, respectively.

\subsubsection{The Zhang model and the Lee model}

To evaluate the performance of the 2SeaColor model, we compare the 2SeaColor model with previous reported empirical and semi-analytical models. The candidate empirical model is the Zhang model (ratio-based) (Zhang and Fell, 2007), and the semi-analytical model is the Lee model (IOPs-based) (Lee et al., 2005a; Lee et al., 2005b).

(i) The Zhang model:

If $\frac{R_{r s}(490)}{R_{r s}(555)} \geq 0.85$ then

$$
K_{d}(490)=10^{\left(-0.843-1.459 X-0.101 X^{2}-0.811 X^{3}\right)}+0.016
$$

where $\mathrm{X}=\log _{10}\left(\frac{R_{r s}(490)}{R_{r s}(555)}\right)$;

If $\frac{R_{r s}(490)}{R_{r s}(555)}<0.85$ then

$$
K_{d}(490)=10^{\left(0.094-1.302 X+0.247 X^{2}-0.021 X^{3}\right)}+0.016
$$

where $\mathrm{X}=\log _{10}\left(\frac{R_{r S}(490)}{R_{r s}(665)}\right)$;

(ii) The Lee model

Total absorption and backscattering coefficient, $a(\lambda)$ and $b_{b}(\lambda)$, are first derived from remote sensing reflectance by the 2 SeaColor model using the spectral optimization. $K_{d}(490)$ is then calculated according to the following equation (Lee et al., 2005a), 


$$
\begin{aligned}
K_{d}(490)=(1 & \left.+0.005 \theta_{s}\right) a(490) \\
& +4.18\left(1-0.52 \mathrm{e}^{-10.8 a(490)}\right) b_{b}(490)
\end{aligned}
$$

where $\theta_{s}$ is the sun zenith angle.

\subsubsection{Data analysis}

Five statistical parameters are used to quantitatively evaluate the goodness-of-fit between derived and known values. They are the slope and intercept of the regression line, the determination coefficient $R^{2}$, the mean of absolute relative difference (rMAD) and the root mean square error (RMSE). The rMAD and RMSE are defined as follows,

$$
\begin{gathered}
\mathrm{rMAD}=\sum \mid 1-\text { derived } / \text { known } \mid / \mathrm{N} \times 100 \% \\
\mathrm{RMSE}=\sqrt{\sum(\text { derived }- \text { known })^{2} / \mathrm{N}}
\end{gathered}
$$

where $\mathrm{N}$ is the number of observations. Additional parameters such as the percentage of observations within $25 \%$ and $100 \%$ relative error (F25 and F100, respectively) are also provided.

\section{$3.3 \quad$ Results}

\subsubsection{Improvement on the parameterizations}

Considering $R_{r s}$ in the NIR bands (>750 nm) are absent in both the NOMAD and the COASTLOOC datasets, the comparison between the original 2SeaColor and the improved version proposed in this study is made on the Yangtze dataset and the IOCCG (International Ocean Colour Coordinating Group) synthetic dataset.

The IOCCG dataset is available at http://www.ioccg.org/groups/OCAG_data.html, and the synthetic data for the sun at $30^{\circ}$ from zenith is used in this study. The comparison is presented in Figure 3.4. As shown in Figure 3.4a, the original 2 SeaColor seems to overestimate $K_{d}$ systematically for observations with high $K_{d}$. It is more obvious in Figure $3.4 \mathrm{~b}$ that the improved version provides more accurate $K_{d}$ estimations for the Yangtze dataset compared to the original one. 
(a) IOCCG dataset

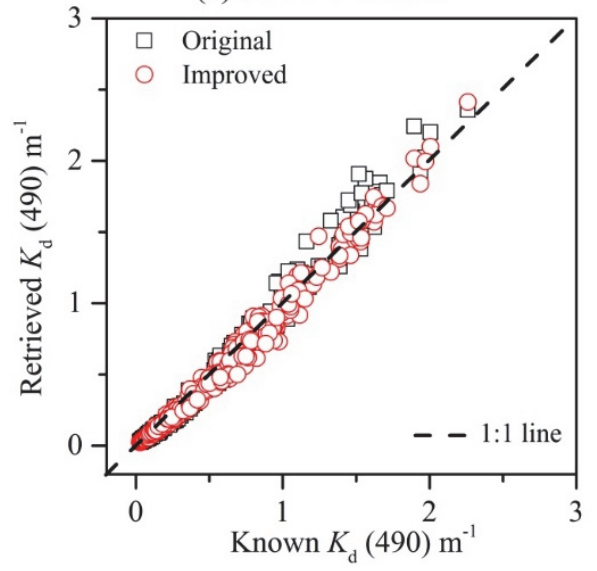

(b) Yangtze dataset

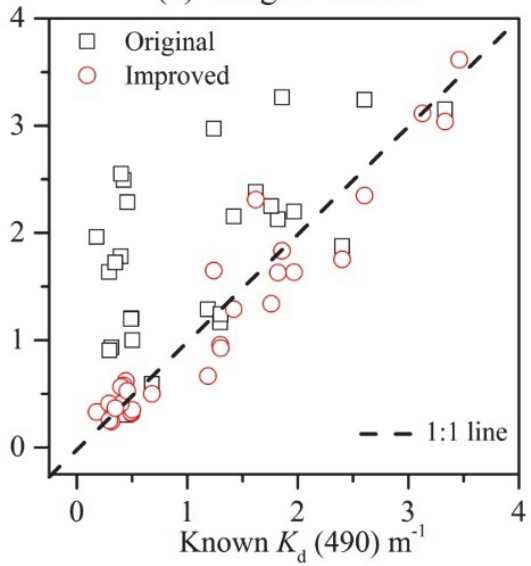

Figure 3.4. Comparison between the original $2 \mathrm{SeaColor}$ model and the $2 \mathrm{SeaColor}$ model with improved parameterizations for (a) IOCCG dataset and (b) Yangtze dataset.

\subsubsection{Validation and inter-comparison for $K_{\mathrm{d}}$ retrieval models}

Three in-situ datasets described in Section 3.2.3 are used to validate the 2SeaColor model. The performance of the 2SeaColor model is compared with the empirical Zhang model and the semi-analytical Lee model with IOPs derived from the 2 SeaColor model. Figure 3.5 shows the known versus derived $K_{d}(490)$ for all $K_{d}$ retrieval models applying on three in-situ datasets. In order to get a better understanding of these models and their limitations, we divide the three datasets into two subsets for observations from clear and turbid water, respectively. The threshold used in the Zhang model is adopted here, which is corresponding to $K_{d}(490)=0.2 \mathrm{~m}^{-1}$. This threshold is also considered as an upper limit for simple empirical algorithms (Lee et al., 2013; Lee et al., 2005a). 

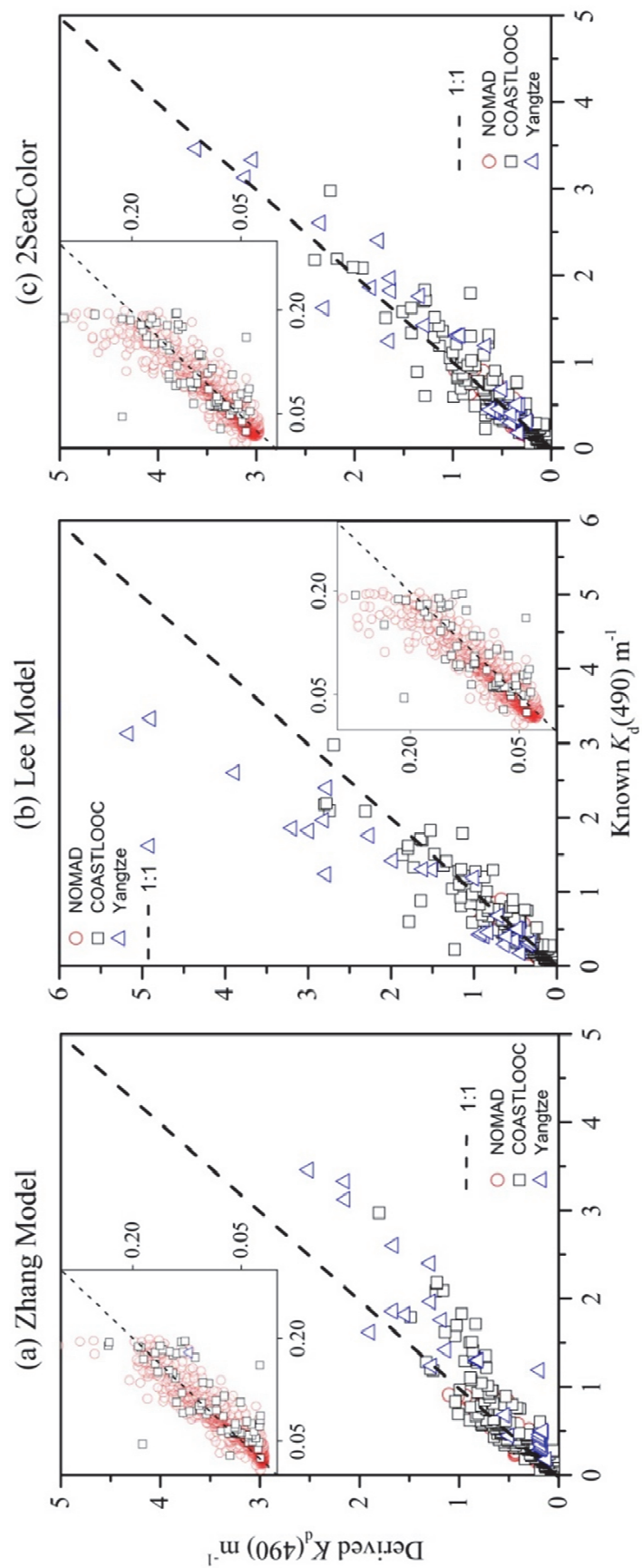

Figure 3.5. Known versus derived $K_{d}(490)$ for (a) Zhang model, (b) Lee model and (c) 2SeaColor model, applied to all three data sets. The insets with smaller markers show the results for low $K_{d}(490)$ observations where known $K_{d}(490) \leq 0.2 \mathrm{~m}-1$. 
The overall performance of the $2 \mathrm{SeaColor}$ model is better than that of the other two models with data points well distributed around the 1:1 line (see Figure 3.5c). The Lee model seems to overestimate $K_{d}$ in turbid waters as shown in Figure 3.5b, especially for the Yangtze dataset, while the Zhang model seems to systematically underestimate $K_{d}$ in turbid waters as shown in Figure 3.5a. From the insets in Figure 3.5, we can find that both the Lee model and the 2SeaColor model generate larger errors for some observations from clear water where $K_{d}$ $(490) \leq 0.2 \mathrm{~m}^{-1}$. Statistical results for the $K_{d}(490)$ estimation from all three models are listed in Table 3-2.

As presented in Table 3-2, we can observe that derived $K_{d}$ (490) from the 2SeaColor for the full range of observations is most accurate with the highest $R^{2}$ $(=0.935)$ and the smallest RMSE $\left(=0.078 \mathrm{~m}^{-1}\right)$, compared to the Zhang model $\left(R^{2}\right.$ $=0.898$ and $\left.\mathrm{RMSE}=0.113 \mathrm{~m}^{-1}\right)$ and the Lee model $\left(R^{2}=0.885\right.$ and RMSE $=$ $\left.0.157 \mathrm{~m}^{-1}\right)$. For observations from turbid waters where $K_{d}(490)>0.2 \mathrm{~m}^{-1}$, the 2SeaColor model provides most accurate $K_{\mathrm{d}}$ estimations, where the RMSE of the Zhang model and the Lee model are $50 \%$ and $109 \%$ greater than that of 2SeaColor. The highest $R^{2}(=0.891)$ and the smallest rMAD $(=21.56 \%)$ are also found for retrievals from the 2 SeaColor model for turbid water observations. Predictions from the 2SeaColor are stable with $64.18 \%$ of the estimations confined within a $25 \%$ relative error margin and $99.29 \%$ of the estimations confined within a $100 \%$ relative error margin. For clear waters where $K_{d}(490) \leq$ $0.2 \mathrm{~m}^{-1}$, the Zhang model provides the best estimates with almost unity slope, the smallest $\mathrm{rMAD}(=21.26 \%)$ and $\mathrm{RMSE}\left(=0.017 \mathrm{~m}^{-1}\right)$. However, the performance of the $2 \mathrm{SeaColor}$, in this case, are rather comparable in terms of both RMSE (= $\left.0.020 \mathrm{~m}^{-1}\right)$ and $\mathrm{rMAD}(=22.58 \%)$.

Table 3-2. Statistical results of three $K_{\mathrm{d}}$ retrieval models with respect to observations divided into two subsets with a threshold of $K_{d}(490)=0.2 \mathrm{~m}^{-1}$.

\begin{tabular}{|c|c|c|c|c|c|c|c|c|c|}
\hline & \multicolumn{3}{|c|}{ All $(N=1764)$} & \multicolumn{3}{|c|}{$K_{d}(490) \leq 0.2 \mathrm{~m}^{-1}(\mathrm{~N}=1481)$} & \multicolumn{3}{|c|}{$K_{d}(490)>0.2 \mathrm{~m}^{-1}(\mathrm{~N}=283)$} \\
\hline & Zhang & Lee & 2SeaColor & Zhang & Lee & 2SeaColor & Zhang & Lee & 2SeaColor \\
\hline Slope & 0.769 & 1.325 & 0.929 & 1.099 & 1.162 & 1.125 & 0.686 & 1.468 & 0.908 \\
\hline Intercept & 0.014 & -0.03 & 0.012 & -0.013 & -0.002 & -0.001 & 0.093 & -0.203 & 0.023 \\
\hline$R^{2}$ & 0.898 & 0.885 & 0.935 & 0.879 & 0.845 & 0.846 & 0.824 & 0.835 & 0.891 \\
\hline RMSE & 0.113 & 0.157 & 0.078 & 0.017 & 0.021 & 0.020 & 0.279 & 0.388 & 0.186 \\
\hline rMAD & 21.78 & 23.32 & 22.43 & 21.26 & 22.99 & 22.58 & 24.52 & 25.03 & 21.56 \\
\hline $\mathrm{F} 25$ & 63.27 & 67.74 & 67.46 & 64.55 & 67.99 & 68.13 & 56.38 & 66.43 & 64.18 \\
\hline $\mathrm{F} 100$ & 99.72 & 98.47 & 99.09 & 99.66 & 98.71 & 99.05 & 100.00 & 97.17 & 99.29 \\
\hline
\end{tabular}


Compared to the 2SeaColor model, the slopes from the linear regression of derived and known $K_{d}(490)$ of the Zhang model and the Lee model are far off unity, especially in turbid waters where the slope is more than $30 \%$ off unity for the Zhang model and almost $50 \%$ off unity for the Lee model. The difference in the slope indicates that predictions from the Zhang model will be underestimated with increasing $K_{d}$, while predictions from the Lee model will be overestimated with increasing $K_{d}$.

\subsubsection{Estimating $K_{d}$ from GOCI images}

\subsubsection{Atmospheric correction for GOCI image}

To demonstrate the performance of the GOCI standard atmospheric correction algorithm, we compared the field measured $R_{\mathrm{rs}}$ and the $R_{\mathrm{rs}}$ product of GOCI at six matchups sites (Figure 3.6). The GOCI standard atmospheric correction algorithm implemented in GDPS 1.3 generates an acceptable error with RMSE = $0.005 \mathrm{sr}^{-1}$ and $\mathrm{rMAD}=27.30 \%$, which is in accordance with the expected error (Salama and Stein, 2009; Wang et al., 2009b). Note that only seven bands were adopted in the comparison because $R_{r s}(865)$ is not available in the Yangtze dataset.

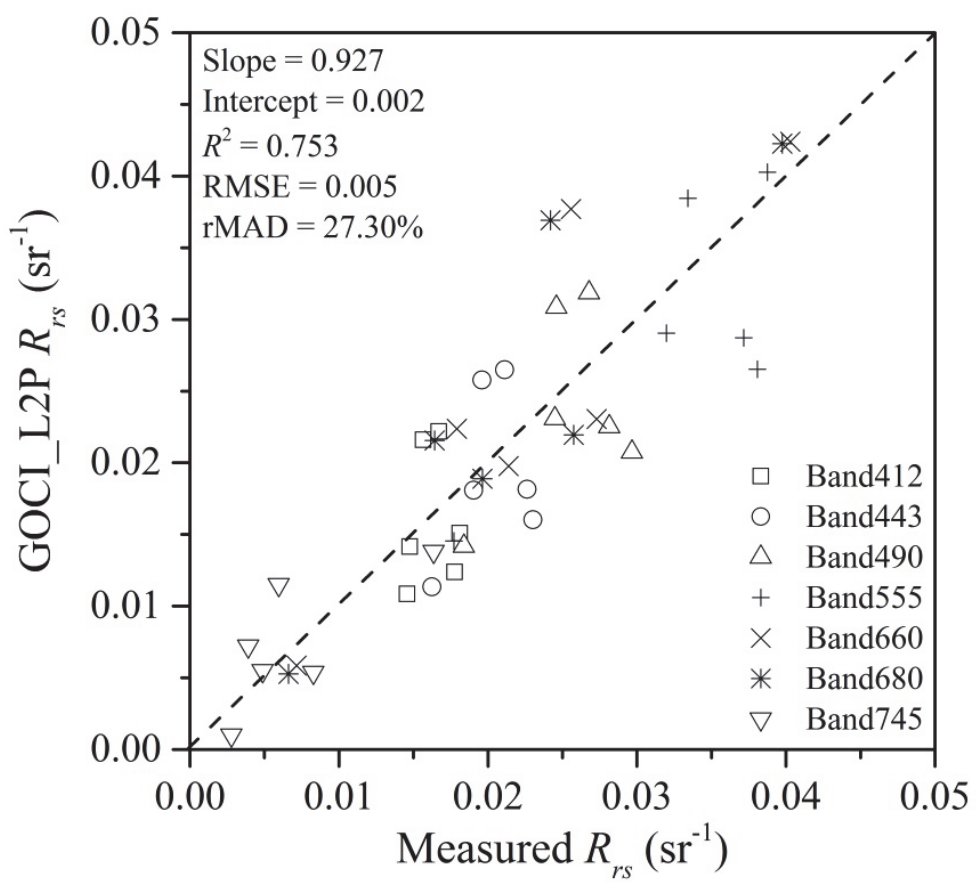

Figure 3.6. Comparisons between field-measured $R_{r s}$ and GOCI $R_{r s}$ product for six matchups at each GOCI bands except band $865 \mathrm{~nm}$. 
It is worthy to mention that the GOCI standard atmospheric correction masks out highly turbid pixels in some of the matched images, even in some of the clear water pixels in this study, which was also reported in previously published results (Hu et al., 2012; Shen et al., 2014). However, developing a more accurate atmospheric correction or recovering the masked pixels (Nordkvist et al., 2009) is out of the scope of this study. The GOCI standard atmospheric correction is considered appropriate for us to focus our study on the retrieval and validation of the diffuse attenuation coefficient.

\subsubsection{Producing $K_{d}$ maps using the 2 SeaColor model}

To better present the distribution of $K_{d}$ over the Yangtze estuary, we selected an image with the minimum number of masked pixels from all matched images, which was captured at 02:16 UTC, on $8^{\text {th }}$ March 2013. The 2SeaColor model was applied to the L2P product of this image to produce $K_{d}$ maps over the Yangtze estuary at wavelengths of $440,490,550$ and $640 \mathrm{~nm}$, respectively. The produced $K_{d}$ maps are shown in Figure 3.7. 

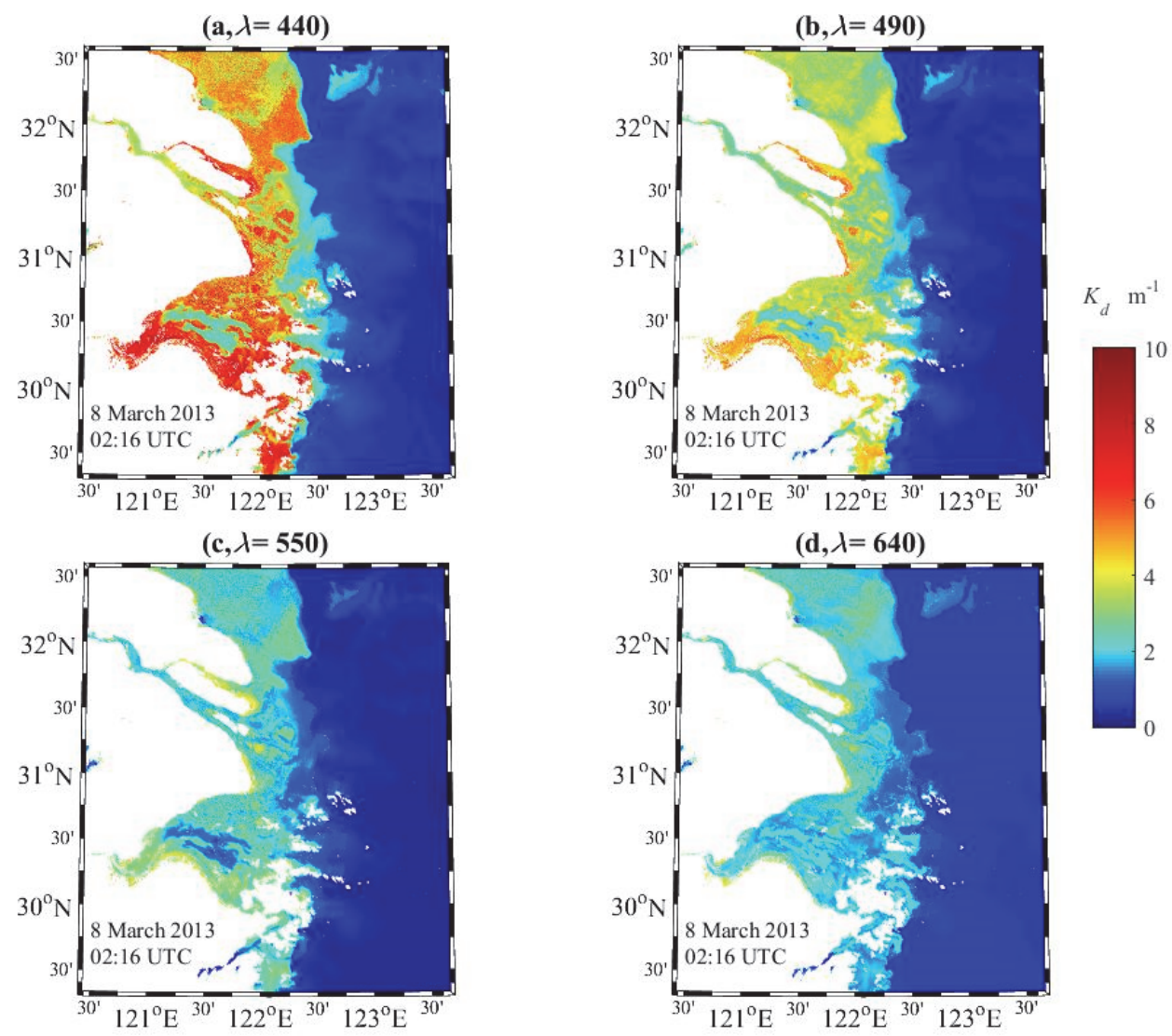

Figure 3.7. $K_{d}$ derived from atmospherically corrected GOCI image using the 2SeaColor model. Four wavelengths are shown: (a) 440nm, (b) 490nm, (c) 550nm and (d) $640 \mathrm{~nm}$.

The spatial distribution of the diffuse attenuation coefficient at the four chosen wavelengths shows the same pattern. A wide range of $K_{d}$ is observed as high $K_{d}$ values are present in nearshore waters, especially in Hangzhou Bay and the North Branch of the Yangtze Estuary (see Figure 3.1c), while $K_{d}$ in offshore waters is about 1 2 orders of magnitude lower. For instance, in Figure 3.7b, $K_{d}(490)$ reaches approximately $10 \mathrm{~m}^{-1}$ in some pixels in Hangzhou Bay and the North Branch but keeps steadily low at around $0.1 \mathrm{~m}^{-1}$ in offshore waters. The $K_{d}$ maps confirm that both Hangzhou bay and the Yangtze Estuary (especially the North Branch) are extremely turbid waters, which is highly consistent with the known distribution of suspended matter in this area (Shen and Verhoef, 2010; Shen et al., 2010b; Shen et al., 2013; Shen et al., 2014).

From Figure 3.7 we can observe that $K_{d}$ decreases from $440 \mathrm{~nm}$ to $640 \mathrm{~nm}$ in nearshore waters, but $K_{d}$ at $640 \mathrm{~nm}$ in offshore waters is higher than at other 
wavelengths. The difference between the $K_{d}$ spectra in clear and turbid waters can also be found in other published studies (Lee et al., 2013) as well as in field measurements in the Yangtze dataset (see Figure 3.3b). The nature of this behavior is the difference in the constituents between clear and turbid waters. For turbid water in the Yangtze estuary, where suspended particulate matter (SPM) and CDOM dominate the inherent optical properties (IOPs), namely a higher absorption coefficient as well as a higher backscattering coefficient at short wavelengths, which leads to a higher $K_{d}$ value in this range. For clear water where chlorophyll and water molecules dominate the IOPs, the behavior of the $K_{d}$ spectrum is mainly determined by the tremendous increase of the absorption coefficient of water molecules beyond $600 \mathrm{~nm}$.

\subsection{Discussion}

\subsubsection{The improved 2SeaColor model}

The improved 2SeaColor model with adopted parameterization provides a better estimation of retrieved $K_{d}(490)$, which proves that the assumption in the original parameterization of the $2 \mathrm{SeaColor}$ model is not valid for turbid waters. This is because the absorption coefficient in turbid waters is far more complex than the backscattering coefficient, and the 2SeaColor model will generate uncertainty if no prior knowledge of the absorption coefficient is available. Water molecules are not the only absorbing material in the NIR region in turbid waters, as laboratory experiments by Röttgers and Gehnke (2011) showed that natural water samples with high amounts of detrital material still absorb strongly in the NIR region after removing the contribution from the water molecules. Compared to the original 2SeaColor model that requires NIR spectral data, the improved parameterizations will enable the 2SeaColor model to be applied to the datasets without NIR spectral data such as the NOMAD and COASTLOOC datasets.

On the other hand, total absorption and backscattering coefficients ( $a$ and $b_{b}$ ) derived from the improved 2SeaColor model are within acceptable uncertainties for both clear and turbid waters. Figure 3.8 shows the validation of $a(490)$ and $b_{b}(490)$ derived from the improved 2SeaColor model using matched observations from the NOMAD and COASTLOOC datasets. For the NOMAD dataset, the accuracy of derived $a(490)$ from the 2SeaColor model is promising with $R^{2}$ of 0.708 and RMSE of $0.708 \mathrm{~m}^{-1}$ (Figure 3.8a). The accuracy of derived $b_{b}(490)$ (Figure 3.8c) is also robust with $R^{2}$ of 0.558 and RMSE of $0.001 \mathrm{~m}^{-1}$. As for the COASTLOOC dataset, the comparison between derived a(490) from the 
2SeaColor model and known $a(490)$ (Figure $3.8 \mathrm{~b}$ ) also shows good accordance with $R^{2}$ of 0.794 and RMSE of $0.201 \mathrm{~m}^{-1}$. Note that no matched $b_{b}(490)$ is available in the COASTLOOC dataset.

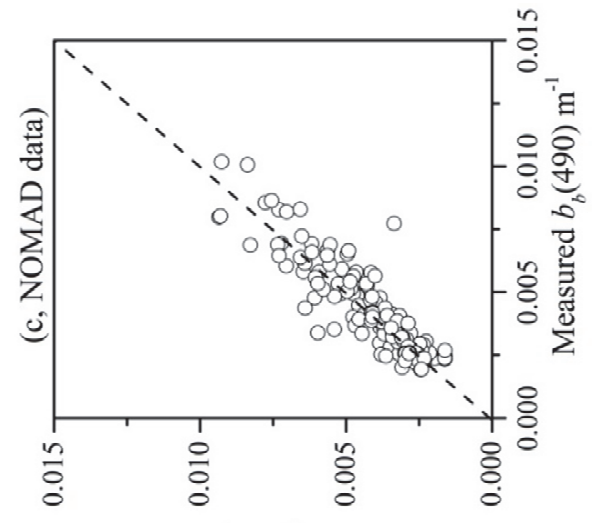

I- ${ }^{\mathrm{wu}}(06 \mathrm{t})^{q} q$ рәм!ฺ्व

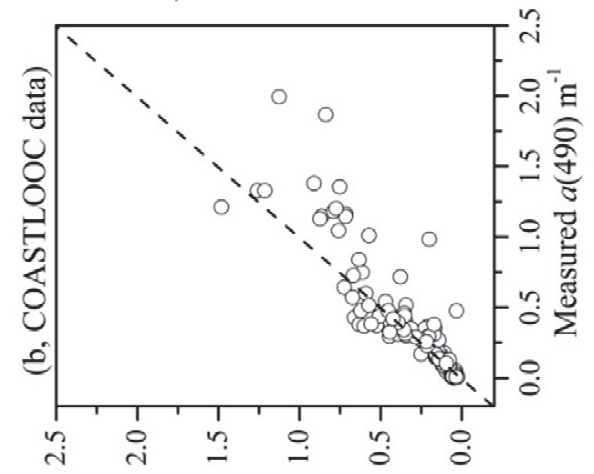

I- $\mathrm{u} \mathrm{(06t)p} \mathrm{рәл!га}$

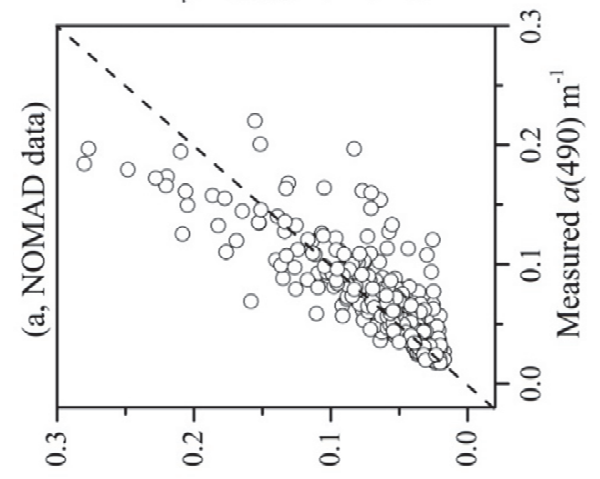

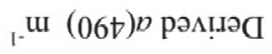

Figure 3.8. Validation of 2SeaColor-derived total absorption and backscattering coefficient at $490 \mathrm{~nm}, a(490)$ and $b_{b}(490)$, using matched observations in the NOMAD and COASTLOOC datasets. Note the difference in scales for $a(490)$ in both cases. 


\subsubsection{Assessments of $K_{d}$ retrieval models}

Empirical models based on simple blue/green $R_{r s}$ ratios are always deemed unsuitable for turbid coastal waters and considerably underestimate $K_{d}$ by a factor of $2 \sim 3$ or more in turbid waters (Chen et al., 2014; Sun et al., 2014a; Wang et al., 2009a). This is mainly because remote sensing reflectance in the blue and green bands is mainly affected by detrital material and gelbstoff in turbid waters. These two constituents absorb strongly in the blue region, which makes the waterleaving signal continually low in the blue region. Therefore, variations in the mixture of detrital material and gelbstoff may not affect the blue/green ratios of $R_{r s}$ but have huge effects on the diffuse attenuation coefficient. Both the Zhang model and the Lee model have often been applied in model inter-comparisons and were validated against various field measurements, showing that they were suitable for $K_{d}$ retrieval in both clear and turbid waters (Jamet et al., 2012; Lee et al., 2005b; Zhang and Fell, 2007). Results in this study show that derived $K_{d}$ from the 2SeaColor model is comparable with these two models in clear waters, while the 2 SeaColor has better performance over highly turbid waters.

The good performance for the Zhang model and the Lee model in clear water can be attributed to the fact that the empirical coefficients in these models have already been fine-tuned to clear waters during model development. For clear waters, where in most cases chlorophyll and water molecules dominate the optical properties, the variability of optical properties is rather limited compared to those of turbid waters. Therefore, the fine-tuned empirical or semi-analytical model should always work well for clear waters. However, when it comes to turbid waters, the empirical models generate large uncertainty since the fine-tuned coefficients are not suitable for optically complex waters, and a fine-tuning of the empirical coefficients would be required (Mitchell et al., 2014; Qiu et al., 2013). This is one of the main reasons that the empirical Zhang model systematically underestimates $K_{d}$, and the semi-analytical Lee model overestimates $K_{d}$ in turbid waters.

Additionally, $K_{d}$ is considered as sun angle dependent, and the ratio-based models are most likely to represent only the diffuse attenuation at a fixed angle (Lee et al., 2013). As for the three datasets, the percentage distribution (Figure 3.2) shows a large variation in sun zenith angle, the mismatch in sun zenith angle would result in large errors for the Zhang model. As presented in Figure 3.2, most observations were measured at sun zenith angles larger than $40^{\circ}$, especially for the COASTLOOC and the Yangtze datasets (the percentage are $85.71 \%$ and 
75.86, respectively). A large solar zenith angle usually results in a higher $K_{d}$ due primarily to the increased photon path length in water (Lee et al., 2013). The mismatch can be corrected for the IOPs-based Lee model and the 2SeaColor model where the solar zenith angle is used as an input parameter. However, for the Zhang model, the mismatch in sun zenith angle could contribute to the large uncertainty of derived $K_{d}$ in turbid waters.

As for the Lee model, the contribution rate of $b_{b}$ to $K_{d}$ is empirically modeled, which means estimations from the Lee model in turbid waters will also involve larger uncertainties without adapting the empirical coefficients. Another reason for the large uncertainty in turbid waters for the Lee model is that the scattering coefficient in turbid waters tends to become more significant in the forward direction, while the Lee model ignores this forward scattering. The forward scattering may have little effect on the reflectance, but it has a large effect on $K_{d}$.

In contrast, the success of the 2SeaColor for clear and turbid waters should be attributed to both the analytical forward model and its inversion scheme. The analytical forward model takes forward scattering into account by applying the similarity transformation, and estimates $K_{d}$ based on radiative transfer physics, while the inversion scheme, with improved parameterizations, can accurately derive the absorption and backscattering coefficients using the spectral optimization technique. In general, the advantages of the 2SeaColor model are: (i) no empirical relationships are involved and a fine-tuning of empirical coefficients is avoided; (ii) no prior knowledge on optical properties of the regions of interest is required; (iii) only the spectrum of remote sensing reflectance is necessary; (iv) it provides consistently accurate estimations for both clear and turbid waters. With these advantages, we can state that 2 SeaColor has little limitations due to regional variability in optical properties. Thus, 2SeaColor forms an attractive optional solution for the retrieval of $K_{d}$ from Earth Observation data for both clear and turbid waters. Furthermore, to produce the best diffuse attenuation coefficient for an image at a large spatial scale covering both clear and turbid waters, a blended algorithm combining the Zhang model for clear waters with the 2 SeaColor model for turbid waters would be an ideal approach.

\subsubsection{Variation of $K_{d}$ maps in Yangtze Estuary}

We reproduced the $K_{d}(490)$ maps from the selected GOCI images acquired on 8 March of 2013 using the Zhang model, the Lee model, and the 2SeaColor model 
and the results are presented in Figure 3.9. We can observe that the $K_{d}(490)$ maps over the Yangtze Estuary from all three models present the similar patterns in spatial distribution, also shown in previous studies (Shi and Wang, 2010; Shi et al., 2011; Sokoletsky et al., 2014; Wang et al., 2009a). As shown in Figure 3.9, results from all three models in clear waters are comparable, but significant differences can be observed in the extremely turbid regions, such as the Hangzhou Bay and North Branch of Yangtze Estuary. The $K_{d}$ map from the 2SeaColor model results in an approximate range from 0.04 to $9.82 \mathrm{~m}^{-1}$ (Figure $3.9 \mathrm{c}$ ), while the ranges of $K_{d}(490)$ from the Zhang model and the Lee model are 0.02 to 3.5 $\mathrm{m}^{-1}$ (Figure 3.9a) and 0.18 to $12.63 \mathrm{~m}^{-1}$ (Figure 3.9b), respectively. The magnitudes of $K_{d}(490)$ also vary largely compared to previously reported results for the Yangtze estuary. $K_{d}$ maps from Shi et al. (2011) and Shi and Wang (2010) are produced from Moderate Resolution Imaging Spectroradiometer (MODISAqua), yielding a range of derived $K_{d}(490)$ approximately from $0 \sim 4 \mathrm{~m}^{-1}$ and 0 $\sim 5 \mathrm{~m}^{-1}$, respectively. The highest $K_{d}(490)$ even reaches $250 \mathrm{~m}^{-1}$ when Sokoletsky et al. (2014) simply calculated $K_{d}$ (490) as the sum of total absorption and backscattering coefficient. 

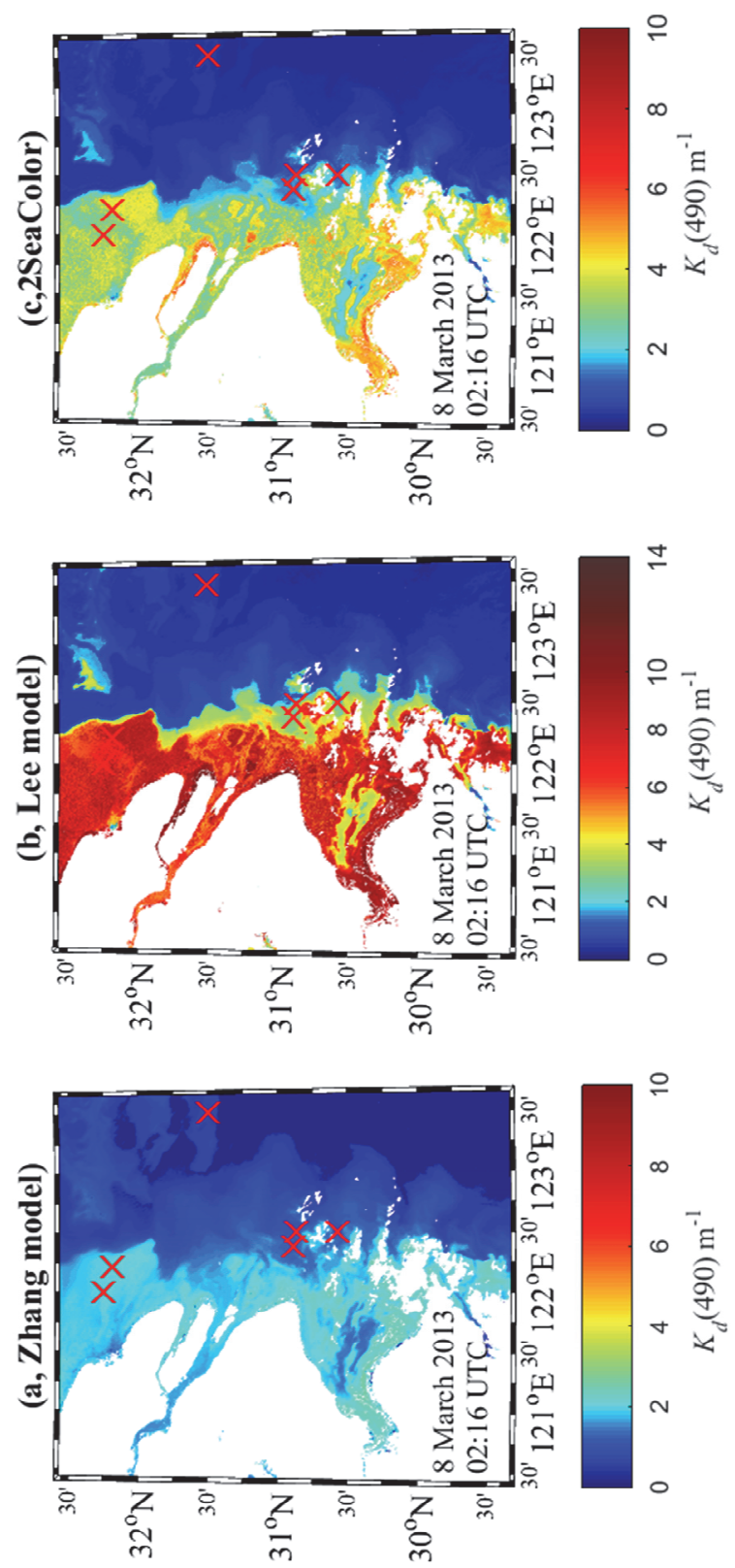

Figure 3.9. $K_{d}$ maps derived from the GOCI level 2 product (L2P) at wavelength 490 $\mathrm{nm}$ using (a) Zhang model, (b) Lee model and (c) 2SeaColor model. The image was captured at 02:16 UTC, 8 March 2013 and ' $\mathrm{X}$ ' marks are matchup sites.

We compared the field measured $K_{d}(490)$ with GOCI-derived $K_{d}(490)$ at six matchup sites for all three models, as presented in Figure 3.10. The results are in 
accordance with the comparison from the Yangtze dataset (Figure 3.8c) since the error from the GOCI standard atmospheric correction is acceptable (Figure 3.6). The 2SeaColor model $\left(R^{2}=0.937\right.$ and $\left.\mathrm{RMSE}=0.317 \mathrm{~m}^{-1}\right)$ is able to provide accurate and stable estimations, while the Zhang model $\left(R^{2}=0.817\right.$ and RMSE $\left.=0.640 \mathrm{~m}^{-1}\right)$ tends to underestimate $K_{d}(490)$ and the Lee model $\left(R^{2}=0.927\right.$ and RMSE $\left.=2.347 \mathrm{~m}^{-1}\right)$ tends to overestimate $K_{d}(490)$ for turbid conditions. Note that there are also six data points for the Zhang model in Figure 3.10, but two data points overlapped because both the measured and derived values are extremely close. These two matchup sites are geographically close to each other (A6-3 and A6-4 in Figure 3.1c).

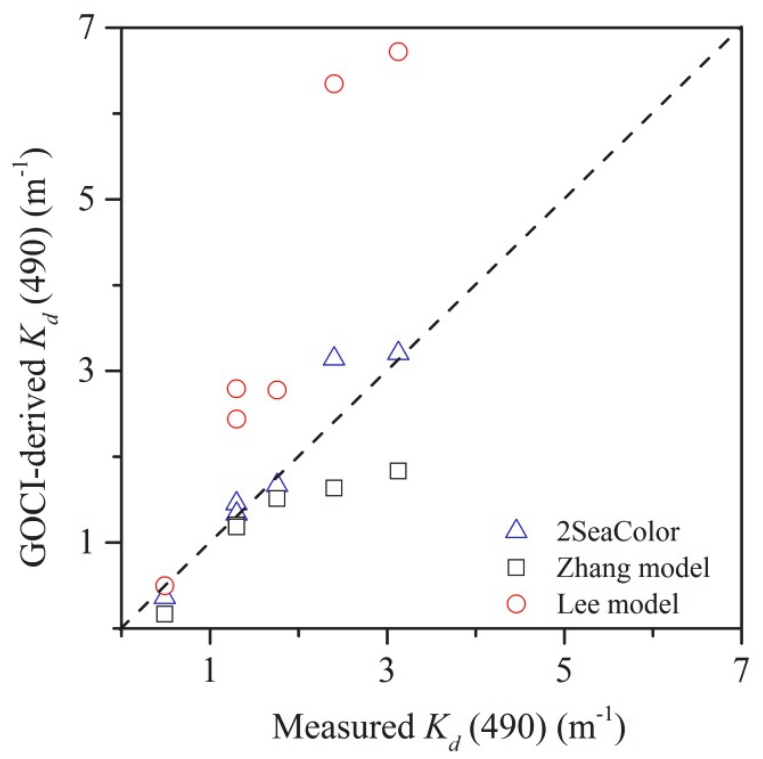

Figure 3.10. Comparison between field-measured $K_{d}(490)$ and GOCI-derived $K_{d}(490)$ using the Zhang model, the Lee model and the 2SeaColor model for the six matchups.

As we can see from Figure 3.9, all matchup sites are located in clear and medium turbid regions. It is worth mentioning that field measurements in the extremely turbid regions are absent for model validation in this study, making validation of derived $K_{d}$ in extremely turbid water impossible in this study. However, The $K_{d}(490)$ range predicted by the 2 SeaColor model is consistent with field measurements from the East China Sea and Yangtze estuarine waters by with $K_{d}(490)$ ranging from 0.03 to $10.3 \mathrm{~m}^{-1}$ with a mean value of $0.92 \pm 1.59 \mathrm{~m}^{-1}$ (Qiu et al., 2013). In addition, the concentration of suspended particulate matter (SPM) in the Hangzhou Bay and the North Branch of Yangtze Estuary is $1 \sim 2$ orders of magnitude greater than the one at the matchup sites (Shen et al., 2010b), which 
should result in a relatively large range of $K_{d}$. However, as shown in Figure 3.9a, the difference in $K_{d}$ derived from the Zhang model is rather small for pixels in the Hangzhou Bay and the two matchup sites at the top of the image that are considered in medium turbid waters, indicating that predictions from the Zhang model are underestimated in turbid waters.

On the other hand, $K_{d}(490)$ derived from the Lee model is above $6 \mathrm{~m}^{-1}$ in most coastal pixels as shown in Figure 3.9b, which is much larger than the average value reported by Qiu et al. (2013). In accordance with the validation of GOCIderived $K_{d}$ as shown in Figure 3.10, predictions from the Lee model could be systematically overestimated in medium and extremely waters. Therefore, we argue that the GOCI-derived $K_{d}$ map from the 2SeaColor model is more reliable, but further validation in extremely turbid waters is still strongly recommended.

\subsection{Conclusions}

In this study, we proposed improvements on the parameterizations in the inverse scheme of the analytical 2 SeaColor model. The 2SeaColor model, with improved parametrizations, can provide stable and accurate estimations of $K_{d}$ for wide ranges of water turbidity without the need for tuning coefficients from field measurements. The 2SeaColor model is more appropriate for $K_{d}$ retrieval in turbid waters, compared to the empirical Zhang model and the semi-analytical Lee model. Reasonable $K_{d}$ maps are also derived when applying the 2 SeaColor model to atmospherically corrected GOCI images, reproducing the expected magnitude and range of $K_{d}$ over the Yangtze Estuary. The successful application of 2SeaColor to GOCI images enables our further study of variations in the $K_{d}$ distribution at large spatial and temporal scales. 


\section{Chapter 4 Retrieval of wide-range suspended particulate matter concentration from remotely sensed particulate backscattering coefficients*}

* This Chapter is based on:

Yu, X., Salama, M.S., Shen, F., \& Verhoef, W. Retrieval of wide-range suspended particulate matter concentration from remotely sensed particulate backscattering coefficients in the Yangtze estuary. Preparing submission to Remote Sensing of Environment. 


\subsection{Introduction}

Suspended particulate matter (SPM) has long been recognized as a fundamental component in determining coastal ecological and biological functioning, as SPM limits available light in the water column and restrains phytoplankton growth and primary production (Cloern, 1987; Redalje and Fahnenstiel, 1994). Knowledge of the SPM dynamics could be beneficial for a better understanding of the transportation of riverine sediments, heavy metals and particulate organic carbon (Bunt et al., 1999; Chen et al., 2001; Liu et al., 2007). Investigating the variation of SPM could also provide practical suggestions for shipping channels maintenance, offshore constructions, and other administrative services. To better monitor SPM dynamics in coastal regions, remotely sensed imagery could be an efficient approach, which allows detection of SPM with synoptic spatial distributions and with high temporal-spatial resolutions (IOCCG, 2000, 2006).

Many efforts have been carried out to remotely retrieve SPM concentrations $\left(C_{\mathrm{SPM}}\right.$, in $\left.\mathrm{mg} / \mathrm{L}\right)$ from satellite images in the coastal waters, and numerous models have been developed empirically (Dogliotti et al., 2015; Zhang et al., 2010) or based on radiative transfer (Doxaran et al., 2006; Shen and Verhoef, 2010; Shen

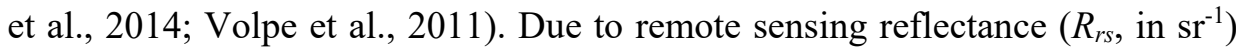
tends to saturate at high SPM concentrations at the visible wavebands (Lee et al., 2016; Nechad et al., 2010; Shen et al., 2010a), most empirically models are calibrated by the least-squares-fit between $C_{\mathrm{SPM}}$ and the reflectance ratio of NIR and visible bands (Doxaran et al., 2002b, 2003). The calibrated relationships, in the meantime, are also expected to switch from linear in less turbid waters (Binding et al., 2005; Hu et al., 2004) to noticeably curved for high-turbidity waters (Doxaran et al., 2002a; He et al., 2013; Mao et al., 2012).

The validity of $R_{r s}-C_{\mathrm{SPM}}$ models could be fundamentally attributed to the fact that SPM concentration is one of the major factors that determine the water absorption and scattering capability in aquatic environment, while $R_{r s}$ is a measure of bulk absorption $\left(a\right.$, in $\left.\mathrm{m}^{-1}\right)$ and backscattering coefficients $\left(b_{b}\right.$, in $\left.\mathrm{m}^{-1}\right)$ (Lee et al., 2002; Salama and Verhoef, 2015). The correlation between $C_{\mathrm{SPM}}$ and the water scattering properties is more profound as suspended particles are the major water constituent that scatters the light. For remote sensing applications, SPM is primarily related to the backscattering coefficient of suspended particles $\left(b_{b p}\right.$, in

$\mathrm{m}^{-1}$ ), as the forward scattering signal cannot be directly received by above-water radiometric measurements or satellites (Babin et al., 2003; Neukermans et al., 2012; Sutherland et al., 2000). In many ocean color practices, $R_{r s}$ at near-infrared 
(NIR) bands is expressed simply as a function of $b_{b p}$, assuming negligible contributions from other optically-active constituents to the inherent optical properties (IOPs) apart from the absorption by pure water (Chen et al., 2013; Doxaran et al., 2003).

The relationship between $b_{b p}$ and $C_{\mathrm{SPM}}$ is mostly considered as linear in clear and moderate turbid waters, with the assumption of constant mass-specific backscattering coefficients $b_{b p}^{*}$ (the ratio of $b_{b p}$ to $C_{\mathrm{SPM}}$ ) (Dogliotti et al., 2015; Doxaran et al., 2006; Forget et al., 1999; Knaeps et al., 2015; Neil et al., 2011). However, the $b_{b p}-C_{\mathrm{SPM}}$ relationship in highly turbid waters is less investigated and documented. One of the reasons is probably due to the absence of reliable $b_{b p}$ measurements. Previous studies have demonstrated that theoretical approaches can improve the retrieval accuracy of IOPs from $R_{r s}(\lambda)$ in optically complex waters (Brewin et al., 2013; IOCCG, 2000; Yu et al., 2016), which allows us to evaluate the $b_{b p}-C_{\text {SPM }}$ relationship in highly turbid waters with remotely retrieved $b_{b p}$.

In this study, we proposed a $C_{\mathrm{SPM}}$ retrieval model based on derived $b_{b p}$ from $R_{r s}(\lambda)$ using the inverse scheme of the 2SeaColor model (Salama and Verhoef, 2015; $\mathrm{Yu}$ et al., 2016). An index of $b_{b p}$ based on sigmoid function $\left(S_{\text {index }}\right)$ is introduced to calibrate the $C_{\mathrm{SPM}}$ retrieval model. The proposed model is found to be promising for both clear and turbid waters without the need for a switching scheme. At last, the proposed $S_{\text {index }}-C_{\mathrm{SPM}}$ model is applied to atmospherically corrected GOCI (Geostationary Ocean Color Imager, 2010 - present) images to investigate the spatial distribution and diurnal dynamics of SPM in the Yangtze estuary.

\subsection{Data and methods}

Two cruises were carried out in the Yangtze estuary in February 2011 from $24^{\text {th }}$ to $25^{\text {th }}$, and in March 2013 from $4^{\text {th }}$ to $19^{\text {th }}$, with shipborne measurements of remote sensing reflectance and IOPs. Water samples were collected for laboratory analysis to measure SPM concentration. The sampling sites are presented in Figure 4.1. Note that during the cruise in February 2011, as shown in Figure 4.1b, we followed the route from site $\mathrm{C}$ to site $\mathrm{D}$, and then to site $\mathrm{E}$, and repeated the route five times. 


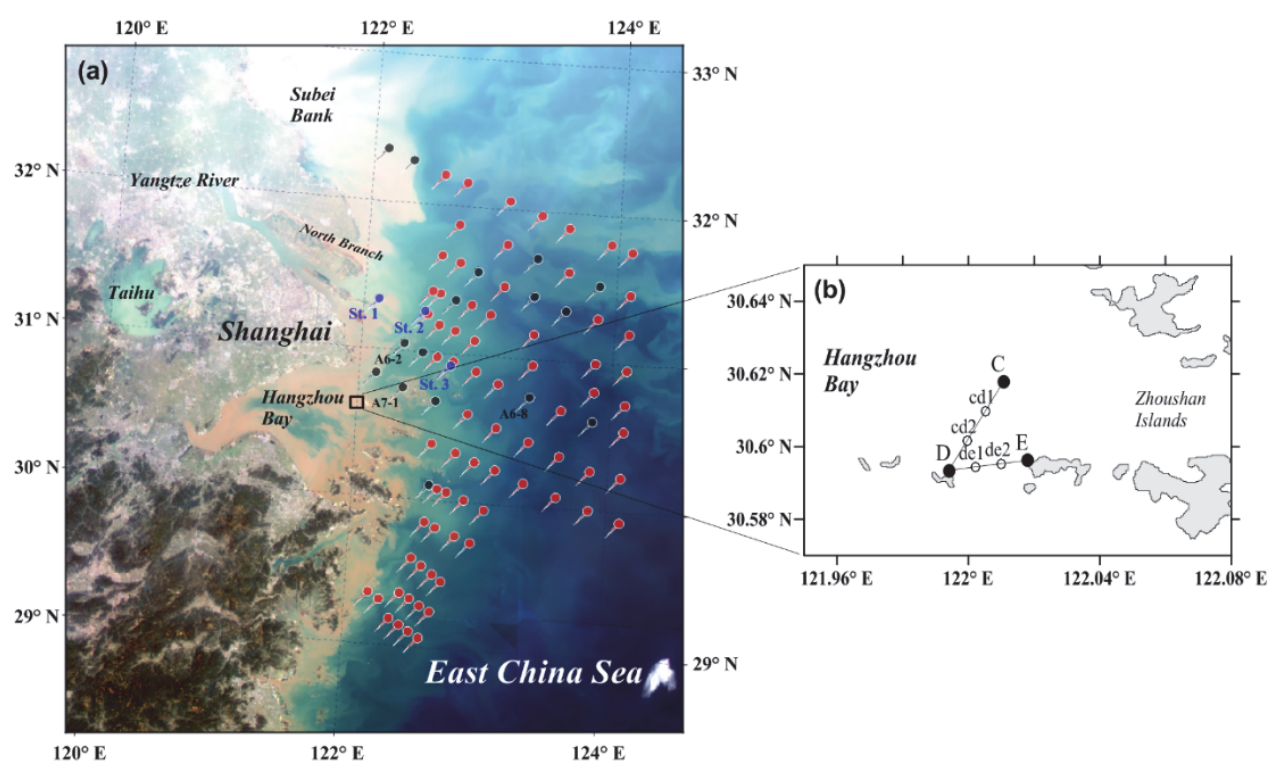

Figure 4.1. Location of the sampling stations for the two cruises in (a) March 2013 and (b) February 2011. The color image in (a) (composited by GOCI bands at $680 \mathrm{~nm}, 555$ $\mathrm{nm}$, and $443 \mathrm{~nm}$ ) was acquired at 01:16 UTC on March $8^{\text {th }}, 2013$. The black pins in (a) indicate the stations with GOCI match-ups and the blue pins in (a) are the hydrologic stations.

GOCI is a geostationary-orbiting ocean color instrument with a spatial resolution of $500 \mathrm{~m}$. It acquires data in 8 spectral bands (6 visible and 2 NIR), and eight images are available for the Yangtze Estuary during daytime from 00:15 UTC to 07:45 UTC (Ryu et al., 2012). The central wavelengths are 412, 443, 490, 555, $660,680,745$ and $865 \mathrm{~nm}$. The match-up sites are defined as in-situ measurements were conducted within one hour of GOCI capturing image, resulting in a total of 16 match-ups. GOCI $R_{r s}$ matchup is calculated as the averaged $R_{r s}$ of a 3-by-3 satellite pixel box that matches in-situ measurement in location and sampling time.

\subsubsection{In-situ measurements of IOPs and $R_{r s}$}

Radiometric measurements were recorded by two radiance sensors and one irradiance sensor of the Hyperspectral Surface Acquisition System (HyperSAS, Satlantic Inc.). The viewing-illumination geometry of the mounted-sensors was confirmed to the NASA protocol (Fargion and Mueller, 2000). The HyperSAS measures sea-surface radiance $\left(L_{t}\right)$, sky radiance $\left(L_{i}\right)$ and down-welling solar irradiance $\left(E_{s}\right)$ from 350 to $858 \mathrm{~nm}$ in 136 spectral channels. The remote sensing reflectance was then calculated by, 


$$
R_{r s}=\left(L_{t}-\rho L_{i}\right) / E_{s}
$$

where $\rho$ is the sea surface reflectance factor and was computed according to Ruddick et al. (2006). Figure 4.2 shows the spectra of measured $R_{r s}$ from the two cruises in February 2011 (33 measurements) and March 2013 (49 measurements).

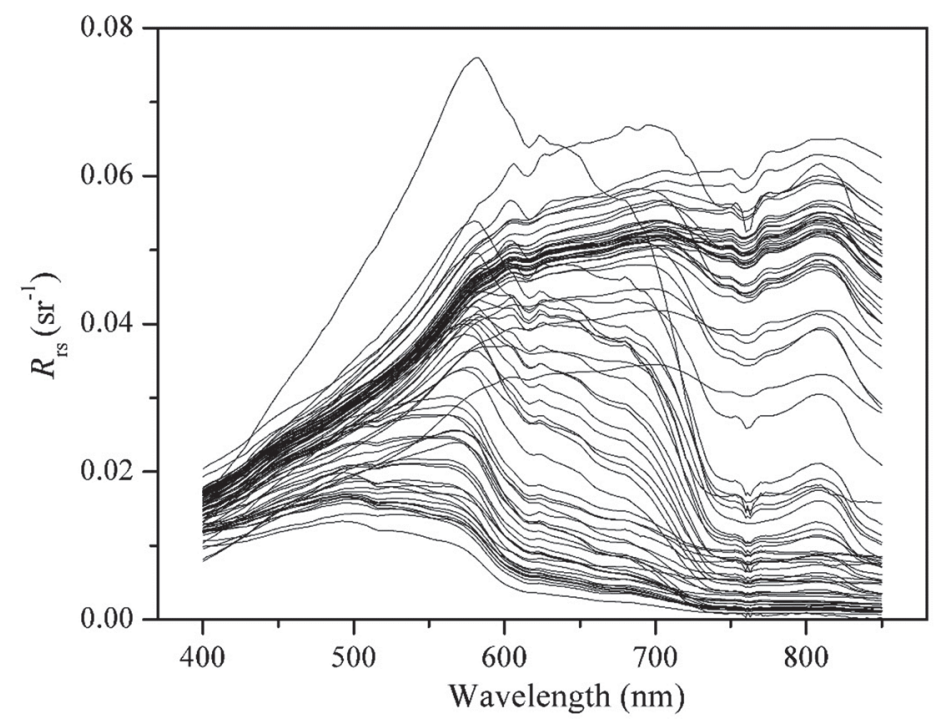

Figure 4.2. Spectra of field-measured $R_{r s}$ during the two cruises.

In this study, we also employed an independent dataset, namely the SeaSWIR dataset (Knaeps et al., 2018), for model validation. The SeaSWIR data was collected from three turbid estuarine sites of Scheldt (Belgium), Gironde (France), and Río de La Plata (Argentina) with 137 measurements of $R_{r s}$ from 350 to 1300 $\mathrm{nm}$ by ASD (Analytical Spectral Devices, Inc.). SPM concentrations, paired with the $R_{r s}$ data, were also analyzed and varied between 48.33 and $1400.54 \mathrm{mg} / \mathrm{L}$.

To account for band equivalent effect, all measured $R_{r s}$ were convoluted to GOCI center bands according to the GOCI relative spectral response function (SRF) by,

$$
R_{r s}^{\text {Convoluted }}\left(B_{i}\right)=\frac{\int R_{r s}(\lambda) S R F_{i}(\lambda) d \lambda}{\int S R F_{i}(\lambda) d \lambda}
$$

where $S R F_{i}(\lambda)$ is the spectral response function at band $i\left(B_{i}\right)$ and $R_{r s}(\lambda)$ is the field measured hyperspectral data. Note that due to the bandwidth of the eighth GOCI band exceed the range of HyperSAS measurement, $R_{r s}(865)$ of the HyperSAS was empirically calculated from $R_{r s}(858)$ based on linear relationship from the SeaSWIR data (i.e., $R_{r s}(865)=0.97 R_{r s}(858), R^{2}=1$ ).

During the cruise in March 2013, a package of in-water instruments was deployed to measure the surface IOPs, which are defined as the averaged IOPs in the upper 
$0.5 \mathrm{~m}$ of water depth. Light attenuation and absorption coefficients of the water body, except for water molecular, were measured by the WET Labs ac-s meter at 83 spectral bands from $400 \mathrm{~nm}$ to $744 \mathrm{~nm}$. Particulate backscattering coefficient was measured by the WET Labs ECO-bb9 (at wavelengths of 412, 440, 488, 510, $532,595,650,676$, and $715 \mathrm{~nm}$, and a scattering angle of $117^{\circ}$ ).

\subsubsection{Field sampling and Lab measurements}

Water samples were collected from the upper $0.5 \mathrm{~m}$, simultaneously with in-situ IOPs measurements. SPM concentration samples were filtered through pre-dried, and pre-weighed $0.45 \mu \mathrm{m}$ pore-size membranes, and then were rinsed three times with milli-Q water to remove dissolved salt before being stored at $-20^{\circ}$ during the cruise. Membranes were then dried at $60^{\circ}$ for $24 \mathrm{~h}$ and re-weighted in the Lab, with $C_{\mathrm{SPM}}$ calculated as the difference between the re-weighted particle-loaded membrane and the pre-weighted blank membrane. The measured $C_{\mathrm{SPM}}$ in surface waters varied from 433.67 to $2068.8 \mathrm{mg} / \mathrm{L}$ in February 2011, and from 0.4 to 591 $\mathrm{mg} / \mathrm{L}$ in March 2013, respectively.

CDOM absorption samples were filtered through $0.22 \mu \mathrm{m}$ polycarbonate membranes and stored in borosilicate glass vials at $-20^{\circ}$ during the cruise. The CDOM absorption coefficient $\left(a_{g}(\lambda)\right.$, in $\left.\mathrm{m}^{-1}\right)$ was measured, at room temperature, using the spectrophotometric method. Details about the shipborne filtration and laboratory measurements can be found in Section 5.2.2.

Prior to the filtration of particulate absorption samples, the $47 \mathrm{~mm} \mathrm{GF} / \mathrm{F}$ (Whatman ${ }^{\circledR}$ ) glass fiber membrane was pre-soaked in Milli-Q water for 15 mins, and the filtration system was rinsed three times by the Milli-Q water. The volume of seawater filtered varied from $10 \mathrm{ml}$ to $2 \mathrm{~L}$ depending on the turbidity of water, which ensured the maximum of the measured optical density would not exceed 0.5 (Röttgers and Gehnke, 2011). The particle-loaded membrane was then moved to the plastic petri dish and immediately frozen in liquid nitrogen. The reference samples were prepared every day following the same procedure whereby seawater was replaced by the Milli-Q water. Immediately back to the lab, the membranes were unfrozen to room temperature in a dark environment. Particulate absorption coefficient $\left(a_{p}(\lambda)\right.$, in $\left.\mathrm{m}^{-1}\right)$ was then determined by the absorption method (Röttgers and Gehnke, 2011), whereby the membranes were placed inside the $150 \mathrm{~mm}$ integrating sphere of the Lambda $1050 \mathrm{UV} / \mathrm{VIS}$ spectrophotometer. The scan was conducted between 300 to $950 \mathrm{~nm}$ with a $1 \mathrm{~nm}$ 
interval, and $a_{p}(\lambda)$ was calculated from the measured optical density of the sample membrane $\left(D_{s}\right)$ and the reference membrane $\left(D_{r}\right)$ by,

$$
a_{p}(\lambda)=\frac{2.303 A}{V \beta}\left(D_{s}(\lambda)-D_{r}(\lambda)\right)
$$

where $A$ (in $\mathrm{m}^{2}$ ) is the membrane clearance area, $V$ (in $\mathrm{m}^{3}$ ) is the filtered volume, and $\beta$ is the path-length amplification factor. The recommended value of $\beta=4.5$ was used for $\left(D_{s}(\lambda)-D_{r}(\lambda)\right)<0.1$. For the cases where $\left(D_{s}(\lambda)-D_{r}(\lambda)\right)>0.1$ (maximum 0.5 ), $\beta$ can be calculated by the polynomial function,

$$
\begin{aligned}
\beta=6.475\left(D_{s}(\lambda)\right. & \left.-D_{r}(\lambda)\right)^{2} \\
& -6.474\left(D_{s}(\lambda)-D_{r}(\lambda)\right)+4.765
\end{aligned}
$$

\subsubsection{Atmospheric correction of GOCI images}

Developing an accurate AC algorithm is beyond the scope of this study, the standard atmospheric correction algorithm of Ahn et al. (2012) was therefore adopted. The GOCI standard AC is based on the SeaWiFS method (Gordon and Wang, 1994b) with a modified algorithm for turbid waters (Ruddick et al., 2000). For the extremely turbid waters (generally $C_{\mathrm{SPM}}>100 \mathrm{mg} / \mathrm{L}$ ), the GOCI standard $\mathrm{AC}$ iteratively restores the normalized water-leaving reflectance at NIR bands $\left(\rho_{w n}(N I R)\right)$ empirically from the red band $\left(\rho_{w n}(R e d)\right)$. However, the CAL/VAL activities of GOCI are mainly performed in the Korean coastal waters where the $C_{\mathrm{SPM}}$ is much lower than $C_{\mathrm{SPM}}$ in the Yangtze estuary, results in larger errors when applying the empirical relationships between $\rho_{w n}(N I R)$ and $\left(\rho_{w n}(R e d)\right.$ to the Yangtze estuary. Figure 4.3 presents the validation of GOCI-derived $R_{r s}$ against the field measurements for match-up pairs, resulting rMAD of $31.6 \%, 25.5 \%$, $18.7 \%, 13 \%, 19 \%, 21.9 \%, 54.6 \%$, and $60.7 \%$ for GOCI $R_{r s}$ at $412,443,490,555$, $660,680,745$, and $865 \mathrm{~nm}$, respectively. 

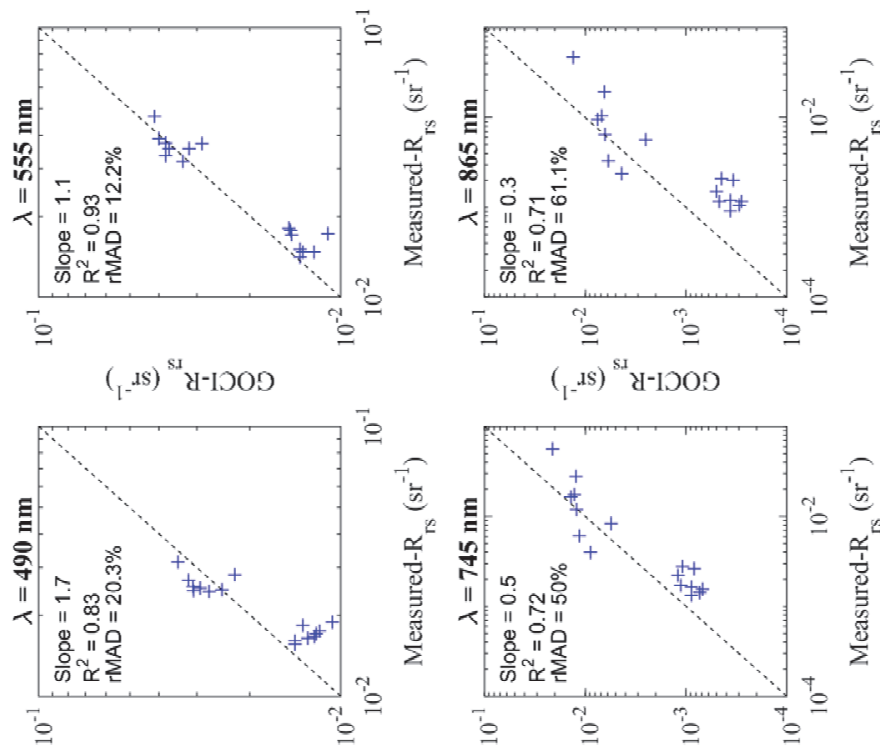

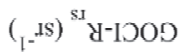

$\left({ }^{2}-12\right) \stackrel{\text { si }}{2}$ y-IDOD
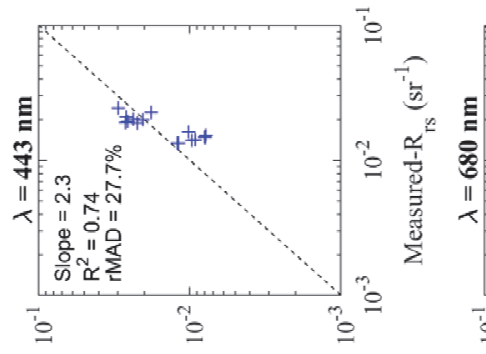

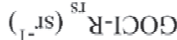
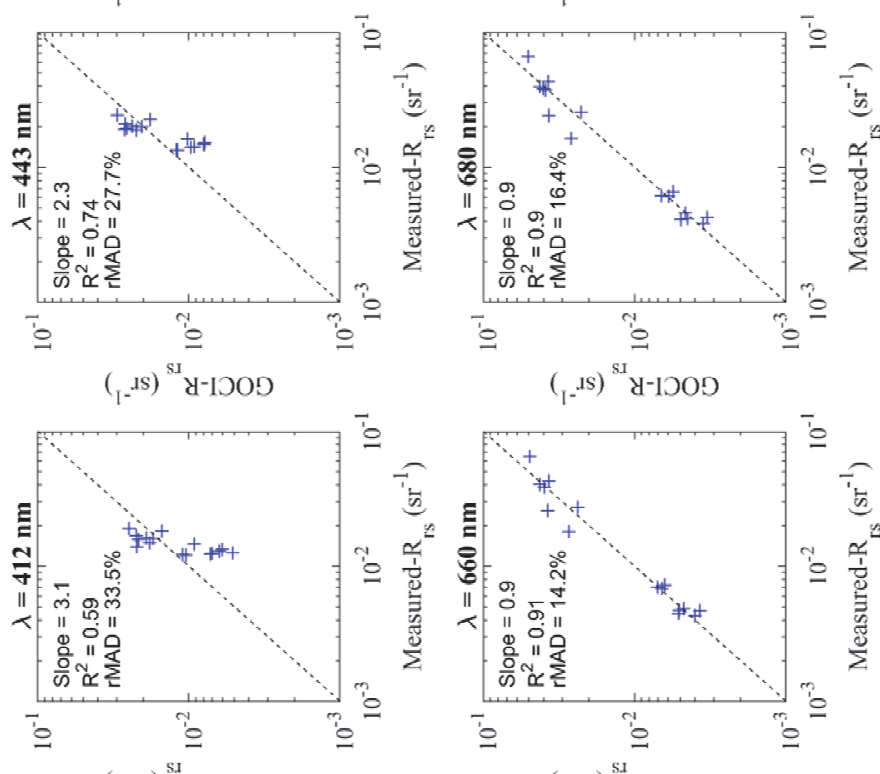

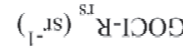

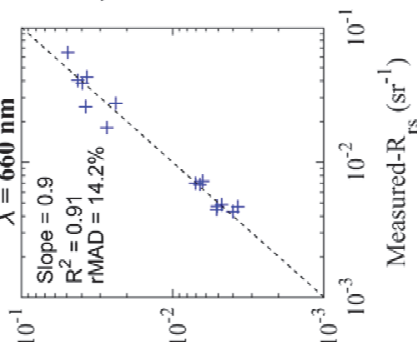

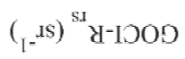

$\left(^{2}-{ }^{2}\right)^{\text {s. }}$ y-IDOD

Figure 4.3. Validation of $R_{r s}$ product of the GOCI standard AC against matched in-situ measurements for GOCI 8 wavebands.

The GOCI standard AC could provide satisfactory reflectance results at blue to red bands but has larger uncertainties $R_{r s}$ at NIR bands (745 nm and $865 \mathrm{~nm}$ ), especially for extremely turbid waters in the Yangtze estuary. The underestimation of GOCI-derived $R_{r s}(\mathrm{NIR})$ is also reported by Pan et al. (2017). 
Figure 4.4 shows an example of $R_{r s}$ mapping products from GOCI standard AC at the eight GOCI center bands. Compared with field-measured $R_{r s}$ spectra (Figure 4.2), GOCI $R_{r s}$ at the two NIR bands are underestimated for extremely turbid waters, e.g., the Hangzhou Bay.
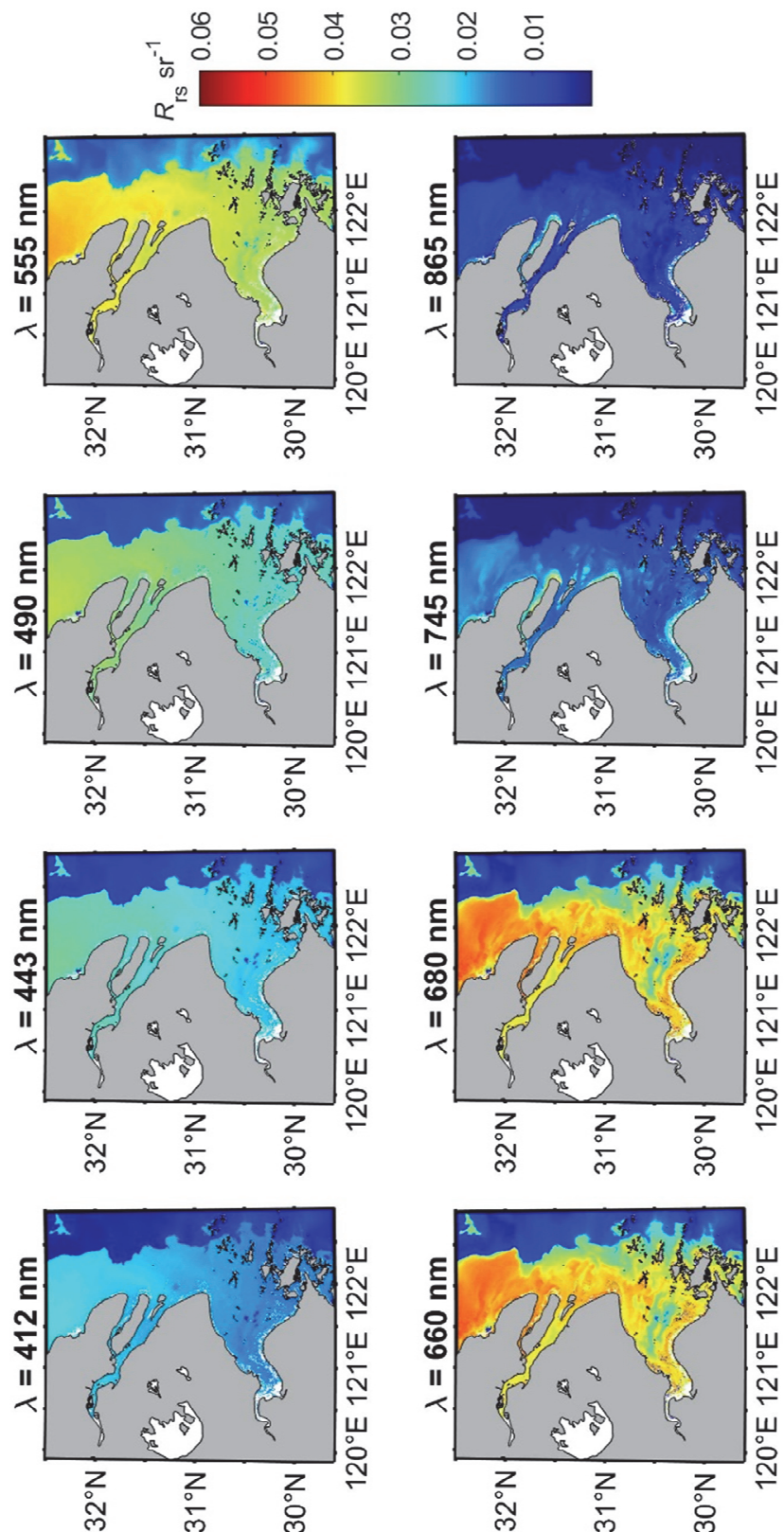

Figure 4.4. $R_{r s}$ mapping products of GOCI standard AC over the Yangtze estuary for the image acquired on 02:16 UTC, March 8 of 2013. 
To address the significant underestimation of the $R_{r s}(\mathrm{NIR})$ by the GOCI standard $\mathrm{AC}$ in extremely turbid waters, we followed the method proposed by Zhang et al. (2010) and adopted regionally calibrated relationships between $R_{r s}(N I R)$ and $R_{r s}(660)$ to correct the $R_{r s}$ (NIR) of GOCI level 2 product (L2P) for extremely turbid pixels. A threshold of $R_{r s}(660)=0.04 \mathrm{sr}^{-1}$ was selected to identify the extremely turbid pixels $\left(C_{\mathrm{SPM}}>100 \mathrm{mg} / \mathrm{L}\right)$ according to field measurements, as $R_{r s}(660)$ of all turbid samples were found beyond $0.04 \mathrm{sr}^{-1}$. As a result, $R_{r s}(745)$ and $R_{r s}(865)$ of extremely turbid pixels were corrected by,

$$
\begin{aligned}
& R_{r s}(745)=\sum_{n=0}^{2} j_{n} * R_{r s}(660)^{n} \\
& R_{r s}(865)=\sum_{n=0}^{2} k_{n} * R_{r s}(745)^{n}
\end{aligned}
$$

where $j_{n}$ and $k_{n}$ are empirical constants that calculated by the least-square fits between field-measured $R_{r s}(660), R_{r s}(745)$, and $R_{r s}(865)$, with $R^{2}$ of 0.78 and 0.97 for Eq. (4.5) and Eq. (4.6), respectively. The best-fit values of $j_{0-2}$ and $k_{0-2}$ are $20.216,-0.705,0.033,9.005,0.393$, and 0.004 , respectively.

\subsubsection{Retrieval models for SPM concentration}

For a proper calibration and validation of the $C_{\mathrm{SPM}}$ retrieval models, we divided $C_{\mathrm{SPM}}$ and matched $b_{b p}(555)$ data pairs into two optimal calibration and validation sets based on the Geo Cal/Val model (Salama et al., 2012), which ensured the selected $\mathrm{Cal}$ and Val datasets with same moments (mean and standard deviation). The Cal dataset includes 50 paired $b_{b p}(555)$ and $C_{\mathrm{SPM}}$ data with $C_{\mathrm{SPM}}$ ranging between 0.4 and $2068.8 \mathrm{mg} / \mathrm{L}$, while the Val dataset includes 50 data pairs with $C_{\mathrm{SPM}}$ between 0.7 and $1865.8 \mathrm{mg} / \mathrm{L}$. Note that both field-measured $b_{b p}(555)$ and $R_{r s}$-derived $b_{b p}(555)$ were used to maximize the number of paired measurements. Since the Val dataset is independent of the Cal dataset, validation results of the calibrated $C_{\mathrm{SPM}}$ retrieval models are expected to be convincing.

\subsubsection{The He model}

The empirical model proposed by He et al. (2013), which was previously calibrated and validated in the Yangtze estuary, is also employed in this study for comparison. This model, hereafter denoted as the He model, is expressed as,

$$
C_{S P M}=10^{S_{1}+s_{2}\left(R_{r S}(745) / R_{r s}(490)\right)}
$$


where $s_{1}$ and $s_{2}$ are empirical constants. These two constants were optimized by the nonlinear least-square fit using the Cal dataset. The optimized $s_{1}$ and $s_{2}$ are 1.137 and 1.080 , respectively.

\subsubsection{The GOCI standard SPM model}

The GOCI standard SPM model is described in the GDPS (GOCI Data Processing System, version 1.3) algorithm description (available at http://222.236.46.37/GDPS/ATBD_master_v9.pdf), where two models are provided for relatively clear and extremely turbid waters. The same switching scheme as the one used in the atmospheric correction (described in Section 4.2.3) is adopted here. The two models are expressed as,

(i) For relatively clear waters $\left(R_{r s}(660)<0.04 \mathrm{sr}^{-1}\right)$,

$$
C_{S P M}=10^{c_{0}+c_{1}\left(R_{r S}(555)+R_{r s}(670)\right)-c_{2}\left(R_{r S}(490) / R_{r S}(555)\right)}
$$

(ii) For extremely turbid waters $\left(R_{r s}(660)>=0.04 \mathrm{sr}^{-1}\right)$,

$$
C_{S P M}=10^{c_{3}+c_{4}\left(R_{r S}(745) / R_{r S}(555)\right)+c_{5}\left(R_{r s}(680) / R_{r s}(490)\right)}
$$

where $c_{0-5}$ are empirical coefficients. In this study, these empirical constants were re-calibrated using the Cal dataset, and the best-fit values are $0.586,13.503$, $0.659,1.77,1.847$, and -0.558 for $c_{0-5}$, respectively.

\subsubsection{The $b_{b p}-C_{S P M}$ model}

In this study, we propose a novel model to estimate $C_{\mathrm{SPM}}$ from remotely sensed $b_{b p}$ at $555 \mathrm{~nm}$, where $b_{b p}(555)$ is first derived from $R_{r s}$, and then convert to $C_{\mathrm{SPM}}$ using a locally calibrated model. The proposed model employs a power-law function between $C_{\mathrm{SPM}}$ and an index of $b_{b p}(555)$. Model calibration and validation are described in Section 4.2.4.2.

The 2SeaColor model is employed to remotely retrieve $b_{b p}$, which includes an analytical forward model based on the solution of the two-stream radiative transfer equations and an inversion scheme (Salama and Verhoef, 2015). The reflectance results predicted by the 2 SeaColor model are the infinite reflectance $\left(r_{\infty}\right)$ and the directional-hemispherical reflectance $\left(r_{s d}^{\infty}\right)$ of the semi-infinite medium, which are a function of $a$ and $b_{b}$ (see. Eq. (2.14) and Eq. (2.15)). Details regarding the 2SeaColor model can be found in Section 2.2. The $b_{b p}$ is retrieved by the 2SeaColor model with improved parameterizations using spectral optimization ( $\mathrm{Yu}$ et al., 2016). See Section 2.2.2 for the improved parameterization. 


\subsubsection{Scattering correction for particulate absorption measured by the ac-s meter}

Scattering issue contributes a large part to the uncertainties in measured absorption by the ac-s meter, because the instrument fails to collect all the scattered light, resulting in overestimations of measured absorption. Therefore, correction for the scattering effects in ac-s measurements is essential. However, the contribution by scattering effects could vary widely from location to location due to the natural variability of SPM (e.g., particle size, type, and concentration). In this study, three correction methods were performed and validated with laboratory measurements to ascertain the most appropriate method for the Yangtze estuary. These methods are,

(i) The proportional method (Petzold, 1972),

$$
a_{c o r r}(\lambda)=a_{m}(\lambda)-a_{m}(715) \frac{c_{m}(\lambda)-c_{m}(\lambda)}{c_{m}(715)-a_{m}(715)}
$$

where subscript $m$ indicates ac-s measured data and $a_{c o r r}$ is the corrected absorption coefficient.

(ii) The semi-analytical method (Röttgers et al., 2013),

$$
a_{\text {corr }}(\lambda)=a_{m}(\lambda)-\left[a_{m}(715)\right.
$$

$$
\left.-a_{e m p}(715)\right] \frac{\left(1 / e_{c}\right) c_{m}(\lambda)-c_{m}(\lambda)}{\left(1 / e_{c}\right) c_{m}(715)-a_{m}(715)}
$$

where $a_{\text {emp }}(715)=0.212 a_{m}(715)^{1.135}$ and $e_{c}=0.56$ (Boss et al., 2009).

(iii) The Boss_13 method (Boss et al., 2013),

$$
a_{\text {corr }}(\lambda)=a_{m}(\lambda)-\varepsilon\left(c_{m}(\lambda)-a_{\text {corr }}(\lambda)\right)
$$

where Eq. (4.12) is solved by non-linear-squares fit with the assumption of $a_{\text {corr }}(\lambda)$ follows $a_{\text {corr }}(\lambda)=a_{\text {corr }}(440) e^{-S(\lambda-440)}$, which is an overconstrained problem with three unknowns $\left(a_{\text {corr }}(440), S\right.$ and $\left.\varepsilon\right)$ and 83 spectral measurements of $a_{m}(\lambda)$ and $c_{m}(\lambda)$ by the ac-s.

\subsubsection{Data analysis}

To quantitatively evaluate the goodness-of-fit between derived and known values, we calculated the slope and intercept of the regression line and the determination coefficient $\mathrm{R}^{2}$ according to the model-II regression (Laws, 1997). The mean of absolute relative difference (rMAD) and the root mean square error (RMSE) were computed by Eq. (3.5) and Eq. (3.6). 


\subsection{Results}

\subsubsection{Quality assurance of in-situ measured IOPs}

\subsubsection{Scattering correction of ac-s measurements}

To evaluate the performance of the three scattering correction methods, comparisons between scattering corrected ac-s measured absorptions and laboratory-measured absorption were made at $440 \mathrm{~nm}$ and $650 \mathrm{~nm}$, and the results are presented in Figure 4.5. The lab-measured total absorption coefficient is calculated as the combination of absorption by suspended particles, CDOM, and pure seawater. The absorption coefficients of pure seawater from 380 to $700 \mathrm{~nm}$ were taken from Pope and Fry (1997).
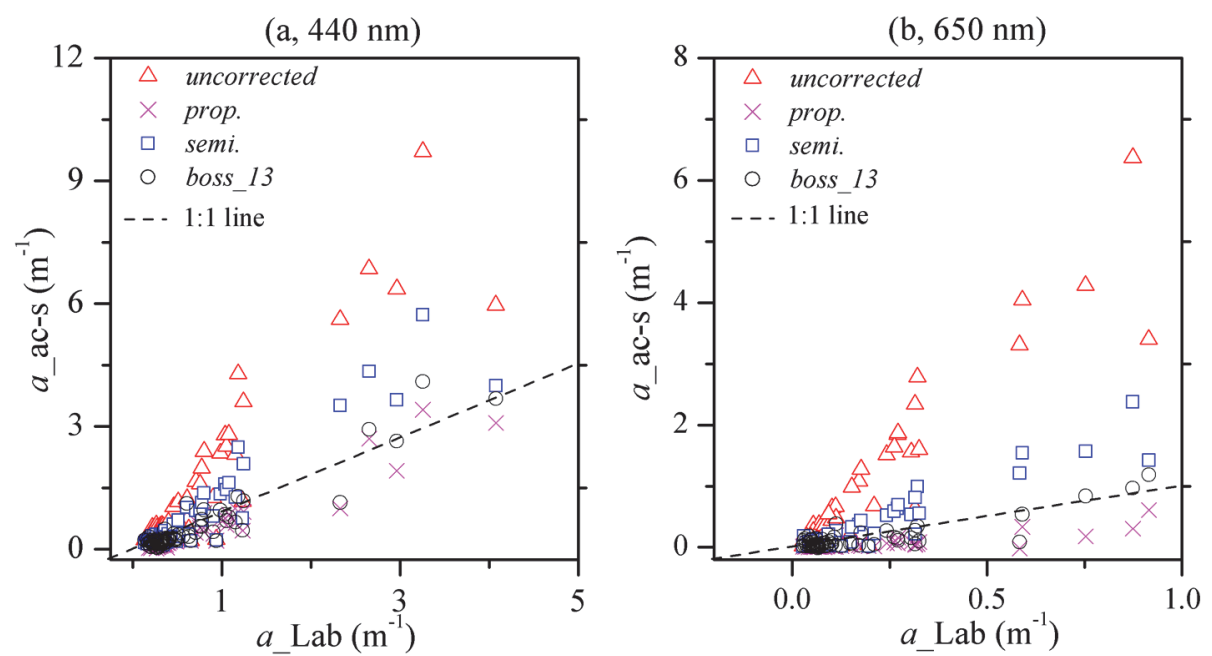

Figure 4.5. Comparison between laboratory and field measured absorption coefficients (uncorrected and corrected results by the three methods) at $440 \mathrm{~nm}$ (a) and $650 \mathrm{~nm}$ (b).

As shown in Figure 4.5, ac-s measurements without scattering correction overestimated the absorption coefficient significantly compared to the laboratory measurements at both 440 and $650 \mathrm{~nm}$, which justified the need for scattering correction for ac-s measurements. From the three correction methods, the Boss 13 model provides the most comparable results with laboratory measurements at both bands with all data points being well distributed alongside the 1:1 line. Whereas the proportion method underestimates the absorption at 650 $\mathrm{nm}$ and the semi-empirical model overestimates the absorption at both 550 and $650 \mathrm{~nm}$, especially for the turbid waters. Table shows the statistic results of the three correction methods, where almost unity slopes and the smallest root mean 
square errors (RMSE) were derived from the Boss_13 model for both $a(440)$ and $a(650)$. Therefore, the Boss_13 method was adopted as the scattering correction method for the WET Labs ac-s meter in this study.

Table 4-1. Statistic results of scattering corrected ac-s measured absorptions by the three methods compared with laboratory measurements at 440 and $650 \mathrm{~nm}$.

\begin{tabular}{|c|c|c|c|c|c|c|c|c|}
\hline & \multicolumn{4}{|c|}{$a(440)$} & \multicolumn{4}{|c|}{$a(650)$} \\
\hline & uncorrected & prop & semi & Boss 13 & uncorrected & prop & semi & Boss13 \\
\hline Slope & 2.478 & 0.886 & 1.484 & 1.030 & 6.374 & 0.506 & 2.364 & 1.133 \\
\hline Intercept & -0.413 & -0.171 & -0.215 & -0.164 & -0.245 & -0.031 & -0.087 & -0.050 \\
\hline$R^{2}$ & 0.860 & 0.886 & 0.886 & 0.890 & 0.881 & 0.620 & 0.895 & 0.751 \\
\hline RMSE & 1.240 & 0.343 & 0.462 & 0.284 & 1.100 & 0.157 & 0.280 & 0.105 \\
\hline
\end{tabular}

\subsubsection{Inter-comparison of in-situ measured $b_{b p}$}

Two concurrent measurements of $b_{b p}$, by the Wet labs ECO-bb9 and ECO-VSF, were cross-compared for the surface layer data, where a good agreement was observed, covering a wide range of $b_{b p}$ from 0.02 to $2.43 \mathrm{~m}^{-1}$ from the ECO-bb9 measurements (Figure 4.6). The robust linear relationship (slope $=1.005, R^{2}=$ 0.99) suggests an insignificant difference between the two measurements and confirms the good data quality of the field measured $b_{b p}$. Considering ECO-bb9 is more widely used by ocean color community and has more spectral bands available, $b_{b p}$ data of the ECO-bb9 were employed for model calibration and validation in this study. 


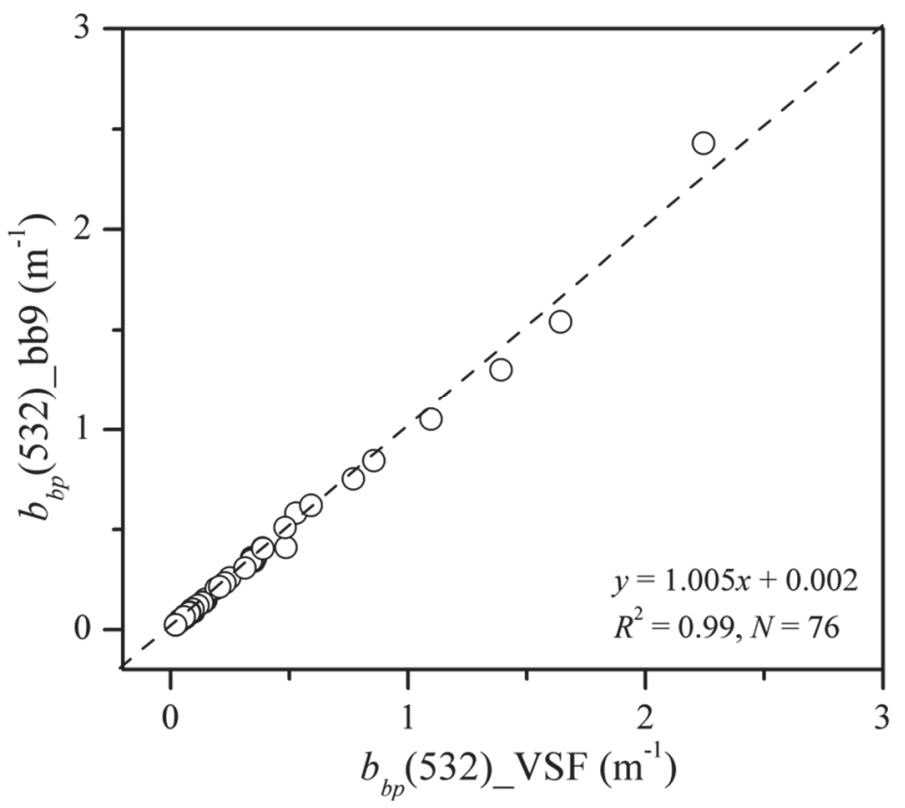

Figure 4.6. Cross-comparison between field-measured $b_{b}$ by the ECO-VSF and ECObb9 for the surface data.

\subsubsection{Validation of retrieved IOPs by the 2SeaColor model}

Figure 4.7 presents the comparison between retrieved IOPs from the 2SeaColor model and field-measured IOPs, take $a(440)$ and $b_{b}(532)$ for example. Note that pure seawater absorption and backscattering coefficients were added to the ac-s and ECO-bb9 measurements to compute the measured $a(440)$ and $b_{b}(532)$. As shown in Figure 4.7, satisfactory retrievals are obtained with RMSEs of $0.25 \mathrm{~m}^{-1}$ and $0.10 \mathrm{~m}^{-1}$ for retrieved $a(440)$ and $b_{b}(532)$, respectively. The slopes and the determination coefficients calculated from the linear regression also suggest the fairly accurate estimations by the $2 \mathrm{SeaColor}$ model. Note that the validation results of derived IOPs in this study are consistent with previous validation efforts of the 2SeaColor model for the COASTLOOC and NOMAD datasets (Figure 3.8). 

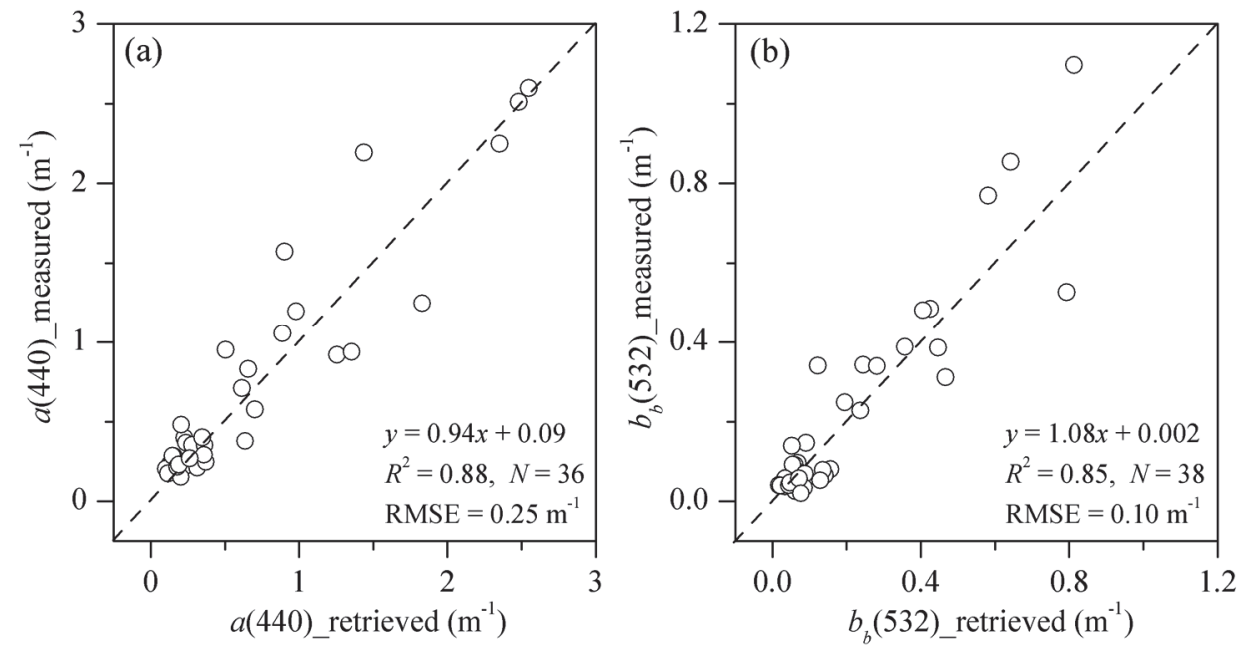

Figure 4.7. Validation of retrieved IOPs by the 2SeaColor model for (a) total absorption coefficient at $440 \mathrm{~nm}$, and (b) total backscattering coefficient at $532 \mathrm{~nm}$.

\subsubsection{Cal/Val of the SPM retrieval model}

Figure 4.8 shows the scatter plots, in log scale, between $b_{b p}(555)$ and $C_{\mathrm{SPM}}$. It is demonstrated in Figure 4.8 that $C_{\mathrm{SPM}}$ is linearly correlated to $b_{b p}(555)$ in relatively clear waters and their relationship becomes significantly curved in extremely turbid waters. The resultant relationships between $b_{b p}(555)$ and $C_{\mathrm{SPM}}$ from Figure 4.8 for relatively clear and extremely turbid waters are formulated as,

$$
\begin{gathered}
C_{\mathrm{SPM}}=59.83 * b_{b p}(555) \\
C_{\mathrm{SPM}}=84.77 * b_{b p}(555)^{1.696}
\end{gathered}
$$

Due to the wide dynamic range of measured $C_{\mathrm{SPM}}(0.4 \sim 2068.8 \mathrm{mg} / \mathrm{L})$, we found that using a single function, linear or non-linear, to fit $b_{b p}(555)$ and $C_{\mathrm{SPM}}$ will inevitably result in overestimations of $C_{\mathrm{SPM}}$ for clear waters or underestimations for extremely turbid waters. However, using two respective relationships to calibrate the $b_{b p}(555)-C_{\mathrm{SPM}}$ model, such as a linear function for relatively clear waters and a power-law function for extremely turbid waters, requires first a robust switching scheme and could result in discontinuities in the estimated SPM (Shen et al., 2013). 


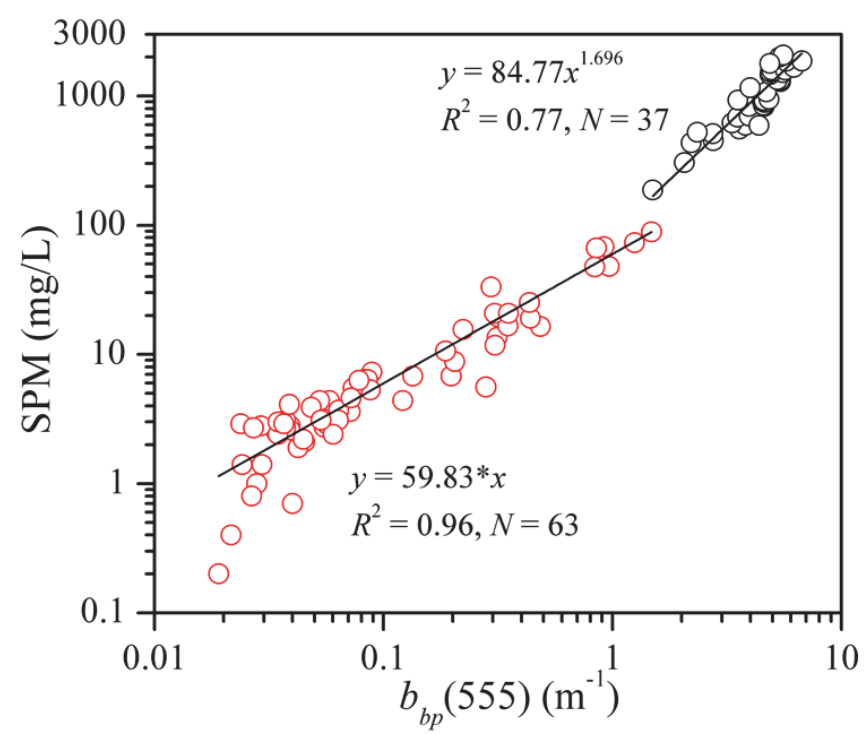

Figure 4.8. Relationship between $b_{b p}(555)$ and $C_{\mathrm{SPM}}$. The red circles mark samples with $C_{\mathrm{SPM}}$ less than $100 \mathrm{mg} / \mathrm{L}$, while the black markers represent samples with $C_{\mathrm{SPM}}>100$ $\mathrm{mg} / \mathrm{L}$.

To account for the wide-range of $C_{\mathrm{SPM}}$ and the turbidity-dependent relationship between $b_{b p}(555)$ and $C_{\mathrm{SPM}}$, we introduce a $b_{b p}$ index based on sigmoid function (hereafter denoted as $S_{\text {index }}$ ) to retrieve $C_{\mathrm{SPM}}$. The $S_{\text {index }}$ is defined as,

$$
S_{\text {index }}=b_{b p} /\left(1+\max \left(b_{b p}\right)-b_{b p}\right)
$$

where the $\max \left(b_{b p}\right)$ represents the maximum $b_{b p}(555)$ of the calibration dataset. The $\max \left(b_{b p}\right)$ from our dataset is about $6.5 \mathrm{~m}^{-1}$ corresponding to an $C_{\mathrm{SPM}}$ of 2000 $\mathrm{mg} / \mathrm{L}$. In this study, we select a maximum $b_{b p}$ of $10 \mathrm{~m}^{-1}$ to cover the wide range of $C_{\mathrm{SPM}}$ in the Yangtze estuary. A detailed discussion is given in Section 4.4.2.1.

Figure 4.9 a presents the scatter plots between $C_{\mathrm{SPM}}$ and the $b_{b p}$ index $\left(S_{\text {index }}\right)$ for the Cal dataset, and a power-law function is employed to calibrate the $C_{\mathrm{SPM}}-S_{\text {index }}$ relationship, which gives,

$$
C_{\mathrm{SPM}}=a * S_{-} \text {index }^{b}
$$

where $a$ and $b$ are empirical constants and derived as 1463.4 and 1.15 from the non-linear-squares fit with a determination coefficient $\left(R^{2}\right)$ of 0.98 . 

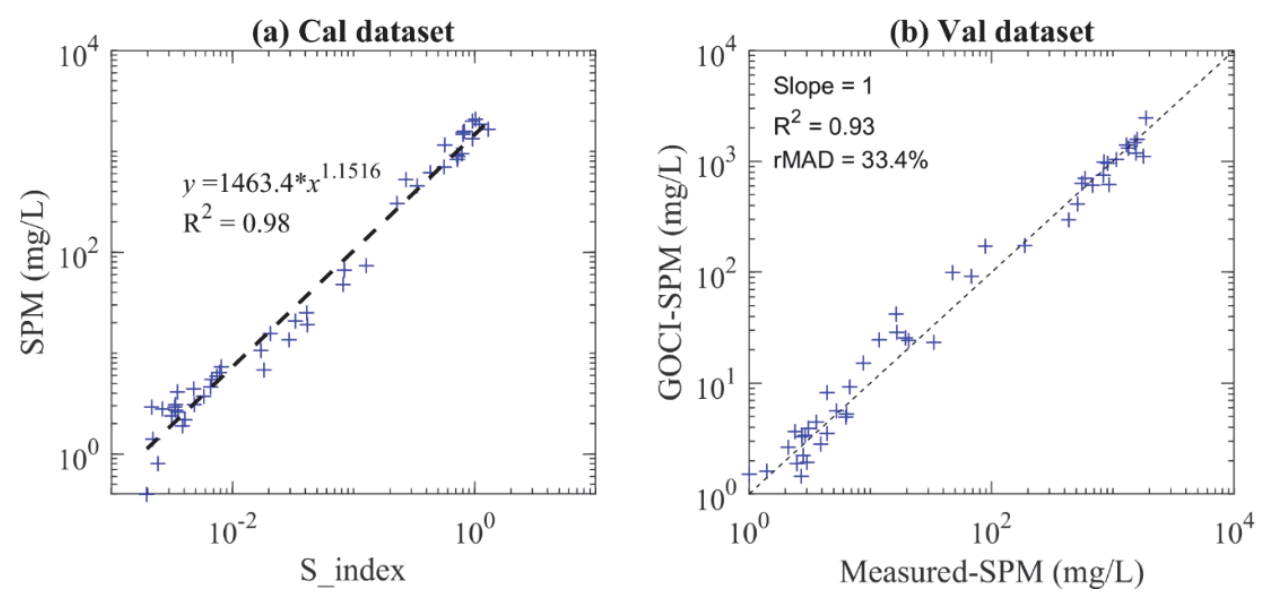

Figure 4.9. Calibration and validation of the $S_{\text {index }}-C_{\mathrm{SPM}}$ model using the Cal and Val datasets.

To evaluate the performance of proposed $S_{\text {index }}-C_{\text {SPM }}$ model, the calibrated Eq. (4.16) was first applied to the Val dataset. As shown in Figure $4.9 \mathrm{~b}$, derived $C_{\mathrm{SPM}}$ matches well with measured $C_{\mathrm{SPM}}$ with an $R^{2}$ of 0.93 and an rMAD of $33.4 \%$. Comparison between our proposed model and the He model and the GOCI standard SPM model are presented in Figure 4.10. All three models have comparable performance for the extremely turbid waters, while for the relatively clear waters, the proposed $S_{\text {index }}-C_{\mathrm{SPM}}$ model seems to be better in the retrieval accuracy.

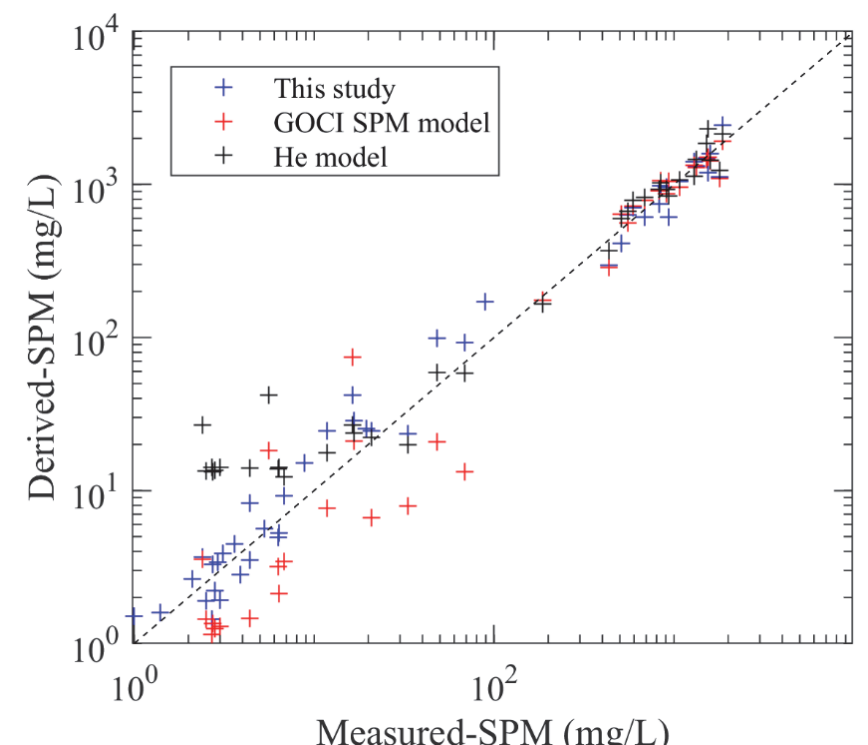

Figure 4.10. Validation results of the three $C_{S P M}$ retrieval models using the Val dataset. 
Statistical data derived from the three models are tabulated in Table 4-2. Considering the He model was mainly developed for turbid waters, evaluation of the three models was also made for extremely turbid samples with $C_{\mathrm{SPM}}>100$ $\mathrm{mg} / \mathrm{L}$. As shown in Table 4-2, validation results show that our proposed model has a better retrieval accuracy of the whole $C_{\mathrm{SPM}}$ range with rMAD of $33.45 \%$ compared to rMAD of $50.2 \%$ for the GOCI SPM model and rMAD of $185.2 \%$ for the He model. The uncertainties of the He model are mainly due to the overestimation of $C_{\mathrm{SPM}}$ for less turbid waters, where an $\mathrm{rMAD}$ of $240.58 \%$ is calculated. As for the extremely turbid waters, the three models show comparable retrieval accuracy with the GOCI SPM model has the smallest rMAD of $12.7 \%$.

Table 4-2. Statistical data of the three SPM retrieval models that support Figure 4.10.

\begin{tabular}{|c|c|c|c|c|c|c|c|c|c|}
\hline & \multicolumn{3}{|c|}{$\mathrm{SPM}<100 \mathrm{mg} / \mathrm{L}$} & \multicolumn{3}{|c|}{$\mathrm{SPM}>100 \mathrm{mg} / \mathrm{L}$} & \multicolumn{3}{|c|}{ All } \\
\hline & Slope & $R^{2}$ & $\begin{array}{l}\text { rMAD } \\
(\%)\end{array}$ & & $R^{2}$ & $\begin{array}{l}\text { rMAD } \\
(\%)\end{array}$ & & $R^{2}$ & $\begin{array}{l}\text { rMAD } \\
(\%)\end{array}$ \\
\hline $\begin{array}{l}\text { GOCI SPM } \\
\text { model }\end{array}$ & 0.94 & 0.08 & 85.70 & 0.89 & 0.85 & 12.72 & 0.95 & 0.95 & 50.20 \\
\hline He model & 0.81 & 0.66 & 344.35 & 1.14 & 0.79 & 17.22 & 1.09 & 0.93 & 185.20 \\
\hline This study & 1.80 & 0.93 & 44.72 & 1.10 & 0.79 & 15.29 & 0.99 & 0.93 & 33.45 \\
\hline
\end{tabular}

\subsubsection{Mapping SPM concentrations in the Yangtze estuary}

To map the spatial distribution of $C_{\mathrm{SPM}}$ in the Yangtze estuary, the proposed $S_{\text {index }}$ $C_{\mathrm{SPM}}$ model was applied to atmospherically corrected GOCI image acquired at 02:16 UTC, March $8^{\text {th }}$ of 2013, as shown in Figure 4.11a. SPM mapping products of the He model (Figure 4.11b) and the GOCI standard SPM model (Figure 4.11c) were also presented for proper comparison. 

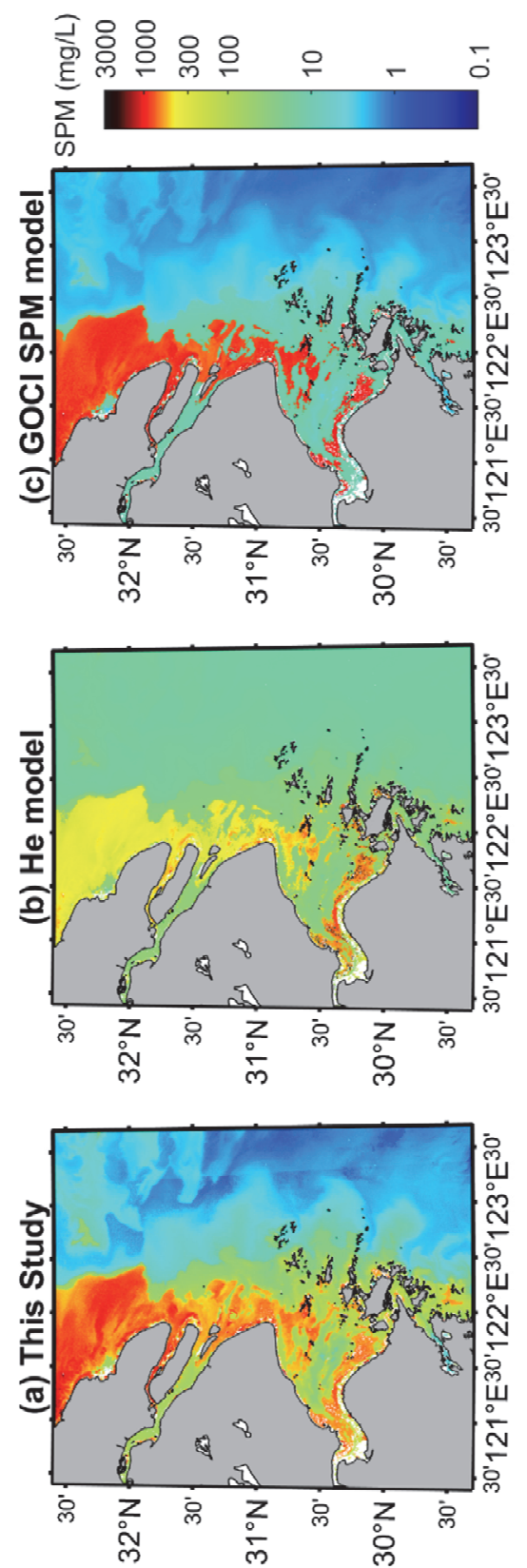

Figure 4.11. SPM Maps over the Yangtze estuary produced by (a) our proposed model, (b) the He model, and (c) the GOCI SPM model. The GOCI image was acquired at 02:16 UTC, March $8^{\text {th }}, 2013$.

As shown in Figure 4.11, the produced $C_{\mathrm{SPM}}$ maps by the three models are consistent in the distribution pattern and spatial gradient, i.e., a decreasing trend of $C_{\mathrm{SPM}}$ from inshore to offshore waters and extremely turbid waters mainly exist 
in the Hangzhou Bay, the North Branch, and the Subei bank. However, there also shows substantial differences in terms of the dynamic ranges of retrieved $C_{\mathrm{SPM}}$ from the three models, which allows immediate evaluation of the models' performance. As shown in Figure 4.11a and Figure 4.11c, our proposed model has comparable $C_{\text {SPM }}$ range with the output of the GOCI SPM model for both clear and turbid waters, while the He model seems to less reasonable in terms of the produced $C_{\mathrm{SPM}}$ range. With field-measured $C_{\mathrm{SPM}}$ in some of the Yangtze estuary regions reported over $1000 \mathrm{mg} / \mathrm{L}$ in winter, it is reasonable to assume that our proposed model and the GOCI standard model are closer to catching the actual variabilities of $C_{\mathrm{SPM}}$.

To better evaluate the performance of these three models, retrieved $C_{\mathrm{SPM}}$ was validated with field-measured $C_{\mathrm{SPM}}$ for the match-ups (the black pins in Figure 4.1a), and the result is presented in Figure 4.12. The statistical data show that the proposed $S_{\text {index }}-C_{\mathrm{SPM}}$ model provides an overall better estimation of $C_{\mathrm{SPM}}$, especially for the match-ups with $C_{\mathrm{SPM}}>10 \mathrm{mg} / \mathrm{L}$. rMAD of the retrieved $C_{\mathrm{SPM}}$ from the $S_{\text {index }}-C_{\mathrm{SPM}}$ model is $62.3 \%$, which is improved with respect to the GOCI standard $C_{\mathrm{SPM}}$ model $(\mathrm{rMAD}=74.9 \%)$ and the He model $(\mathrm{rMAD}=180.2 \%)$.
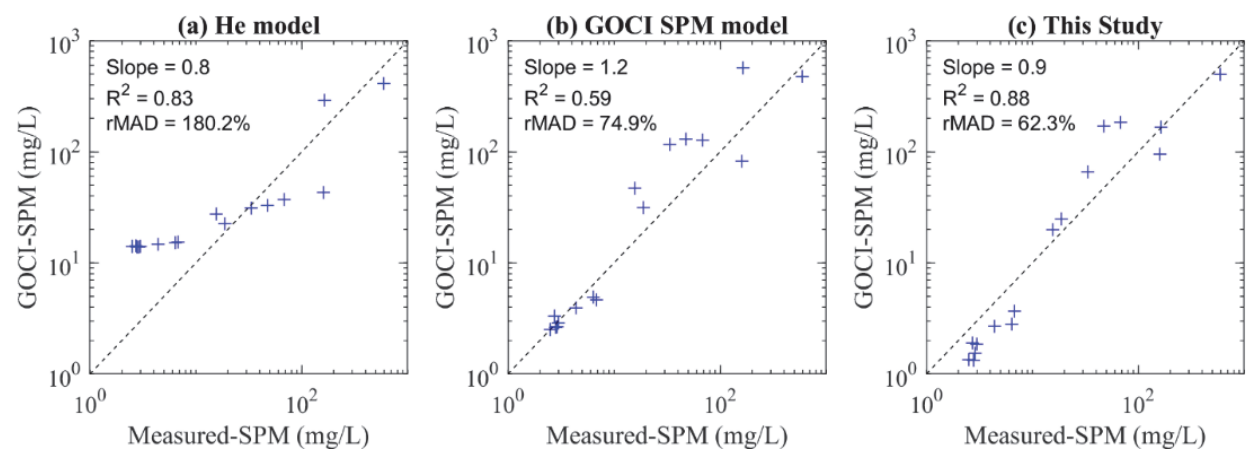

Figure 4.12. Validation of retrieved SPM for GOCI match-ups by the GOCI standard model, the He model, and our proposed model.

\subsection{Discussion}

\subsubsection{Uncertainties in the atmospheric correction algorithm}

Due to no GOCI data available for the cruise in February of 2011, we were not able to validate the performance of the revised AC in extremely turbid waters. As shown in Figure 4.3, $R_{r s}(660)$ derived from the GOCI standard AC matches very well with in-situ measurements with an rMAD of $14.2 \%$. Note that the maximum $C_{\mathrm{SPM}}$ of the 16 match-ups is $591 \mathrm{mg} / \mathrm{L}$, which indicates that GOCI standard AC 
could derive acceptable $R_{r s}(660)$ for turbid waters, which is also reported in Doxaran et al. (2014). However, it is reasonable to assume that the empirical-innature relationships between $R_{r s}(\mathrm{NIR})$ and $R_{r s}(660)$ for extremely turbid waters, of which majority data was collected in February of 2011, could probably result in uncertainties when applied to GOCI images acquired in 2013.

As shown in Figure 4.11, both our model and the GOCI SPM model show a comparable range of derived $C_{\mathrm{SPM}}$, while $C_{\mathrm{SPM}}$ from the He model seems to be underestimated. The recalibrated He model has shown comparable performance when applied to the Val dataset for extremely turbid waters (see Figure 4.10 and Table 4-2), which means the underestimation in the SPM map is associated with $R_{r s}(745)$ from the revised AC, if we assume GOCI derived $R_{r s}(490)$ is of less uncertainties in the extremely turbid waters.

Although the AC may be imperfect, the mapping SPM products provide still useful insights into the applicability of the three models. The He model utilizes only two wavebands at 745 and $490 \mathrm{~nm}$, and uncertainties in $R_{r s}(745)$ could heavily affect the retrieval accuracy of $C_{S P M}$ using Eq. (4.7). In contrast, the GOCI SPM model involves four wavebands, three of which in the visible range, and the $S_{\text {index }}-C_{\mathrm{SPM}}$ model is based on retrieved $b_{b p}$, which is derived by taking account of all the spectral information of $R_{r s}$. In the latter two cases, the uncertainty of $R_{r s}$ (NIR) would be partly compensated for if $R_{r s}$ at visible bands is of good accuracy.

\subsubsection{The proposed $S_{\text {index }}-C_{\text {SPM }}$ model}

\subsubsection{The sigmoid index of $b_{b p}$}

The sigmoid function (Eq. (4.16)) is not simply the mathematical approach to avoid the discontinuities issue that could result from the two respective relationships between $b_{b p}$ and $C_{\mathrm{SPM}}$ for clear and turbid waters, but also has physical meaning that considers the saturation of $b_{b p}$ under extremely turbid conditions. The power-law relationship expressed in Eq. (4.14) suggests a logarithmic increase of $b_{b p}$ with increasing turbidity, which is to the contrary of observations in natural waters. Remote sensing reflectance has been observed to saturate in the visible bands when $C_{\mathrm{SPM}}$ reach a certain level, and the saturation will shift to longer wavelengths with continuing increasing of $C_{\text {SPM }}$ (Knaeps et al., 2012; Knaeps et al., 2015; Luo et al., 2018; Shen et al., 2010b). The key physics behind the $R_{r s}$ saturation at the given waveband is that the wave-leaving signal, mainly due to the particulate backscattering, is less sensitive to the increasing turbidity. Also, for commercial devices that measure the 
backscattering coefficient, saturation of the $b_{b p}$ is also observed when the $C_{\mathrm{SPM}}$ extend a certain limit. Though current $b_{b p}$ device, e.g., WET Labs ECO-BB and HOBI Labs HydroScat, is not able to obtain reasonable reading in extremely waters due to complex multi-scattering events (Doxaran et al., 2016), it is, however, reasonable to assume that $b_{b p}$ device won't be able to distinguish $C_{\mathrm{SPM}}$ between $4000 \mathrm{mg} / \mathrm{L}$ and $5000 \mathrm{mg} / \mathrm{L}$.

Mathematically, the sigmoid function forces the $b_{b p}$ index saturated, or with limited increment, for extremely turbid waters. For example, in order to increase derived $C_{\text {SPM }}$ from $4000 \mathrm{mg} / \mathrm{L}$ to $5000 \mathrm{mg} / \mathrm{L}$, the power-law function expressed in Eq. (4.14) requires derived- $b_{b p}$ increasing from 9.7 to $11 \mathrm{~m}^{-1}$, while increment of $b_{b p}$ from 7.8 to $8.1 \mathrm{~m}^{-1}$ will satisfy the $C_{\mathrm{SPM}}$ changes from the sigmoid function of Eq. (4.16). The determination should be as close as the "true" maximum $b_{b p}$ for better model performance. However, it is hard to pre-determine the maximum $b_{b p}$ for optically-complex environments like the Yangtze estuary, especially for remote sensing applications. The selected $\max \left(b_{b p}\right)$ of $10 \mathrm{~m}^{-1}$ in this study for model calibration is arbitrary, which attempts to cover the maximum potential $C_{\mathrm{SPM}}$ that could exist in the Yangtze estuary, as field measured $C_{\mathrm{SPM}}$ could beyond $5000 \mathrm{mg} / \mathrm{L}$ (He et al., 2013).

\subsubsection{Uncertainties of the $S_{\text {index }}$-CSPM model}

The 2SeaColor model was previously validated in various types of waters with fairly accurate estimations of IOPs (Arabi et al., 2016; Salama and Verhoef, 2015; $\mathrm{Yu}$ et al., 2016). The consistently good performance of the model could enhance our confidence in adopting it to retrieve $b_{b p}$ in extremely turbid waters. More importantly, $b_{b p}$ in this study serves as an intermediate variable of $R_{r s}$ to $C_{S P M}$, which means the uncertainties in the retrieved $b_{b p}$ could be compensated for by regionally well calibrated $b_{b p}-C_{\mathrm{SPM}}$ relationships.

The empirical constants of $S_{\text {index }}-C_{\mathrm{SPM}}$ model expressed in Eq. (4.16) is fundamentally determined by the two respective relationships between $b_{b p}$ and $C_{\mathrm{SPM}}$ in the Cal dataset for clear and turbid waters. Therefore, the calibrated $S_{\text {index- }}$ $C_{\mathrm{SPM}}$ model could be subjected to the uncertainties raised from the two respective $b_{b p}-C_{\mathrm{SPM}}$ relationships when applied to different regions or the same region of different seasons.

For relatively clear waters, the slope of the linear regression between $C_{\mathrm{SPM}}$ and $b_{b p}$, which can be interpreted as the projected concentration per unit area (hereafter denoted as $\eta$ ) (Mikkelsen, 2002), and its variation could be significant 
in global coastal waters. The $\eta$ is 59.83 g.m $\mathrm{m}^{-2}$ in the Yangtze estuary (Eq. (4.13)), while the $\eta$ values are $112.71 \mathrm{~g} \cdot \mathrm{m}^{-2}\left(R^{2}=0.62, \mathrm{~N}=56\right)$ and $143.13 \mathrm{~g} \cdot \mathrm{m}^{-2}\left(R^{2}=\right.$ $0.66, \mathrm{~N}=73$ ) for coastal waters in the Baltic Sea and the North Sea, respectively (figures not shown here). Calculations for the latter two $\eta$ values are based on the COASTALOOC dataset (Babin et al., 2003), with $b_{b p}(555)$ retrieved from $R_{r s}$ using the $2 \mathrm{SeaColor}$ model. The regional and temporal variability of the $b_{b p}-C_{\mathrm{SPM}}$ relationship can be explained by the differences in particles type, composition (refractive index) and concentration, which determine the $b_{b p}$ (Neukermans et al., 2012; Woźniak et al., 2010). Besides, the presence of large amounts of phytoplankton in water would have a notable impact on the linear relationship between $b_{b p}$ and $C_{\mathrm{SPM}}$, even though phytoplankton itself has an insignificant contribution to $b_{b}$ (Babin et al., 2003; Boss et al., 2004). Therefore, the calibrated linear relationship between $b_{b p}$ and $C_{\mathrm{SPM}}$ could be expected with larger errors for application in other estuarine and coastal waters.

For extremely turbid waters, the impact of particle type and composition on the $b_{b p}-C_{\mathrm{SPM}}$ relationship, though less documented, was indirectly demonstrated in this study. The power law relationship between $C_{\mathrm{SPM}}$ and $b_{b p}$ (i.e., Eq. (4.14)), with an exponent $>1$, represents the decline of backscattering efficiency by suspended particles with increasing turbidity. This is mainly because fine fluvial sediments are expected to flocculate when they meet saline water and dispersal in the form of flocs in the Yangtze estuary (Guo and He, 2011; Shi, 2010). Due to fine particles backscatter more pronouncedly than coarse ones, the flocs in the extremely turbid waters in the Yangtze estuary, with the mean diameter up to an order of magnitude larger than the primary particles (Guo and He, 2011), would significantly reduce the backscattering efficiency. Flocculated particles are believed to be the dominant form of suspended sediments in most world's rivers and estuaries, and could account for more than $80 \%$ of the total suspended sediments in the estuary (Droppo and Ongley, 1994). Therefore, the proposed power-law relationship between $b_{b p}$ and $C_{\mathrm{SPM}}$ could potentially be also applicable to other major turbid estuaries.

To evaluate the performance of the calibrated $b_{b p}-C_{\mathrm{SPM}}$ relationships in other optically-complex estuaries, we applied the calibrated $b_{b p}-C_{\mathrm{SPM}}$ models (includes Eq. (4.13) and Eq. (4.14)) and the $S_{\text {index }}-C_{\mathrm{SPM}}$ model (Eq. (4.16)) to the independent SeaSWIR dataset without tuning the empirical constants. $b_{b p}$ of the SeaSWIR dataset was first retrieved from convoluted $R_{r s}$ at $8 \mathrm{GOCI}$ bands using the 2 SeaColor model. Figure 4.13 shows the comparison between measured $C_{\mathrm{SPM}}$ and retrieved $C_{\mathrm{SPM}}$ from the $S_{\text {index }}-C_{\mathrm{SPM}}$ model (blue cross) and the $b_{b p}-C_{\mathrm{SPM}}$ model 
(black circle). Note that retrievals of the $b_{b p}-C_{\text {SPM }}$ model in Figure 4.13 employ Eq. (4.13) for samples with $C_{\mathrm{SPM}}<100 \mathrm{mg} / \mathrm{L}$ and Eq. (4.14) for samples with $C_{\mathrm{SPM}}>100 \mathrm{mg} / \mathrm{L}$, respectively. As shown in Figure 4.13, the power-law $b_{b p}-C_{\mathrm{SPM}}$ relationship for turbid waters seems to be robust for the SeaSWIR dataset with data points well-distributed along the 1:1 line, especially for samples with $C_{\mathrm{SPM}}>$ $200 \mathrm{mg} / \mathrm{L}$. However, the linear $b_{b p}-C_{\mathrm{SPM}}$ relationship for relatively clear waters shows substantial errors, which echoes our previous discussion on the applicability of the $b_{b p}-C_{\mathrm{SPM}}$ relationships in different types of water. The performance of the $S_{\text {index }}-C_{\text {SPM }}$ model for the whole SPM range shows a great improvement of $C_{\text {SPM }}$ retrieval accuracy with $\mathrm{rMAD}$ of $30.8 \%$ compared to $45.2 \%$ of the $b_{b p}-C_{\mathrm{SPM}}$ model. More encouragingly, the $S_{\text {index }}-C_{\mathrm{SPM}}$ model presents strong resistance to uncertainties even for the relatively clear waters. The rMAD of the $S_{\text {index }}-C_{\mathrm{SPM}}$ model for $C_{\mathrm{SPM}}<100 \mathrm{mg} / \mathrm{L}$ is $20.8 \%$ and is $42.8 \%$ for the linear $b_{b p^{-}}$ $C_{\mathrm{SPM}}$ model.

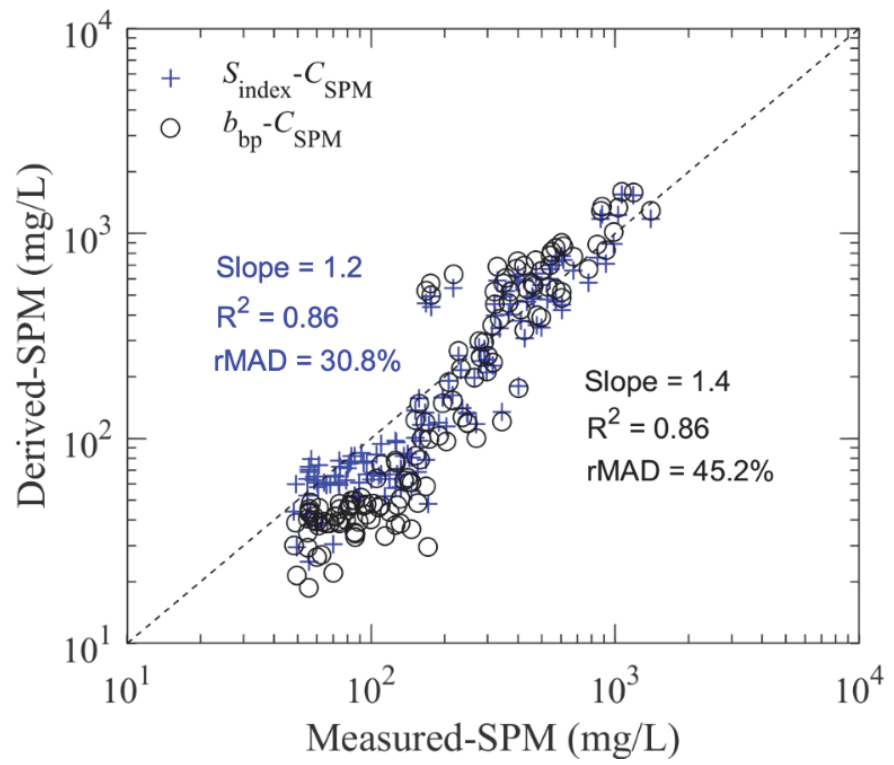

Figure 4.13. Retrieval of $C_{\text {SPM }}$ for the SeaSWIR dataset using the $b_{b p}-C_{\text {SPM }}$ (Eq. (4.13) and Eq. (4.14) and the $S_{\text {index }}-C_{\text {SPM }}$ (Eq. (4.16)) relationships calibrated in this study.

\subsubsection{Discontinuity issue of the retrieved CSPM}

For the $C_{\mathrm{SPM}}$ retrieval models that employ a switching scheme to pre-classify water types, the predicted $C_{\mathrm{SPM}}$ are always involved with discontinuity issue (Shen et al., 2010b; Shen et al., 2013). For example, as shown in Figure 4.8, for a given $b_{b p}$ of $1.5 \mathrm{~m}^{-1}$, which roughly locates at the switching threshold of the two $b_{b p}-C_{\mathrm{SPM}}$ relationships, estimated $C_{\mathrm{SPM}}$ could increase from $90 \mathrm{mg} / \mathrm{L}$ using the 
linear model to $169 \mathrm{mg} / \mathrm{L}$ when the power-law function applies. For the GOCI SPM model, a threshold of $R_{r s}(660)=0.04 \mathrm{sr}^{-1}$ was used to initiate the switch between Eq. (4.8) and Eq.(4.9). As a result, produced $C_{\mathrm{SPM}}$ map by the GOCI SPM model present obvious discontinuities at the front of the turbid plume in the Subei Bank and the inshore area of the Yangtze estuary (Figure 4.11c). Contrarily, the proposed $S_{\text {index }}-C_{\mathrm{SPM}}$ model, which uses a single equation to retrieve the widerange $C_{\mathrm{SPM}}$, avoid the discontinuity problem. As shown in Figure $4.11 \mathrm{a}$, the spatial distribution of $C_{\mathrm{SPM}}$ is more realistic at the front of the turbid plume. Therefore, the $S_{\text {index }}-C_{\mathrm{SPM}}$ model could be more suitable for $C_{\mathrm{SPM}}$ retrieval in the optically-complex environment where $C_{\mathrm{SPM}}$ varies in 3 to 4 orders of magnitude.

\subsubsection{Diurnal dynamics of SPM concentrations}

The GOCI image, available each hour continuously from 00:16 UTC to 07:16 UTC per day, greatly facilitates the investigation on diurnal dynamics of $C_{\mathrm{SPM}}$ at large spatial scale. The tidal type in the Yangtze estuary is semidiurnal, which means the GOCI data could be adequate to reveal the temporal dynamics of $C_{\mathrm{SPM}}$ during, at least, a half tidal cycle. To present the diurnal dynamics of SPM, the proposed $S_{\text {index }}-C_{\text {SPM }}$ model was applied to 8 GOCI images acquired on March $8^{\text {th }}$, 2013, as shown in Figure 4.14. 

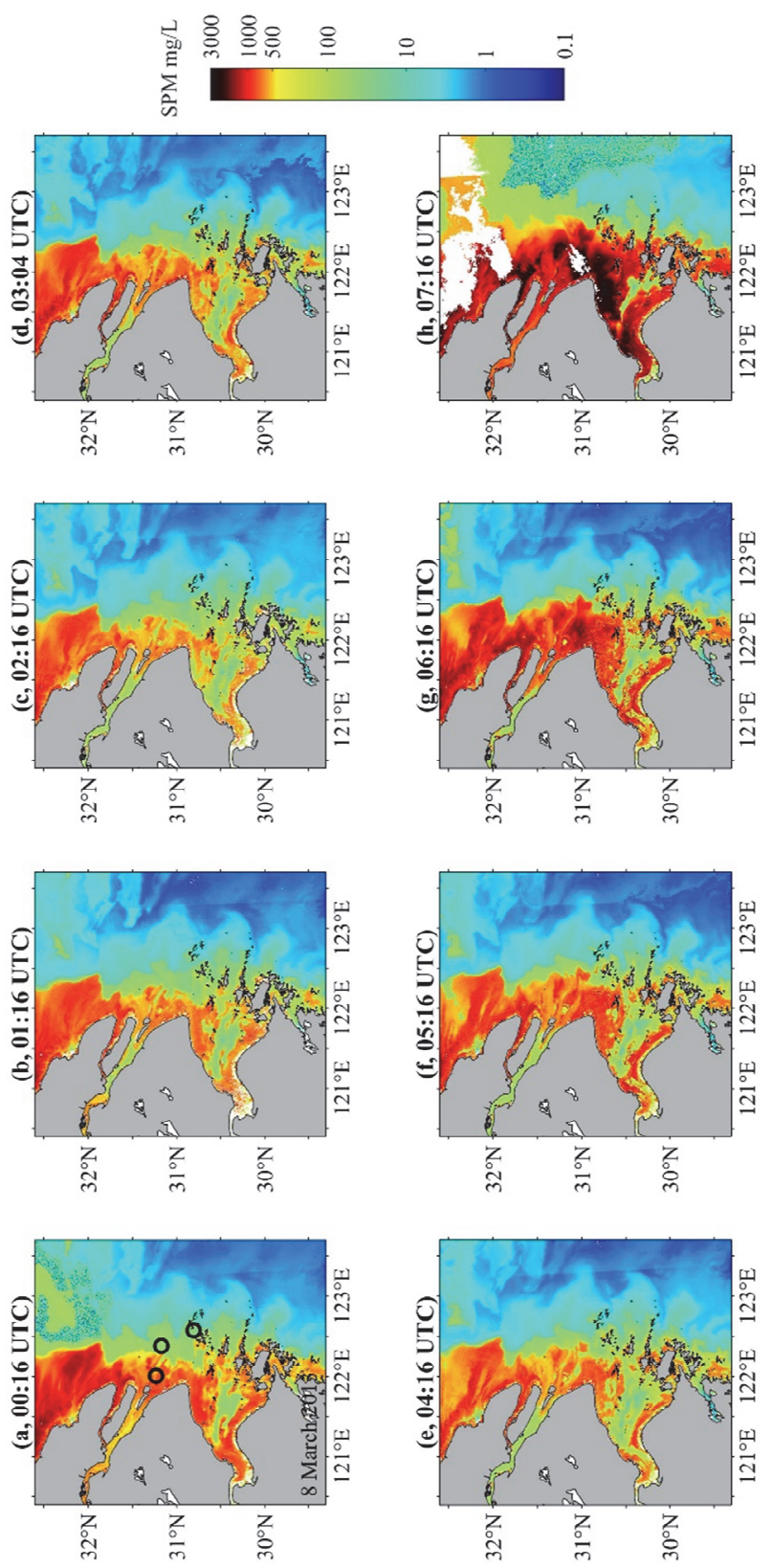

Figure 4.14. Diurnal variations of SPM concentrations in the Yangtze estuary on March 8th, 2013. The black circles in (a) represent the locations of the hydrologic stations.

It is clearly demonstrated that diurnal variation of $C_{\mathrm{SPM}}$ is noteworthy in the Yangtze estuary, where SPM concentrations could vary by 1 to 2 orders of magnitude for some areas. To better understand the dynamics of SPM during this 
time period and the influence of the tide, tidal level data at three hydrologic stations (the black cycles in Figure 4.14a, also referred to St. 1, St. 2 and St.3 in Figure 4.1a) were compared with retrieved $C_{\mathrm{SPM}}$ from GOCI images for matched location and time, as presented in Figure 4.15.

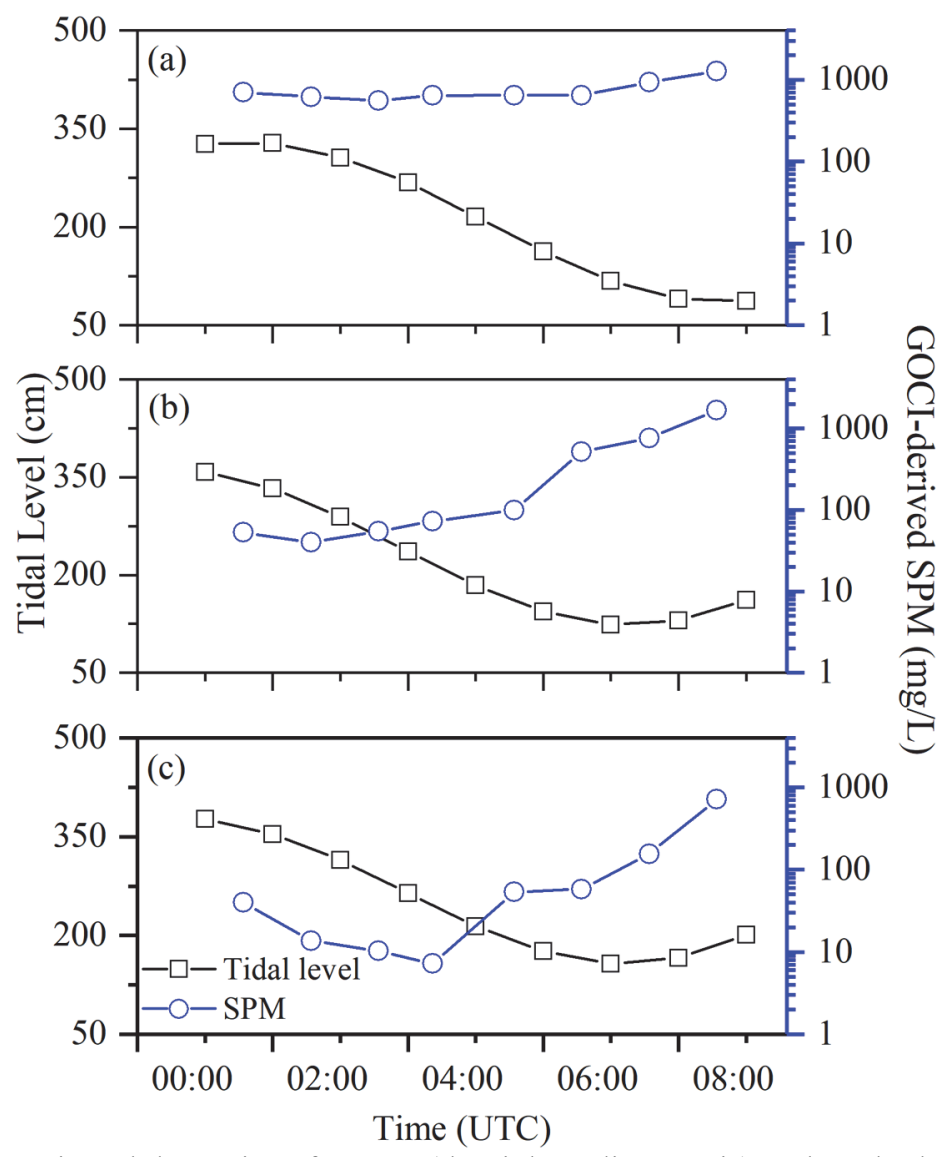

Figure 4.15. Diurnal dynamics of CSPM (the right ordinate axis) at three hydrometric stations corresponding to the variations of the tidal level (the left ordinate axis). Figs. a, b, and c are corresponding to the stations labeled St. 1, St.2, and St. 3 in Figure 4.1a, respectively.

As shown in Figure 4.15, SPM concentrations show a strong dependency on the tide, with increasing $C_{\mathrm{SPM}}$ during the ebb tide. This can be explained by the transportation of suspended sediments during the ebb tide, where ebb-dominated tidal flow transits from landward high- $C_{\mathrm{SPM}}$ regions to the offshore carrying large amounts of suspended sediments (Liu et al., 2010). Additionally, tide-induced mixing and resuspension will be enhanced during the ebb tide, with more sediments from the bottom layer re-suspended to surface waters (Chen et al., 
2006). Sediment resuspension, as a key factor in dominating the SPM spatialtemporal variation in coastal waters, has also been observed in other turbid estuaries (Doxaran et al., 2009).

Figure 4.15 also shows that $C_{\mathrm{SPM}}$ increases more rapidly after the tidal current speed reaches its maximum, which is roughly in the middle phase of the ebb tide. This is mainly because the surface $C_{\mathrm{SPM}}$ is much slower in responding to sediment exchange, especially horizontally, than other layers in water column because of the larger depth (Yang et al., 2004). This time lag could be attributed to the fluid shear stress that determines the suspension and settling velocities of flocs in the estuary (Guo and He, 2011; Shi, 2010), which results in the phase difference between tidal current and surface $C_{\mathrm{SPM}}$. The same reason explains why the maximum $C_{\mathrm{SPM}}$ is observed approximately 1-2 hours later after ebb slack water (the status when ebb tide reaches the lowest level), as observed in all three stations in Fig. 10. This phenomenon has also been reported from field observations in the Yangtze estuary by (Yang et al., 2004; Zhang et al., 2015), from whose study the time lag between the slack water and maximum $C_{\text {SPM }}$ could vary from 1 to 3 hours from location to location. Vice versa, there could also be time lags for the surface $C_{\mathrm{SPM}}$ decreases to the minimum after the flood slack water. For instance, as shown in Figure 4.15, it takes 2 to 3 hours for seawater to dilute and compensate the tidal-induced SPM mixing and resuspension before $C_{\mathrm{SPM}}$ reaches the minimum.

It is also expected that winds, river discharges, and ocean currents could also have significant effects on the spatial-temporal distribution of SPM in the Yangtze estuary (Chen et al., 2003). However, their impact on a diurnal scale could rather be limited, and tide could be the most dominant factor in determining the diurnal dynamics of $C_{\mathrm{SPM}}$ (He et al., 2013). The results presented here indicate that reasonable and realistic diurnal dynamics of $C_{\mathrm{SPM}}$ in the Yangtze estuary could be reconstituted from GOCI imagery by our proposed model. Further efforts could be a focus on using GOCI imagery to better understand and monitor SPM dynamics in the Yangtze estuary at large temporal-spatial scales.

\subsection{Conclusions}

In this study, we proposed a novel model to estimate wide-range SPM concentrations in the Yangtze estuary from remotely retrieved $b_{b p}(555)$ using the 2SeaColor model. This model, using a sigmoid function to take account of the

different relationships between $b_{b p}(555)$ and $C_{\mathrm{SPM}}$ for relatively clear and 
extremely turbid waters, was calibrated for data collected in the Yangtze estuary with $C_{\mathrm{SPM}}$ ranging from 0.4 to $2068.8 \mathrm{mg} / \mathrm{L}$. Validation results with both the Yangtze dataset and an independent SeaSWIR dataset show the robustness of the proposed $S_{\text {index }}-C_{\text {SPM }}$ model in retrieving $C_{\text {SPM }}$ for optically-complex coastal waters with a wide range of $C_{\mathrm{SPM}}$.

The $S_{\text {index }}-C_{\mathrm{SPM}}$ model was later applied to GOCI images and reproduced reasonable and repeatable $C_{\mathrm{SPM}}$ maps for both clear and turbid waters, where switching-based model shows conspicuous discontinuities at the front of the turbid plume. The model was further implemented to a time-series of GOCI imagery and produced realistic diurnal dynamics of $C_{\mathrm{SPM}}$, which can be well explained by the hydrologic process. The encouraging performance of the proposed $S_{\text {index }}-C_{\text {SPM }}$ model shows the potential of monitoring SPM in the optically complex water in the Yangtze estuary with high accuracy. 


\section{Chapter 5 Light absorption properties of CDOM in the Yangtze estuarine and coastal waters: an alternative approach for DOC estimation*}

* This Chapter is based on:

Yu, X., Shen, F., \& Liu, Y. (2016b). Light absorption properties of CDOM in the

Changjiang (Yangtze) estuarine and coastal waters: An alternative approach for DOC estimation. Estuarine, Coastal and Shelf Science, 181, 302-311 


\subsection{Introduction}

Colored dissolved organic matter (CDOM) is an important component of natural waters and plays various roles in the functioning of ecological processes and biogeochemical cycles in coastal ecosystems. Light absorption property of CDOM mainly depends on the origins of CDOM, as terrestrial source contains more humic acid and large size of dissolved organic matter (DOM) molecules while aquatic source contains more fulvic acid and small size of DOM molecules (Helms et al., 2008). Riverine discharge is always considered as the main source of CDOM in most coastal waters, resulting in a robust correlation between salinity and CDOM absorption coefficient (Fichot and Benner, 2011; Granskog, 2012; Xie et al., 2012). The aquatic CDOM is mainly produced locally by phytoplankton degradation and bacterial decomposition. To get better insights of CDOM sources, spectral slope $\left(S\right.$, in $\left.\mathrm{nm}^{-1}\right)$ of CDOM absorption was recommended as it is related to the ratio of fulvic to humic acids and the molecular weight (MW) of fulvic acids (Carder et al., 1989; Keith et al., 2002). Moreover, $S$ calculated from a narrow waveband in the ultraviolet spectral range (e.g., 275-295 nm) is more sensitive to CDOM sources than the $S$ determined from a broader waveband (Asmala et al., 2012; Fichot and Benner, 2011, 2012). This is mainly because the $S_{275-295}$ is negatively related to DOM molecular weight (MW) (Helms et al., 2008).

For the past few decades, the global carbon cycle has been one of the hottest researches in the field of global climate change due to $\mathrm{CO} 2$, the major greenhouse gas (Canadell and Dickinson, 2006). Dissolved organic carbon (DOC), on the other hand, represents $97 \%$ of the organic carbon in the ocean (Hansell and Carlson, 1998), is an essential part of the global carbon cycle. Phytoplankton converts inorganic carbon to organic carbon through photosynthesis (Longhurst and Harrison, 1989), which represents a substantial source of DOC in the oceans. Other sources of DOC in the oceans mostly come from riverine discharge and zooplankton activity (Kuliński and Pempkowiak, 2008). However, traditional DOC measurements are always limited due to discrete sampling and measurement. Therefore, a prompt and continuous estimation from earth observation data on large spatial scales would be strongly recommended (Liu et al., 2013; Mannino et al., 2008).

CDOM is the optically active component of DOM and therefore can be potentially linked to DOC concentration. Although CDOM only represents a portion of the entire DOC pool, optical properties of CDOM have been found to 
be empirically related to DOC concentration in some estuarine and coastal regions (Asmala et al., 2012; Ferrari, 2000; Fichot and Benner, 2011, 2012; Matsuoka et al., 2012a; Rochelle-Newall et al., 2014; Spencer et al., 2007). There are mainly two methods to estimate DOC concentration from CDOM optical properties. The first approach is linking DOC concentration to CDOM absorption coefficient at a reference wavelength (e.g., $250 \mathrm{~nm}$ or $350 \mathrm{~nm})$ by single linear regression (Baker and Spencer 2004; Matsuoka et al. 2012a; Spencer et al., 2009a). However, linear models rely heavily on the conservative mixing of DOC and CDOM, and sometimes generate large uncertainties and are not practical in some of the coastal waters, such as the Mississippi River estuary (Chen and Gardner, 2004), the Pearl River estuary (Chen et al., 2004) and Finnish estuaries (Asmala et al., 2012). The other approach is using the non-linear model developed by (Fichot and Benner, 2012) to estimate DOC from spectral slope $S_{275-295}$ and DOC-normalized CDOM absorption coefficient. The non-linear model is supposed to be more suitable for coastal waters, especially for riverinfluenced coastal waters with the lignin as the important chromophore of CDOM pool and the main terrigenous component of DOC.

The hydrodynamic environment is unique in the Yangtze estuarine and coastal waters due to joint influences by runoffs, tides and coastal circulations, which makes the mixing behavior between DOC and CDOM more complicated and variable in seasonal and regional scales. For example, the conservative mixing behavior was observed in the Yangtze estuary, and DOC concentration was linearly estimated from CDOM absorption coefficient (Liu et al., 2013; Liu et al., 2014; Zhang et al., 2013). However, the linear relationship was not always practical in this region (Cauwet and Mackenzie, 1993; Liu et al., 2013). Hence, a better understanding of the variation of DOC and CDOM relationship and more detailed information on the spatial-temporal variation of CDOM optical properties in the Yangtze estuary are required.

In this study, we first investigate the seasonal and vertical distributions of CDOM absorption coefficient that were less documented in the Yangtze estuarine and coastal waters. We further discuss the potential sources of CDOM in this region and develop an empirical model to estimate DOC concentration from CDOM optical properties. The developed relationship was found robust in the Yangtze estuarine and coastal waters, providing an alternative approach to estimate DOC concentration in large spatial scales from remotely retrieved CDOM optical properties. 


\subsection{Materials and methods}

\subsubsection{Sampling and field measurement}

Water samples were collected during five cruises in the Yangtze estuarine and coastal waters from 2011 to 2013, and the sampling stations are presented in Figure 5.1. A total number of $114 \mathrm{CDOM}$ samples were collected in summer from the surface layer in July 2011 (32 samples), July 2012 (29 samples) and August 2013 (53 samples). Another 61 CDOM samples were collected in winter in February 2012 (37 samples) and March 2012 (24 samples). Salinity (in PSU, practical salinity units) was recorded by the CTD device (SeaBird Electronics INC) synchronously to CDOM sampling, with salinities at four of the sampling stations were missing record. DOC samples were collected simultaneously with surface CDOM samples in July of 2011 (31 samples) and August 2013 (53 samples). During the cruise in July 2011, we also collected CDOM samples at the water depth of $5 \mathrm{~m}$ (31 samples) and $10 \mathrm{~m}$ (29 samples) below the surface layer to investigate the vertical variation of CDOM optical properties. 


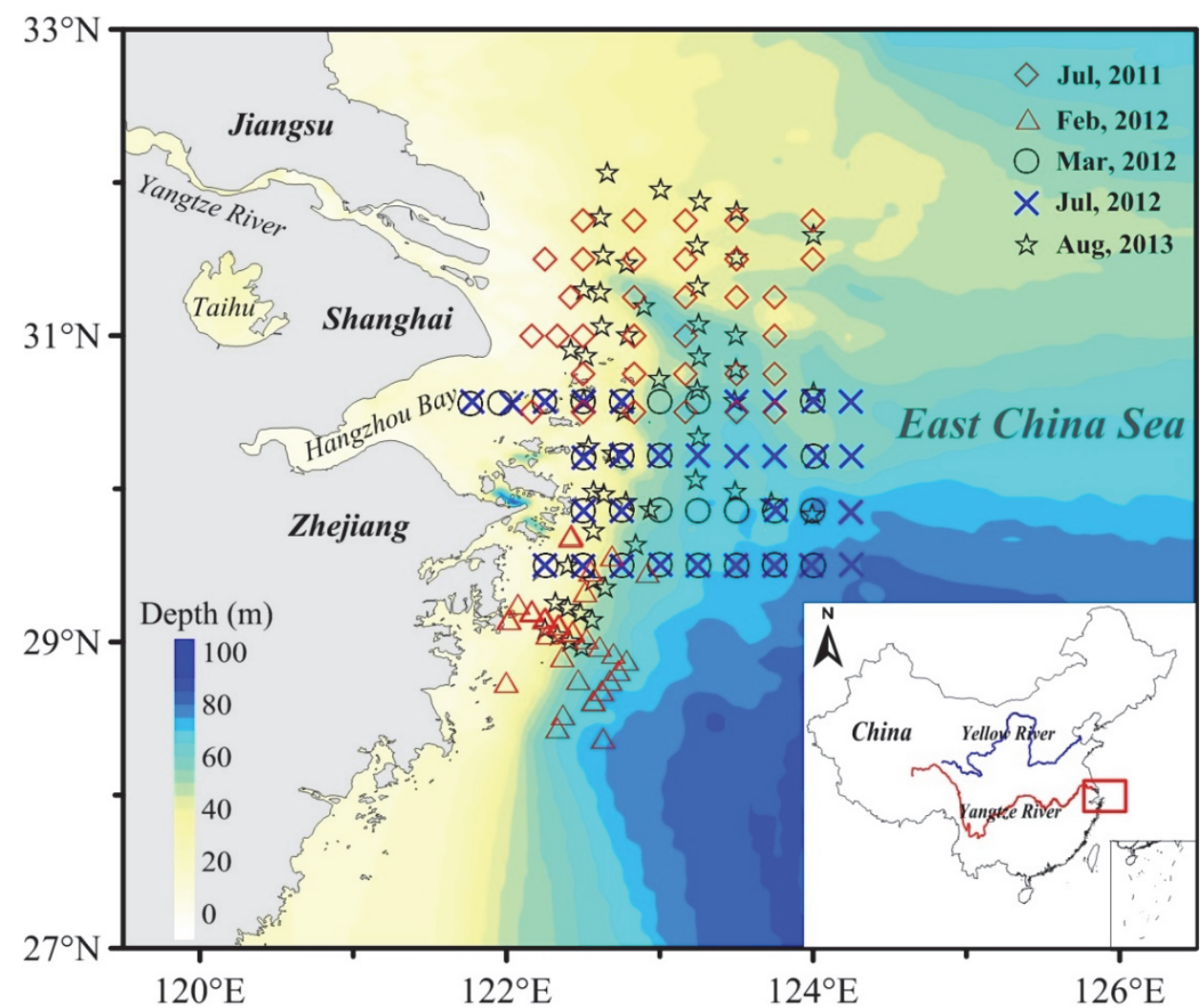

Figure 5.1. Location of sampling stations in the Yangtze estuarine and coastal waters. Samples were collected from five cruises in summer (July 2011, July 2012 and August 2013) and winter (February and March of 2012).

CDOM samples were collected according to the NASA protocol of marine optical measurements (Mueller and Fargion, 2002). Water samples were gravityfiltered on shipboard using $0.22 \mu \mathrm{m}$ polycarbonate membrane (Millipore, $\Phi 47 \mathrm{~mm}$ ) under low vacuum. The membranes were soaked in $10 \% \mathrm{HCl}$ for 15 mins and then rinsed by Milli-Q water three times before the filtration. The filtered CDOM samples were collected in borosilicate glass vials and then stored in the $-40^{\circ} \mathrm{C}$ refrigerator during the cruises. All vials were pre-soaked in $10 \%$ $\mathrm{HCl}$ for $24 \mathrm{~h}$, rinsed by Milli-Q water three times, and pre-combusted in an oven at $450^{\circ} \mathrm{C}$ for $5 \mathrm{~h}$.

DOC samples were filtered to ampoule bottles by a disposable pinhole filter with an aperture of $0.45 \mu \mathrm{m}$ immediately after the water samples were collected. Ampoule bottles were pre-combusted in an oven at $500^{\circ} \mathrm{C}$ for $4 \mathrm{~h}$. After the filtration, the ampoule bottles were sealed by fusing the bottleneck and then stored in the $-40^{\circ} \mathrm{C}$ refrigerator. 


\subsubsection{Measurements in lab}

To minimize the freezing influence on the CDOM absorption spectra, CDOM samples were unfrozen and warmed in fully dark condition to room temperature immediately prior to measurement. The absorbance spectra were recorded by the PerkinElmer Lambda 1050 UV/VIS spectrophotometer. CDOM absorptance was recorded from 250 to $900 \mathrm{~nm}$ with $2 \mathrm{~nm}$ interval fitted with a $10 \mathrm{~cm}$ quartz cuvette and referenced to the Milli-Q water. The absorbance of CDOM $(D(\lambda))$ was converted to absorption coefficient $\left(a_{g}^{\prime}(\lambda)\right.$, in $\left.\mathrm{m}^{-1}\right)$ according to,

$$
a_{g}^{\prime}(\lambda)=2.303 \times D(\lambda) / l
$$

where $l$ is the cuvette path length (i.e., $0.1 \mathrm{~m}$ ) (Pegau et al. 1997). In order to remove the scattering contribution from the measurements, the CDOM absorption coefficient was normalized to zero at $700 \mathrm{~nm}$ (Bricaud et al., 1981),

$$
a_{g}(\lambda)=a_{g}^{\prime}(\lambda)-a_{g}^{\prime}\left(\lambda_{0}\right) \times \lambda / \lambda_{0}
$$

where $a_{g}(\lambda)$ is the CDOM absorption coefficient after the scattering correction and used for data analysis in this study. Figure 5.2 shows the absorption spectra of all CDOM samples.

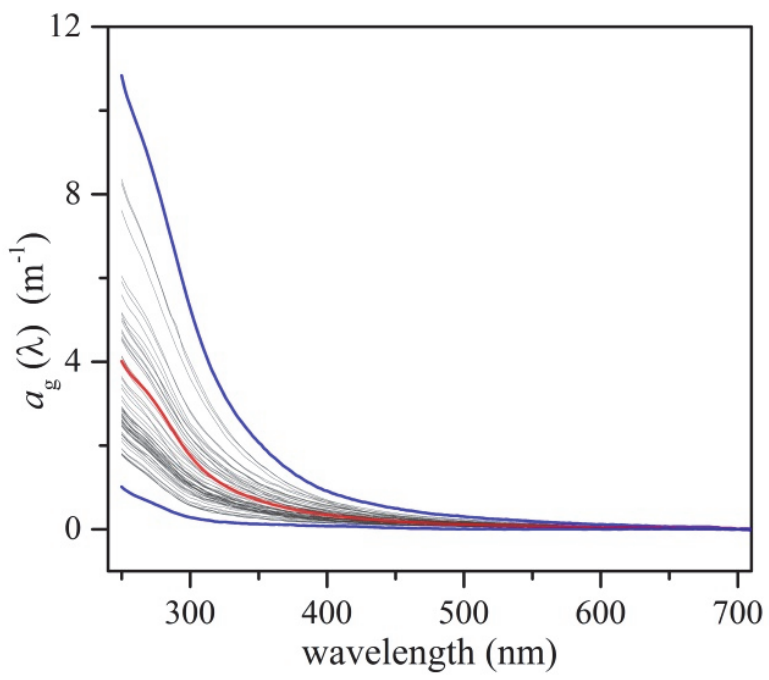

Figure 5.2. CDOM absorption spectra of all measurements. The two blue spectra represent samples with maximum and minimum absorption coefficients, while the red spectrum is the mean absorption coefficient of all samples.

The spectral slope $\left(S, \mathrm{~nm}^{-1}\right)$ is derived from CDOM absorption spectra by fitting the absorption data to the exponential equation (i.e., Eq. (5.3)) using the optimization method (Bricaud et al., 1981; Green and Blough, 1994),

$$
a_{g}(\lambda)=a_{g}\left(\lambda_{0}\right) e^{-S\left(\lambda-\lambda_{0}\right)}
$$


where $\lambda$ is wavelength (nm), and $\lambda_{0}$ is the reference wavelength (nm). As shown in Eq. (5.3), $S$ is depended on the wavelength interval over which it is calculated. We chose $440 \mathrm{~nm}$ as the reference wavelength to calculate the spectral slope for the broad range from 250 and $700 \mathrm{~nm}$, which is hereafter denoted as $S_{440} . S_{275-295}$ and $S_{350-400}$ were also calculated for the narrow wavelength interval from 275 to $295 \mathrm{~nm}$ and 350 to $400 \mathrm{~nm}$, respectively. $S_{\mathrm{R}}$ was then defined as the ratio of $S_{275-}$ 295 and $S_{350-400 .}$

DOC concentration (in $\mu \mathrm{mol} / \mathrm{L}$ ) was determined in duplicate with a Shimadzu TOC-VCPH Total Organic Carbon analyzer using potassium hydrogen phthalate as the standard for the DOC calibration curve. The typical precision of this instrument is less than $2 \%$ in term of the coefficient of variation. DOC samples were acidified by adding $100 \mu \mathrm{L} 2 \mu \mathrm{mol} / \mathrm{L}$ phosphoric acid before the measurement to remove the inorganic carbon. In addition, the Florida Strait seawater reference, provided by Dr. Hansell's laboratory at the University of Miami, was determined every day to ensure the data quality of our measurements. DOC concentration was calculated as the average value of the duplicate measurements and the DOC-normalized CDOM absorption coefficient $\left(a_{g}^{*}\left(\lambda_{0}\right)\right.$, in $\left.\mathrm{L} \mu \mathrm{mol}^{-1} \mathrm{~m}^{-1}\right)$ was defined as the ratio of $a_{g}\left(\lambda_{0}\right)$ and DOC concentration.

\subsubsection{Data analysis}

To quantitatively evaluate the linear relationship between salinity and CDOM absorption coefficient and spectral slopes, we calculate the Pearson's coefficient $r$ and probability $p$ of the linear regression equation. For the goodness-of-fit between derived and known DOC concentration, statistical parameters such as the determination coefficient $R^{2}$, the mean of absolute relative difference (rMAD) and the root mean square error (RMSE) are determined. The rMAD and the RMSE are determined by Eq. (3.5) and Eq. (3.6).

\section{$5.3 \quad$ Results}

\subsubsection{CDOM light absorption and its spatial-temporal distribution}

Based on the CDOM measurements from the five cruises over the Yangtze estuarine and coastal water, the spatial distribution of CDOM absorption coefficient $\left(a_{g}(355)\right)$ at the surface layer is presented in Figure 5.3. 

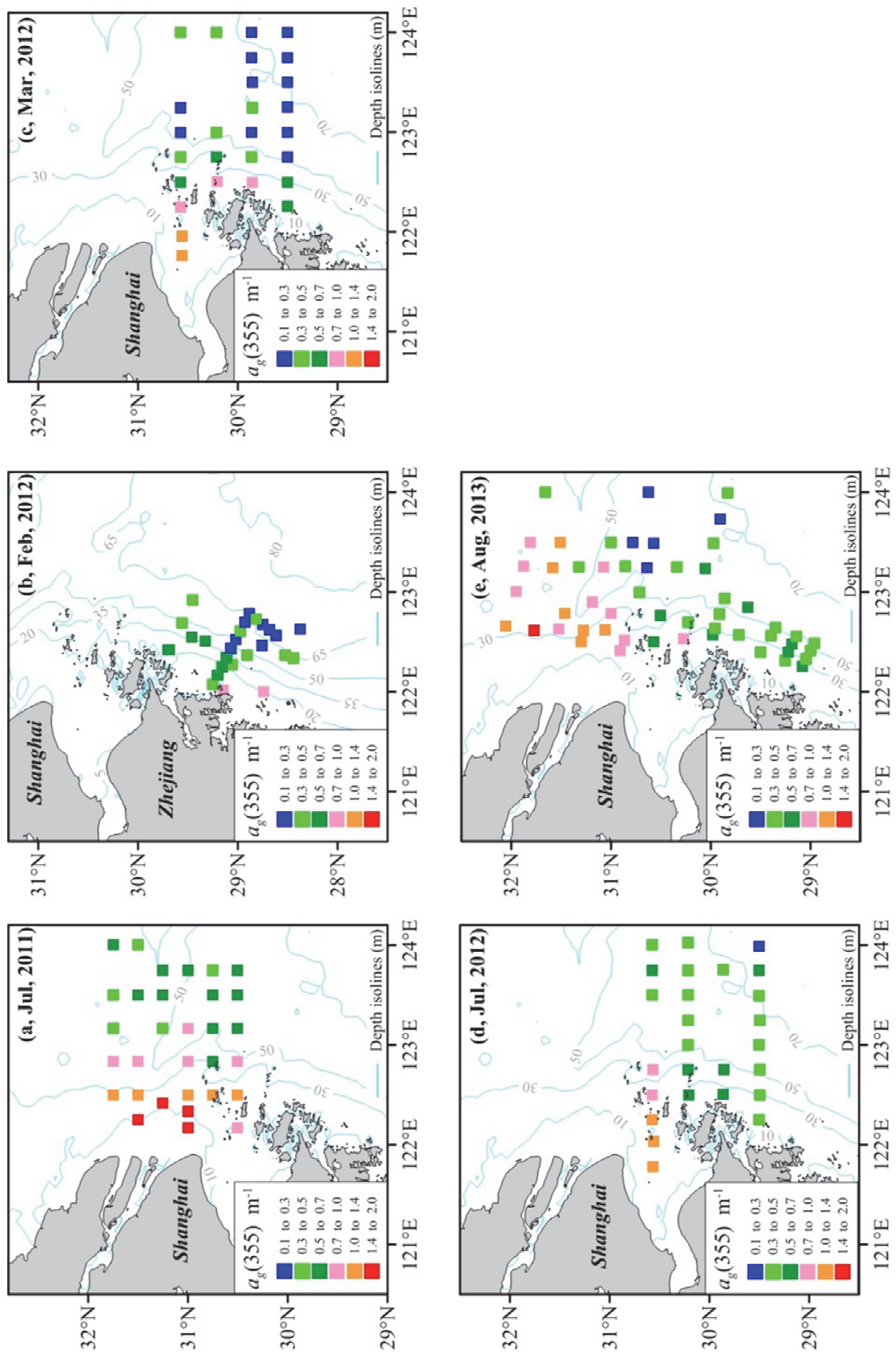

Figure 5.3. Spatial distribution of surface over the Yangtze estuarine and coastal region. Data were collected from five cruises in July of 2011 (a), February (b), March (c), July (d) of 2012 and August of 2013 (e).

Figure 5.3 shows a noticeable spatial-temporal variation of surface $a_{g}(355)$ over the Yangtze estuarine and coastal waters. The value of surface $a_{g}(355)$ ranged 
from 0.42 to $1.91 \mathrm{~m}^{-1}$ in July 2011, from 0.11 to $0.84 \mathrm{~m}^{-1}$ in February 2012, from 0.13 to $1.21 \mathrm{~m}^{-1}$ in March 2012, from 0.26 to $1.36 \mathrm{~m}^{-1}$ in July 2012 and from 0.23 to $1.45 \mathrm{~m}^{-1}$ in August 2013, respectively. The surface $a_{g}(355)$ exhibited a gradual decrease from nearshore to offshore, formed a northwest-southeast gradient, and eventually kept steady and low (less than $0.5 \mathrm{~m}^{-1}$ ) in regions far from the river mouth. Most samples in March and July 2012 were collected at same sites (See Figure 5.3c and Figure 5.3d), from which we can observe that CDOM absorption coefficients in summer (e.g., in July) were higher than that in winter (e.g., in March). The annual variation of $a_{g}(355)$ over the study area in summer from 2011 to 2013 is also observed according to Figures 5.3a, 5.3d, and 5.3e. The average values of $a_{g}(355)$ are $0.89 \mathrm{~m}^{-1}, 0.52 \mathrm{~m}^{-1}$ and $0.60 \mathrm{~m}^{-1}$ in July 2011, July 2012 and August 2013, respectively.

As shown in Figure 5.4, the variations of $a_{g}(355)$ in July 2011 in a vertical direction among different stations are rather flexible, and no clear pattern can be found. In general, water is more stratified at inshore stations compared to offshore stations. The largest variations of $a_{g}(355)$ depth-profile are found at stations adjacent to the Yangtze River mouth (e.g., stations within longitude of $122.5^{\circ} \mathrm{E}$ in Figures $5.4 \mathrm{c}, 5.4 \mathrm{e}$ and $5.4 \mathrm{f}$ ), while vertical variations at most offshore stations are rather small, especially for stations with longitude larger than $123^{\circ} \mathrm{E}$.
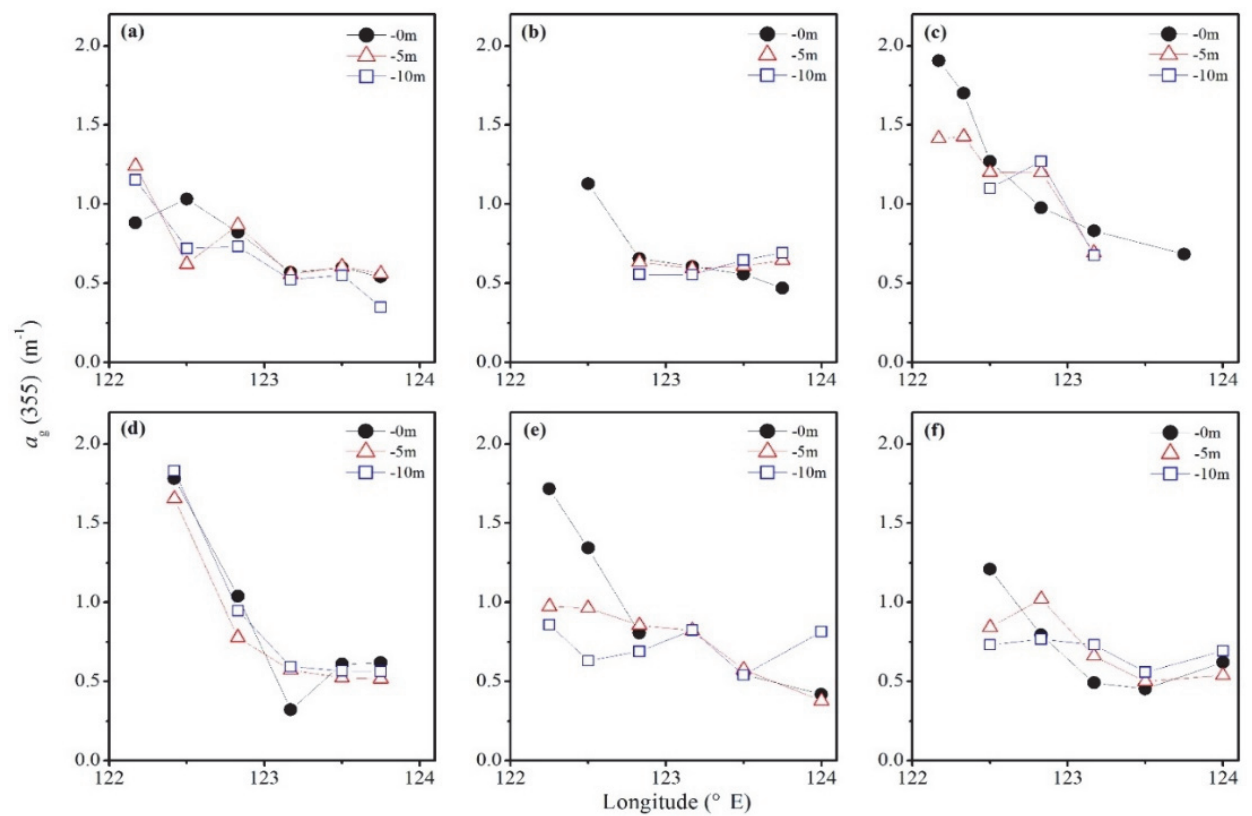

Figure 5.4. Vertical distribution of $a_{g}(355)$ along geographic longitude increasing in July 
2011. Panels 4a - 4f are corresponding to the six axial transections in Figure 5.3a from the bottom to the top.

\subsubsection{CDOM absorption coefficient and salinity}

Salinity is a perfect indicator of the influence of river runoff in the estuarine regions. The variation of salinity is mainly due to the mixture of fresh water from river and ocean water. Freshwater is almost extinguished from salinity while the surface salinity in Open Ocean is typically between 32 and 37 PSU (Lagerloef et al., 1995). To better explore the relationship between CDOM absorption coefficient and salinity, CDOM measurements are divided into subsets based on two criteria. The first classification is based on sampling seasons, i.e., winter and summer. The other one is according to the salinity, from which three subsets are classified with two thresholds of 20 PSU and 32 PSU. We consider that samples with salinity lower than 20 PSU are riverine-dominant while marine-dominant samples have salinities greater than 32 PSU. Figure 5.5 shows the relationships between salinities and $a_{g}(355)$, as well as their linear fitting parameters.
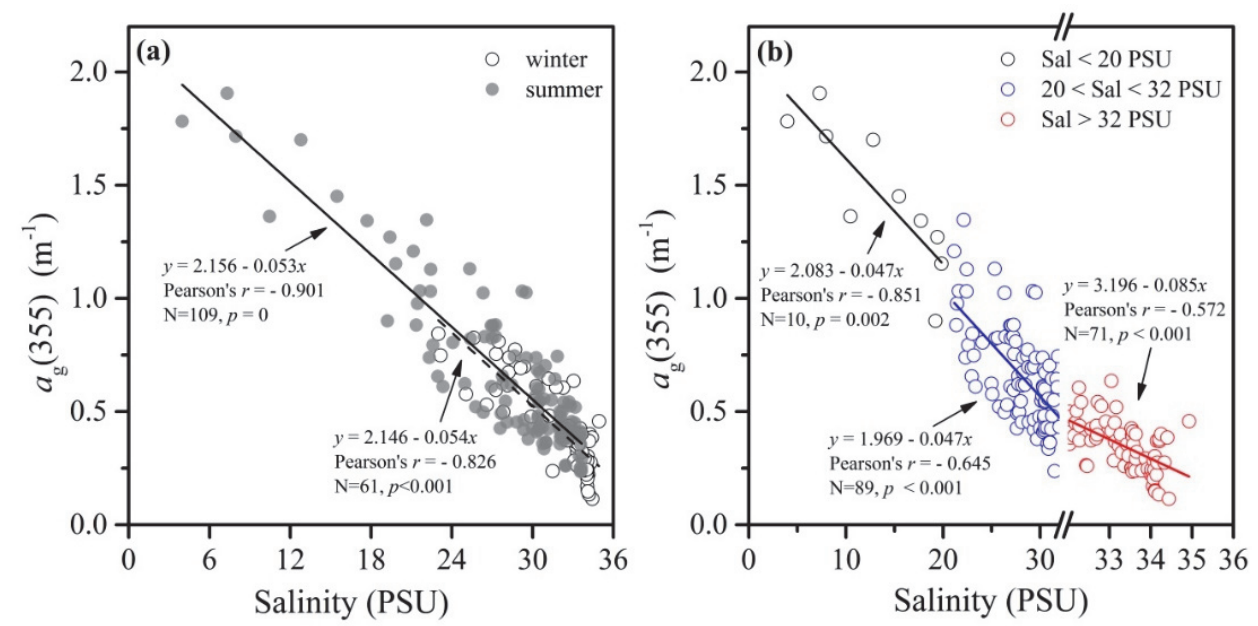

Figure 5.5. Relationships between salinity and $a_{g}$ (355). All CDOM measurements are divided into (a) two subsets for samples collected in winter and summer and (b) three subsets according to the salinity with two thresholds at 20 and 32 PSU.

From Figure 5.5 we can find that $a_{g}(355)$ is negatively correlated with salinity in our study area. However, this relationship is more robust in summer (Figure 5.5a, Pearson's coefficient $r=-0.901, \mathrm{~N}=109, p=0$ ) than that in winter (Figure 5.5a, Pearson's coefficient $r=-0.826, \mathrm{~N}=61, p<0.001$ ). It also can be found that the negative relationship is more robust for samples with salinity lower than $20 \mathrm{PSU}$ 
(Figure 5.5b, Pearson's coefficient $r=-0.851, \mathrm{~N}=10, p=0.002$ ) compared to samples with higher salinities.

\subsubsection{Spectral slope of CDOM absorption and salinity}

Spectral slope of CDOM light absorption also varied significantly in spatial and temporal scales in this study. The range of $S_{440}$ for all samples was from 0.009 to $0.019 \mathrm{~nm}^{-1}$ with the average value of $0.015 \mathrm{~nm}^{-1}$. Seasonal variations of $S_{440}$ are also observed as the average value of $S_{440}$ in July 2012 was $0.017 \pm 0.001 \mathrm{~nm}^{-1}$ while the average value in March 2012 was $0.0145 \pm 0.0017 \mathrm{~nm}^{-1}$. On the other hand, $S_{275-295}$ ranges from 0.015 to $0.032 \mathrm{~nm}^{-1}$ for all observations with the average value of $0.021 \mathrm{~nm}^{-1}$. However, opposite to the seasonal variation of $S_{440}$, the average value of $S_{275-295}$ in March $2012\left(0.023 \pm 0.004 \mathrm{~nm}^{-1}\right)$ was higher than that in July $2012\left(0.018 \pm 0.002 \mathrm{~nm}^{-1}\right)$.

There is no clear relationship between $S_{440}$ and salinity in this study (figure not shown here), while both $S_{275-295}$ and $S_{\mathrm{R}}$ increased along the increasing salinity gradient as shown in Figure 5.6. The patterns between salinity and $S_{275-295}$ and $S_{\mathrm{R}}$ are consistent with previous studies (Fichot and Benner, 2012; Helms et al., $2008)$. Moreover, the linearity is more robust in low salinity samples ( $<20$ PSU) for both $S_{275-295}$ and $S_{\mathrm{R}}$.
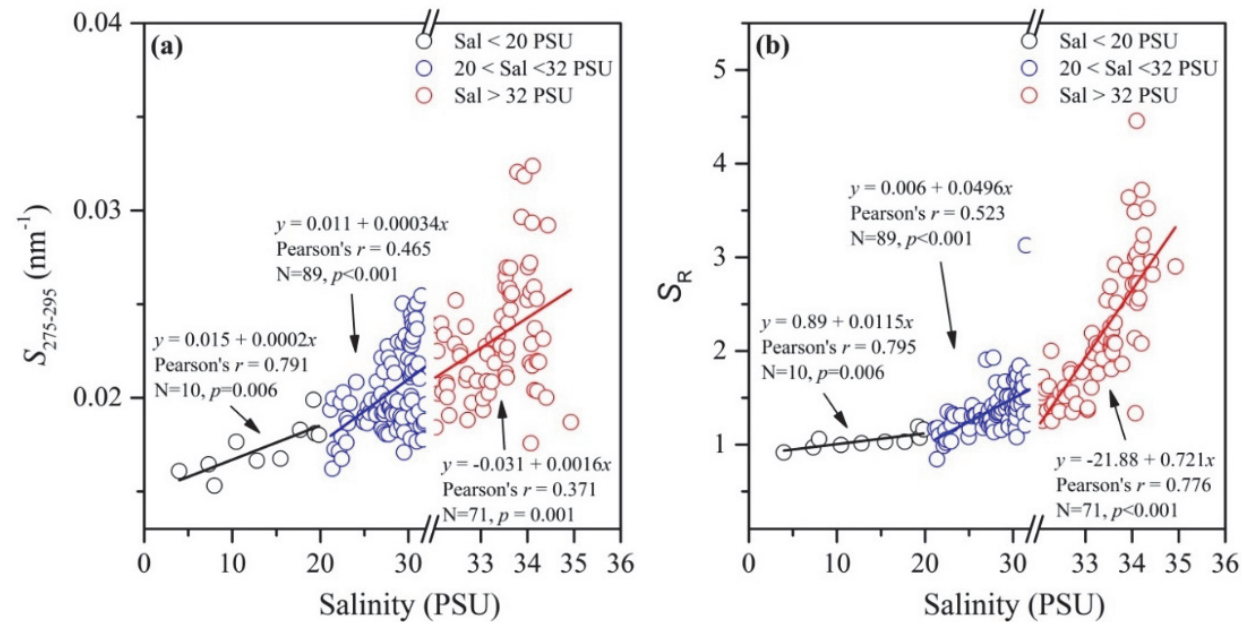

Figure 5.6. Scatter plots between salinity and $S_{275-295}$ (a) and $S_{\mathrm{R}}$ (b). All observations are divided into three subsets using thresholds of salinity at 20 PSU and 32 PSU.

\subsubsection{CDOM properties and DOC}

DOC concentrations ranged from 60.54 to $217.06 \mu \mathrm{mol} / \mathrm{L}$ for measurements from July 2011 and August 2013 with an average value of $115.41 \mu \mathrm{mol} / \mathrm{L}$. DOC 
was unrelated to both salinity and the CDOM absorption coefficient in this study, presenting a non-conservative mixing behavior between CDOM and DOC. To estimate DOC from CDOM properties, we adopted the approach of Fichot and Benner (2012) and developed a non-linear relationship between $S_{275-295}$ and DOC-normalized CDOM absorption coefficient at $355 \mathrm{~nm}$ (i.e., $a_{g}(355) / \mathrm{DOC}$, denoted as $a_{g}^{*}(355)$ ). All the DOC samples were divided into two optimal calibration and validation sets according to the Cal/Val model (Salama et al., 2012). The Cal and Val sets were selected such that they have the same moments (mean and standard deviation). An exponential function was used to fit $a_{g}^{*}(355)$ and $S_{275-295}$ for the calibration dataset (Figure 5.7a), resulting in a coefficient of determination $\left(R^{2}\right)$ of 0.78 . The fitting equation is expressed as,

$$
\begin{aligned}
& a_{g}^{*}(355)=a_{g}(355) / D O C=\exp (-2.45- \\
& \left.130.79 S_{275-295}\right)
\end{aligned}
$$

The fitting equation from Fichot and Benner (2012) is also provided in Figure 5.7a for comparison. The developed model was applied to the Val dataset to estimate DOC from CDOM absorption coefficient and $S_{275-295}$ as shown in Figure $5.7 \mathrm{~b}$. The uncertainty of this model is clarified with the $R^{2}$ of 0.746 , an RMSE of $20.99 \mu \mathrm{mol} / \mathrm{L}$ and an $\mathrm{rMAD}$ of $14.46 \%$.
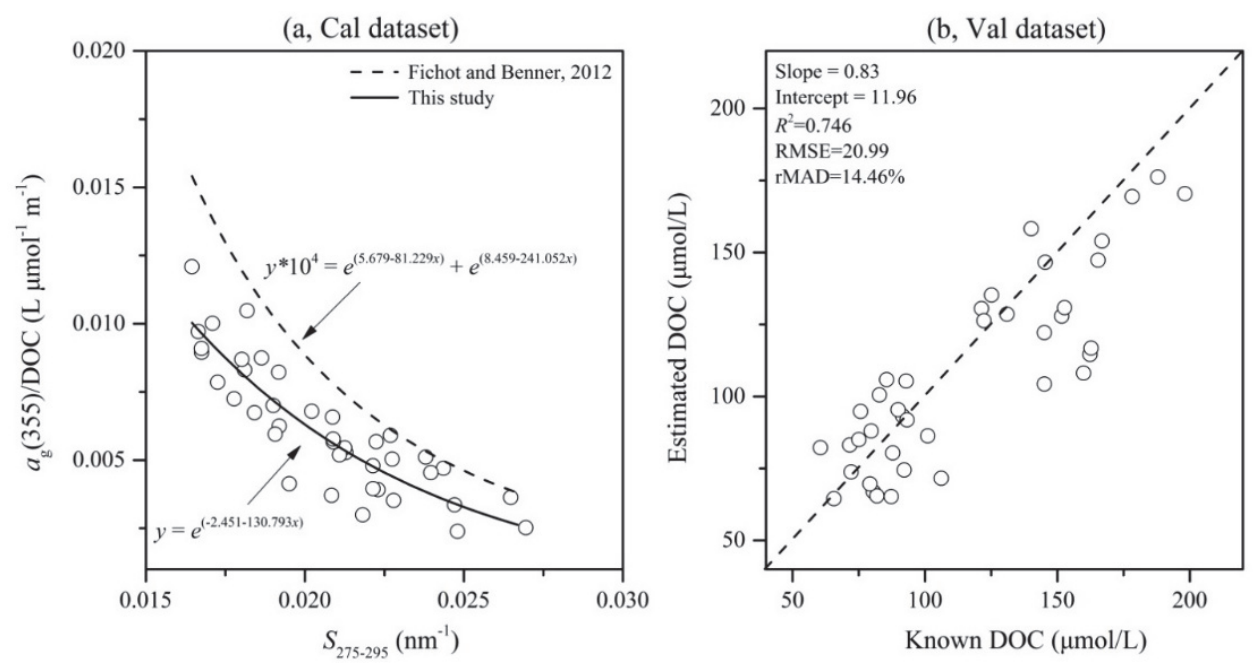

Figure 5.7. Calibration and validation for DOC estimation model using the Cal and Val datasets. (a) A non-linear relationship (black line) is used to fit $a_{g}(355) / \mathrm{DOC}$ and $S_{275-295}$ using the Cal dataset. A reference relationship from Fichot and Benner (2012) is also provided (dash line). (b) Validation of the developed model using the Val dataset. 


\subsection{Discussion}

\subsubsection{CDOM optical properties among world's estuarine and coastal waters}

Table 5-1 presents the comparison of several investigated parameters around the world's estuarine and coastal waters, including the ranges of CDOM absorption coefficient, spectral slope $S_{440}$, salinity, and DOC concentration. In general, the level of $a_{g}(355)$ in this study was on par with results from Pearl River estuary and Mackenzie River estuary but was much lower than that in some other major estuaries as shown in Table 5-1.

The abundance of DOM in the estuarine and coastal water is always influenced by vegetation, climate, the type of rock and soil in the river basins. As shown by the Terra MODIS NDVI images, the coverage of vegetation in the Yangtze River basin is lower compared to other drainage basins of major world rivers, which is probably due to rapid urbanization and massive deforestation in the past decades. Therefore, the low degree of vegetative cover in the Yangtze River basin could be an important factor in determining the relatively low content of soil organic matter in the drainage basins, resulting in the relatively low concentration of $\mathrm{CDOM}$ in the Yangtze estuary. The low degree of vegetative cover in the drainage basin could also be the key factor leading to the relatively low level of CDOM in Pearl River estuary (Chen et al., 2004; Hong et al., 2005). In addition, extensive use of inorganic fertilizers in Chinese agriculture reduces one of the important sources of DOM in the soils and rivers that come from traditional manure and organic fertilizer (Chen et al., 2004).

On the other hand, the recharge types of the stream could also have a huge impact on the level of CDOM in the river. Compared to streams originated from marshland, peatland, and rainforest, streams originated from glacier and mountain area usually have a low degree of DOM and their recharges into the Yangtze river will dilute the concentration of DOM (Pan et al., 2012). The Yangtze River is originated from the Tanggula Mountains that are underlain by glaciers in large expanses. Dilution by stream recharged from glacial melting could also be an important factor in determining the low concentration of CDOM in the estuary. The other factor that results in the low degree of CDOM in Yangtze estuary could be attributed to the high turbidity in the Yangtze River and estuary. Compared to other major rivers in the world, the Yangtze River has a relatively high sediment load with an average annual discharge of 0.39 billions 
of tons of sediments from 1951 to 2010, observed at Datong Station (Changiiang Sediment Bulletin of 2012, available in Chinese at http://www.cjh.com.cn/fileupload/2013-09-13/130913171010455.pdf). The high load of suspended matter prevents the light penetrating the water and limits the photosynthesis of phytoplankton in the upper layer. Therefore, the aquatic source of CDOM from photosynthesis could be reduced significantly. However, the relative importance of each of these driven factors could vary spatially and seasonal and cannot be quantified with further investigation.

Table 5-1. Comparisons of CDOM absorption $a_{g}(355), S_{440}$ and salinity among different estuarine and coastal waters.

\begin{tabular}{|c|c|c|c|c|c|c|}
\hline Region & $a_{g}(355) / m^{-1}$ & $\mathrm{~S}_{440} / \mathrm{nm}^{-1}$ & $\begin{array}{l}\text { Sal } \\
\text { (PSU) }\end{array}$ & $\begin{array}{l}\text { DOC } \\
(\mu \mathrm{mol} / \mathrm{L})\end{array}$ & Season & References \\
\hline $\begin{array}{l}\text { Amazon River } \\
\text { and Estuary }\end{array}$ & $0.14 \sim 3.12$ & $0.014 \sim 0.033$ & $0 \sim 36.4$ & NA & winter & $\begin{array}{l}\text { (Green and Blough } \\
\text { 1994) }\end{array}$ \\
\hline $\begin{array}{l}\text { Orinoco River } \\
\text { plume }\end{array}$ & $0.43 \sim 4.17$ & $0.012 \sim 0.022$ & $19.7 \sim 33.7$ & $70 \sim 276$ & fall & $\begin{array}{l}\text { (Del Castillo et al. } \\
\text { 1999) }\end{array}$ \\
\hline $\begin{array}{l}\text { St. Lawrence } \\
\text { River Estuary }\end{array}$ & $0.2 \sim 3.8 a_{\mathrm{g}}(365)$ & 0.015 & $0 \sim 35.5$ & NA & summer & (Nieke et al. 1997) \\
\hline $\begin{array}{l}\text { Mackenzie } \\
\text { River Estuary }\end{array}$ & $0.6 \sim 2.02 \mathrm{a}_{\mathrm{g}}(320)$ & $\begin{array}{l}0.018 \sim 0.025 \\
S_{320}\end{array}$ & $24.5 \sim 30.1$ & 73.3 205.8 & fall & (Retamal et al. 2007) \\
\hline $\begin{array}{l}\text { Scheldt } \\
\text { estuary }\end{array}$ & $\begin{array}{l}0.97 \sim 4.22 \mathrm{a}_{\mathrm{g}}(375) \\
2.34 \sim 4.29 \mathrm{ag}_{\mathrm{g}}(375)\end{array}$ & $\begin{array}{l}0.017 \sim 0.019 \\
0.018 \sim 0.019\end{array}$ & $\begin{array}{l}0.7 \sim 29.6 \\
2.7 \sim 19.9\end{array}$ & NA & $\begin{array}{l}\text { winter } \\
\text { summer }\end{array}$ & (Astoreca et al. 2009) \\
\hline $\begin{array}{l}\text { Chesapeake } \\
\text { Bay }\end{array}$ & $0.4 \sim 4.6$ & $0.015 \sim 0.024$ & $0 \sim 33$ & $60 \sim 290$ & spring & $\begin{array}{l}\text { (Rochelle-Newall and } \\
\text { Fisher 2002) }\end{array}$ \\
\hline $\begin{array}{l}\text { Southern } \\
\text { Beaufort Sea }\end{array}$ & $\begin{array}{l}0.018 \sim 1.08 \\
a_{g}(440)\end{array}$ & $0.015 \sim 0.023$ & $0 \sim 35.0$ & $49-460$ & summer & $\begin{array}{l}\text { (Matsuoka et al. } \\
\text { 2012a) }\end{array}$ \\
\hline $\begin{array}{l}\text { Pearl River } \\
\text { estuary }\end{array}$ & $0.24 \sim 1.93$ & $0.014 \sim 0.018$ & $0 \sim 32.5$ & NA & winter & (Hong et al. 2005) \\
\hline $\begin{array}{l}\text { Pearl River } \\
\text { estuary }\end{array}$ & $0.34 \sim 1.40$ & & $0 \sim 35.0$ & $86 \sim 250$ & summer & (Chen et al. 2004) \\
\hline Yangtze & $0.1 \sim 3.2$ & $0.017 \sim 0.020$ & $0 \sim 32.0$ & & summer & (Guo et al. 2007) \\
\hline \multirow[t]{3}{*}{ Estuary $^{a}$} & $0.10 \sim 2.82$ & $\begin{array}{l}0.017 \sim 0.02 \\
0\end{array}$ & $0.12 \sim 29.4$ & $41.7 \sim 126.2$ & spring & (Sun et al. 2014b) \\
\hline & $0.43 \sim 3.74$ & $\begin{array}{l}0.018 \sim 0.02 \\
2\end{array}$ & $0.2 \sim 26.5$ & 139.4 220 & summer & (Zhang et al. 2013) \\
\hline & $0.05 \sim 1.15$ & $\begin{array}{l}0.012 \sim 0.02 \\
3\end{array}$ & $19 \sim 34.5$ & $63.7 \sim 129.5$ & winter ${ }^{b}$ & \\
\hline Yangtze & $0.11 \sim 1.20$ & $0.008 \sim 0.018$ & $18.7 \sim 34.9$ & & winter & This study \\
\hline Estuary ${ }^{c}$ & $0.23 \sim 1.91$ & $0.012 \sim 0.025$ & $4.0 \sim 33.6$ & $60.5 \sim 217$ & summer & \\
\hline
\end{tabular}

a) Include samples collected from the river mouth;

b) Winter subset includes data collected from the PN section in March of 2011;

c) Only data from surface layer is counted. 


\subsubsection{Spatial-temporal variation of CDOM in the Yangtze estuary}

The exhibited distribution of surface $a_{g}(355)$ in the Yangtze estuarine and coastal waters is mainly because the Yangtze River runoff contributes most parts to the $\mathrm{CDOM}$ concentration in this area. The influence of runoff is weakening with the increasing distance away from the river mouth, resulting in a decline of terrestrial material along the downstream transit and forming the northwest-southeast decreasing gradient of CDOM. This kind of spatial distribution was in accordance with previous studies in this area (Lei et al., 2012; Sun et al., 2014b). The gradient of CDOM from the inner shelf to outer shelf was also observed in other riverinfluenced estuarine and coastal waters such as the St. Lawrence Estuary (Nieke et al., 1997), the Southern Bight of the North Sea (Warnock et al., 1999) and two estuaries of Canadian Arctic (Retamal et al., 2007). Note that the spatial distribution of CDOM in February 2012 (Figure 5.3b) was not a regular gradient. A more likely explanation related to this fact is that samples were collected during a tidal cycle. The tide type in the Hangzhou Bay and adjacent water is typical semidiurnal tide, and sampling interval in February cruise was less than 1 hour. Therefore, CDOM could probably be remobilized from the interstitial waters of bottom sediments and injected into overlying waters during the reverse phase of the tide.

The seasonal difference in CDOM between March 2012 (Figure 5.3c) and July 2012 (Figure 5.3d) in the Zhejiang coastal waters was mainly because of the seasonal changes in Yangtze runoff. Yangtze runoff was almost doubled from March to July in 2012 (See also the Changjiang Sediment Bulletin of 2012), resulting in a higher level of CDOM in summer. However, the seasonal variation in CDOM is not obvious for the two stations in the Hangzhou Bay (Figure 5.3c and Figure 5.3d), which is most likely due to the resuspension of bottom sediment resuspension. Sediment resuspension in the Hangzhou Bay in winter is mainly due to the distinct structure of the bay and the mutual effects by wind and tide (Chen et al., 2003). During the resuspension, bottom sediments with terrestrial matter injected into overlying waters and thus increase the CDOM concentration (Bodineau et al., 1998), resulting in the almost same level of CDOM at these two sites in March and July.

The vertical distribution of $a_{g}(355)$ in July of 2011 (Figure 5.4) was more stratified in coastal water and peaked at the surface layer, which might be due to hydrological dynamics and the mixing behavior between fresh water and salt 
water. For example, water density has been reported closely correlated to DOC in the vertical direction in the Yangtze estuary (Liu et al., 2014). Similar phenomena were also observed in previous studies (Del Castillo and Miller 2011; Gardner et al., 2005). The stratification was not significant in most offshore stations above the $10 \mathrm{~m}$ depth might because the runoff influence was weak, and water was well mixed.

The interannual variation of CDOM absorption coefficient is also observed by comparing our study with reported results by Guo et al. (2007) and Zhang et al. (2013). Note that the ranges of $a_{g}$ (355) in Guo et al. (2007) and Zhang et al. (2013) as shown in Table 5-1 include samples collected from the river mouth with high absorption. In general, $a_{g}(355)$ in summer from our study and these published results are comparable, and the interannual variation of CDOM in the Yangtze estuarine and coastal waters is rather small. Therefore, field measurements of CDOM properties in this study (e.g., average $a_{g}(355)$ and $S_{400}$ ) could be useful in reducing the uncertainties of retrieval models on inherent optical properties (IOPs). This is mainly because CDOM contributes a large portion to the total absorption coefficient in most estuaries and is therefore sensitive in IOPsretrieval models (Garver and Siegel, 1997; Lee et al., 2007; Lee et al., 2002; Maritorena et al., 2002; Yang et al., 2013). However, CDOM parameterization (Eq. (5.3)) in these models always requires empirical coefficient (e.g., $\left.S_{440}\right)$ and a fine-tuned value from field measurements would meet the demand.

\subsubsection{Implications: CDOM sources}

The negative correlation between salinity and $a_{g}(355)$ (shown in Figure 5.5a) suggests that terrestrial inputs were the main source of CDOM in the study area, especially for the riverine end observations with low salinity samples (Figure 5.6b). The lower Pearson's $r(=-0.572)$ between salinity and $a_{g}(355)$ in high salinity water ( $>32 \mathrm{PSU}$ ) shows that river influence got weakened in marine end observations, resulting in a decline of the proportion of terrigenous CDOM.

The same conclusion can be found by the relationship between salinity and $S_{275-}$ 295 the dimensionless ratio $S_{\mathrm{R}}$. The smaller $S_{275-295}$ and $S_{\mathrm{R}}$ are corresponding to the higher MW, which is mostly determined by humic acid from the terrestrial source (Helms et al., 2008). Therefore, as shown in Figure 5.6, we can find that the DOM shifted from high MW to low MW with increasing salinity, corresponding to a decreasing proportion of terrigenous CDOM. The consistent increase of $S_{275-295}$ along the salinity gradient could be attributed to the photobleaching of 
terrigenous CDOM, which reduced the molecular size of DOM during downstream transit and thereby increased the $S_{275-295}$ (Helms et al., 2008). Additionally, responses of CDOM absorption at $275 \mathrm{~nm}$ and $295 \mathrm{~nm}$ to the exposure to solar radiation are different, where a much greater fractional decrease in $a_{g}(295)$ was found than $a_{g}(275)$, resulting in a larger $S_{275-295}$ in upstream (Del Vecchio and Blough, 2002, 2004; Fichot and Benner, 2012). Another factor determined the high $S_{275-295}$ in marine end waters could be attributed to the aquatic $\mathrm{CDOM}$, especially the protein-rich plankton CDOM production, which is proved to have a significant effect on the $S_{275-295}$ (Fichot and Benner, 2012).

Compared to the $S_{275-295}$, the $S_{\mathrm{R}}$ seems to be a more effective indicator for the proportion of terrigenous DOM in this study, since the negative relationships between the $S_{\mathrm{R}}$ and the salinity are more robust for the three types of waters (i.e., riverine-dominated water, mixed water, and marine water) as shown in Figure $5.6 \mathrm{~b}$. This is mainly due to the values of spectral slope $S_{350-400}$ generally decreased with increasing salinity (blue circles in Figure 5.8), which is consistent with (Helms et al., 2008). The increase of $S_{\mathrm{R}}$ is mainly due to the increase of $S_{275-295}$, while the decreasing trend of $S_{350-400}$ enhanced the sensitivity of $S_{\mathrm{R}}$ to the terrigenous DOM.

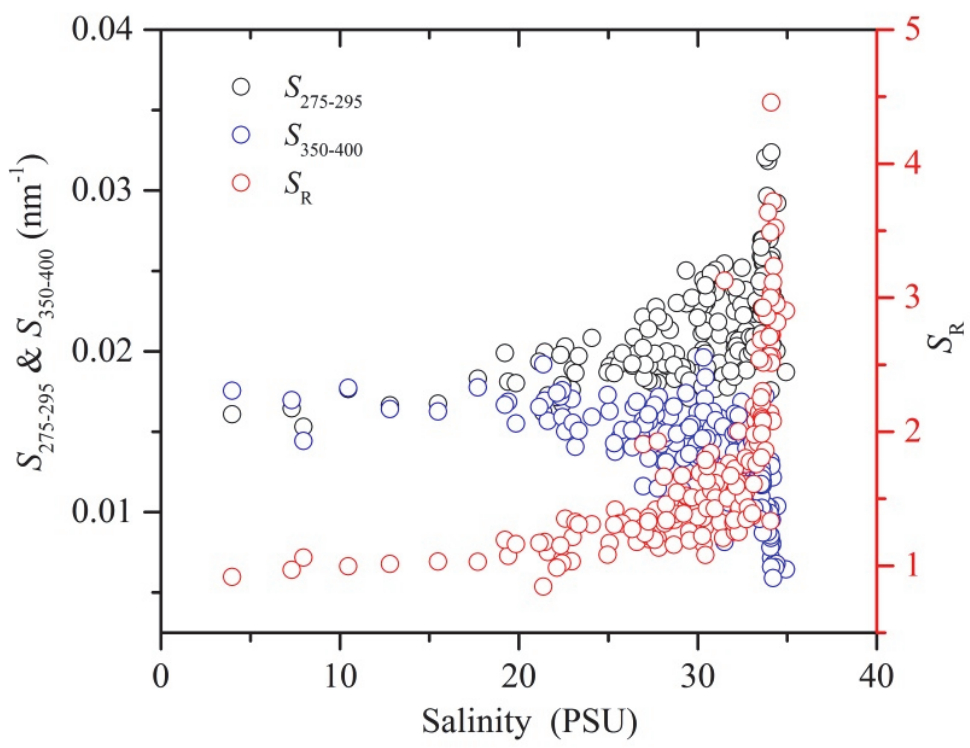

Figure 5.8. The trends of the spectral slopes $\left(S_{275-295}\right.$ and $\left.S_{350-400}\right)$ and the slope ratio $S_{\mathrm{R}}$ to the increasing salinity. 


\subsubsection{Implications: DOC source and estimation}

The range of DOC concentration in this study (i.e., 60.54 to $217.06 \mu \mathrm{mol} / \mathrm{L}$ ) is comparable with the investigations from Zhang et al. (2013) in the same study area, with reported DOC ranging from 76.4 to $264.4 \mu \mathrm{mol} / \mathrm{L}$. Note that results in Zhang et al. (2013) include several samples inside the river mouth that were rich in DOC concentration. On the other hand, DOC concentrations in this study agreed with CDOM absorption, are much lower than other major estuarine and coastal waters in the world. For instance, DOC in the Mississippi River estuary was as high as $446 \mu \mathrm{mol} / \mathrm{L}$ (Chen and Gardner, 2004), while averaged at $350 \pm$ $75 \mu \mathrm{mol} / \mathrm{L}$ in the Amazon River estuary (Ward et al., 2015), and even reached $800 \mu \mathrm{mol} / \mathrm{L}$ in the Congo River estuary (Spencer et al., 2009b). It is most likely the same driven factors to the distribution of CDOM that result in the low concentration of DOC in the Yangtze estuary.

The mixture behavior between DOC and CDOM is non-conservative, which was also observed in the previous study in the Yangtze estuary (Cauwet and Mackenzie, 1993) and other river-dominated estuarine and coastal waters such as the Mississippi River estuary (Chen and Gardner, 2004), the Pearl River estuary (Chen et al., 2004) and Finnish estuaries (Asmala et al., 2012). However, the fact is that a conservative mixture behavior between DOC and CDOM was also reported in the Yangtze estuarine and coastal waters (Zhang et al., 2013), indicating the mixing behavior between the two parameters is highly variable in seasonal and regional scales. This could be potentially due to the asynchronous changes between DOC and CDOM (Vodacek et al., 1997), resulting in a variation of the CDOM portion in the DOM. For example, the discrepancy between DOC and CDOM in their stabilities and residence period is always significant in estuarine and coastal waters, as DOC are commonly unstable and easily decomposed compared to the CDOM in coastal waters (Spitzy and Ittekkot, 1986).

As shown in Figure 5.7, the developed non-linear model presents a robust method to estimate DOC concentration from the $S_{275-295}$ and $a_{g}$ (355). Note that despite the $S_{\mathrm{R}}$ is a more indicative parameter to terrestrial DOM in this study, it seems to be independent to DOC, which is consistent with results from (Helms et al., 2008). The developed model can be considered as satisfied, and the validation result is not biased since the adopted Cal/Val model (Salama et al., 2012) allows both calibration and validation datasets are independent to each other. It is worthy to note that the relationship between $a_{g}^{*}(355)$ and $S_{275-295}$ could work well for riverinfluenced coastal waters with the lignin as the important chromophore of CDOM 
pool and the main terrigenous component of DOC (Fichot and Benner, 2012), which could probably be the reason for the good performance of this non-linear relationship in the Yangtze estuary.

However, due to the nature of this non-linear relationship is empirical, applying this relationship to different regions could require a fine-tuning on the empirical coefficients. For instance, the coefficients developed by Fichot and Benner (2012) will overestimate DOC in the Yangtze estuarine and coastal waters as shown in Figure 5.7a. On the other hand, as shown in this study, the developed relationship worked well for observations collected from both July 2011 and August 2013, indicating that the fine-tuned empirical coefficients could potentially work well for the coefficients-developed region in different temporal scales. Moreover, with the regionally applicable DOC-CDOM relationship, DOC can be potentially estimated from earth observation data since CDOM absorption coefficient can be retrieved from remote sensing reflectance $\left(R_{\mathrm{rs}}\right)$ with acceptable accuracy (Lee et al., 2002; Matsuoka et al., 2012b; Siswanto et al., 2011).

\subsection{Conclusions}

Investigation in this study shows that the CDOM properties in the Yangtze estuarine and coastal waters varied significantly at spatial and temporal scales. CDOM absorption coefficient, $a_{\mathrm{g}}(355)$, at the surface layer, generally decreased with the increasing distance from the river mouth and was overall much higher in summer (July 2012) than in winter (March 2012). Vertical variation of $a_{\mathrm{g}}$ (355) was more profound in near-shore waters than that in offshore waters. The analysis in this study indicates that terrestrial input was the main source of CDOM in the investigated region, but the proportion of terrigenous CDOM declined with increasing salinity, which was probably due to photobleaching during downstream transit. Sediment resuspension could also be an important source of CDOM in the Hangzhou Bay in winter. The aquatic source could contribute to a large proportion of CDOM in marine waters with high salinities.

The slope ratio $S_{\mathrm{R}}$ was a more indicative parameter to terrigenous DOM compared to the $S_{275-295}$ in the Yangtze estuarine and coastal waters, but it was independent to DOC. A non-linear empirical relationship between $a_{g}^{*}(355)$ and $S_{275-295}$ was developed to estimate DOC from CDOM optical properties, which was proved robust in the Yangtze estuarine and coastal waters. This relationship provides an alternative approach to estimate DOC in large spatial scale from 
Light absorption properties of CDOM in the Yangtze estuarine and coastal waters

remotely retrieved CDOM optical properties over the Yangtze estuarine and coastal water. 
Chapter 6 Synthesis 
The purpose of this chapter is to synthesize the key findings resulting from this study and to put them into a broader perspective. This chapter begins with the research findings from Chapter 3, Chapter 4, and Chapter 5. It is followed by putting the scientific work of this thesis in a broader context and closing with an outlook on future efforts in ocean color remote sensing in turbid coastal waters.

\subsection{Research Findings}

To summarize, in this study, the author employed the analytical 2SeaColor model, with his contribution of improved parameterizations, to derive the inherent optical properties and diffuse attenuation coefficient in the optically-complex Yangtze estuary. The derived particulate backscattering coefficient was later adopted to empirically estimate the concentration of SPM, in which a novel model was proposed to retrieve wide-range $C_{S P M}$ without the need for a switching scheme. The last effort the author made was to investigate the seasonal variability of CDOM absorption properties and develop a locally calibrated model to estimate the concentration of DOC. The key findings resulting from the work mentioned above are discussed in the following text.

1) For the retrieval of IOPs and $K_{d}$ using the 2 SeaColor model as discussed in Chapter 2, the assumption of negligible absorption by non-water in NIR band does not hold for optically complex waters, such as the Yangtze estuary. Figure 3.4 shows that the 2 SeaColor model with improved parameterization improves the retrieval accuracy compared with the original 2SeaColor model, in which model the assumption was adopted.

2) The 2 SeaColor model, with improved parameterizations, should be recommended for $K_{d}$ retrieval in optically complex waters instead of the empirical and semi-analytical models, which is mainly attributed to the fact that the other two types of models employ empirical coefficients that require adjustments or fine-tuning for different types of water in order to achieve the minimum retrieval error. To the contrary, the $2 \mathrm{SeaColor}$ model, without the need of fine-tuning of empirical constants, predicts the optimum solution by spectral optimization. However, for optically-simple waters, such as Open Ocean or offshore water, a regionally calibrated empirical model could be more suitable, with fast data process and comparable, if not better, performance with the semi-analytical and analytical models (Table 3-2).

3) In Chapter 4, the author shows that the relationship between $C_{\mathrm{SPM}}$ and $b_{b p}$ changed from linear in clear waters to significantly curved in extremely turbid waters, which indicates that the retrieval models that assume constant 
specific backscattering coefficient would face larger errors when applied to turbid waters. The change in the relationship also points out that using a single function to calibrate the relationship for a wide-range $C_{\mathrm{SPM}}$ could result in significant uncertainties while using two respective models will introduce discontinuity issues. The same situation should also apply to $R_{r s}$-based SPM retrieval models. The sigmoid function used in this study could provide a hint for the future development of wide-range SPM retrieval models.

4) Also, in Chapter 4, it is clearly observed that the GOCI standard AC product significantly underestimates $R_{r s}$ at the two NIR bands (Figure 4.4). Even with the empirical correction (Eq. (4.5) and Eq. (4.6)), the $R_{r s}(\mathrm{NIR})$ could be still underestimated. However, the imperfect AC provides important information regarding the SPM retrieval models, which is that a multi-band algorithm could compensate for the uncertainties caused by $R_{r s}(\mathrm{NIR})$ if the visible bands are relatively accurate. The He model employs $R_{r s}$ only at $745 \mathrm{~nm}$ and 490 $\mathrm{nm}$, and the mapping product shows significant underestimation compared with the GOCI model (uses three visible bands plus $745 \mathrm{~nm}$ ) and the 2SeaColor model (uses all the 8 bands).

5) The $b_{b p}$ index using the sigmoid function seems to be robust when applied to other coastal waters, while the $b_{b p}-C_{\mathrm{SPM}}$ relationships show relatively large variations. However, the physics or mathematics behind the model's robustness in less turbid waters requires further investigation. Nevertheless, the validation against the independent SeaSWIR dataset shows that the proposed $S_{\text {index }}-C_{\mathrm{SPM}}$ model is applicable to other turbid coastal waters.

6) The $b_{b p}$ derived from the 2 SeaColor model was not validated in the extremely turbid waters (concentration $>100 \mathrm{mg} / \mathrm{L}$ ). However, its robust correlation with $C_{\text {SPM }}$ indicates that by using the spectral optimization technique, the resulting $b_{b p}$ contains the integral information from all wavebands. The error in the derived $b_{b p}$ from the "ground-truth" value, if there is any, does not matter that much in terms of retrieving the $C_{\mathrm{SPM}}$. On the other hand, the semianalytical retrieval model using a single band to derive $b_{b p}$ was not suitable for developing the $b_{b p}-C_{\mathrm{SPM}}$ relationship in extremely turbid waters.

7) In Chapter 5, the comparisons between CDOM absorption properties, especially the spectral slope of $a_{g}(\lambda)$, in global coastal waters demonstrate that spatial-temporal variation of $S$ is significant. Therefore, for IOPs retrieval models, the author would not recommend using the constant $S$ for model development.

8) The relationships between CDOM and salinity show very limited variation in winter and summer in terms of the slope from the regression analysis (Figure 
5.5), which indicates that the CDOM could be potentially used to estimate salinity in coastal environments where the salinity satellite (such as the SMOS) has large uncertainties. The relationship between DOC and CDOM demonstrates the potential of remotely retrieving DOC from satellite imagery, but it does involve special requests that UV bands should be included in order to implement the Eq. (5.4).

\subsection{Sustainable Development Goals}

This thesis contributes to our understanding of SPM and CDOM variations, in diurnal and seasonal scales, respectively, in the Yangtze estuary as related to their sources and the environmental conditions. As SPM and CDOM, reduce light transparency, contain particulate and dissolved carbon, and indicate land-based pollution, the scientific work presented here could be a direct contribution to the United Nations' Sustainable Development Goals (SDGs).

In particular, the SDGs Goal 6 indicators 6.3 and 6.6 require protecting and restoring water-related ecosystems, including the estuaries, and improving water quality globally by 2020 and 2030, respectively. The SDGs Goal 14 indicators 14.1 and 14.2 , on the other hand, demand sustainably managing and protecting the coastal ecosystem to avoid significant adverse impacts and preventing and significantly reducing marine pollution of all kinds, especially from land-based activities, by 2020 and 2025, respectively. Overall, problems that threaten the sustainable development of the aquatic ecosystem, to some extent, are all related to human activities. To better understand how the ecosystem responds associated with human activities and provide expert advice to society for ecosystem governance, the scientist must rest on a solid scientific basis and long-term time series observations.

The scientific work of this dissertation shows that remote sensing technique could provide a synoptic view of the variations of water constituents, which are closely associated with the biogeochemical substances in the water. Thereby, the variations of water constituents, if correctly interpreted, can serve as proper indexes of the health status of the ecosystem regarding the biological productivity, nutrient pollution, and hazardous chemicals and materials. Current operational ocean color satellites, along with their predecessor CZCS since 1978, provide time series and near real-time images that can be employed to analysis, monitor and predict the water quality at large temporal and spatial scales for the aquatic ecosystem. Interpretation of the long-term time series satellite data will provide 
a scientific basis for governments and social communities to take action to achieve a healthy and productive ecosystem.

\subsection{Outlook}

Research of ocean color remote sensing in turbid coastal waters is no doubt still full of great challenges for many years ahead. Dedicated efforts and innovative thoughts are required to promote the research and overcome the challenges and problems. Based on the research the author has done in this dissertation, the author thinks that there is still plenty of space for development and there are more topics raising from this study that could be worth studying in the near future.

1) The GOCI images, with great spatial and temporal resolutions, could serve as a tool in monitoring the optical properties in the Yangtze estuary if the AC can be improved for NIR bands for turbid waters.

2) The sigmoid function could be incorporated directly with $R_{r s}$ to see if a continuous and accurate $C_{\mathrm{SPM}}$ can be derived for wide-range $C_{\mathrm{SPM}}$ data.

3) All the semi-analytical models and the 2 SeaColor model do not consider the impact of the particle phase function on the accuracy of retrieved IOPs, especially the $b_{b}$. Further efforts could at least investigate the impact of the phase function on retrieved IOPs using simulated data generated by, for example, the Hydrolight ${ }^{\circledR}$ model.

4) The similar absorption spectral features between CDOM and NAP make it difficult to distinguish the two in the semi-analytical model. Partitioning the combined absorption by CDOM and NAP to their individual absorptions requires empirical relationships, which is less reported for the Yangtze estuary.

5) With the proposed model in this study, it is possible to investigate the monthly and annually variation of IOPs, $K_{d}$ and SPM. It would be of interest to understand how the estuary ecosystem has changed in the last decades and how sensitive it responds to extreme climate events and global climate change. 


\section{Bibliography}

Adler-Golden, S.M., Matthew, M.W., Bernstein, L.S., Levine, R.Y., Berk, A., Richtsmeier, S.C., Acharya, P.K., Anderson, G.P., Felde, G., Gardner, J., \& Others (1999). Atmospheric correction for short-wave spectral imagery based on MODTRAN 4. In (pp. 61--69)

Ahn, J.H., Park, Y.J., Ryu, J.H., Lee, B., \& Oh, I.S. (2012). Development of Atmospheric Correction Algorithm for Geostationary Ocean Color Imager (GOCI). Ocean Science Journal, 47, 247-259

Ambarwulan, W., Verhoef, W., Mannaerts, C.M., \& Salama, M.S. (2012). Estimating total suspended matter concentration in tropical coastal waters of the Berau estuary, Indonesia. International Journal of Remote Sensing, 33, 4919-4936

Arabi, B., Salama, M.S., Wernand, M.R., \& Verhoef, W. (2016). MOD2SEA: A Coupled Atmosphere-Hydro-Optical Model for the Retrieval of Chlorophylla from Remote Sensing Observations in Complex Turbid Waters. Remote Sensing, 8, 722

Asmala, E., Stedmon, C.A., \& Thomas, D.N. (2012). Linking CDOM spectral absorption to dissolved organic carbon concentrations and loadings in boreal estuaries. Estuarine Coastal and Shelf Science, 111, 107-117

Astoreca, R., Rousseau, V., \& Lancelot, C. (2009). Coloured dissolved organic matter (CDOM) in Southern North Sea waters: Optical characterization and possible origin. Estuarine Coastal and Shelf Science, 85, 633-640

Austin, R.W., \& Petzold, T.J. (1981). The determination of the diffuse attenuation coefficient of sea water using the Coastal Zone Color Scanner. Oceanography from space (pp. 239-256). New York: Springer

Babin, M., Morel, A., Fournier-Sicre, V., Fell, F., \& Stramski, D. (2003). Light scattering properties of marine particles in coastal and open ocean waters as related to the particle mass concentration. Limnology and Oceanography, 48, 843-859

Bailey, S.W., Franz, B.A., \& Werdell, P.J. (2010). Estimation of near-infrared water-leaving reflectance for satellite ocean color data processing. Optics Express, 18, 7521-7527

Baker, A., \& Spencer, R.G. (2004). Characterization of dissolved organic matter from source to sea using fluorescence and absorbance spectroscopy. Science of the total environment, 333, 217-232

Bergamino, N., Horion, S., Stenuite, S., Cornet, Y., Loiselle, S., Plisnier, P.D., \& Descy, J.P. (2010). Spatio-temporal dynamics of phytoplankton and primary 
production in Lake Tanganyika using a MODIS based bio-optical time series. Remote Sensing of Environment, 114, 772-780

Berk, A., Anderson, G.P., Bernstein, L.S., Acharya, P.K., Dothe, H., Matthew, M.W., Adler-Golden, S.M., Chetwynd Jr, J.H., Richtsmeier, S.C., Pukall, B., \& Others (1999). MODTRAN4 radiative transfer modeling for atmospheric correction. In (pp. 348--353)

Binding, C., Bowers, D., \& Mitchelson-Jacob, E. (2005). Estimating suspended sediment concentrations from ocean colour measurements in moderately turbid waters; the impact of variable particle scattering properties. Remote Sensing of Environment, 94, 373-383

Bodineau, L., Thoumelin, G., Beghin, V., \& Wartel, M. (1998). Tidal time-scale changes in the composition of particulate organic matter within the estuarine turbidity maximum zone in the macrotidal Seine estuary, France: the use of fatty acid and sterol biomarkers. Estuarine, Coastal and Shelf Science, 47, $37-49$

Boss, E., Gildor, H., Slade, W., Sokoletsky, L., Oren, A., \& Loftin, J. (2013). Optical properties of the Dead Sea. Journal of Geophysical Research: Oceans, 118, 1821-1829

Boss, E., Pegau, W., Lee, M., Twardowski, M., Shybanov, E., Korotaev, G., \& Baratange, F. (2004). Particulate backscattering ratio at LEO 15 and its use to study particle composition and distribution. Journal of Geophysical Research: Oceans, 109

Boss, E., Slade, W.H., Behrenfeld, M., \& Dall'Olmo, G.J.O.E. (2009). Acceptance angle effects on the beam attenuation in the ocean, 17, 1535-1550

Brajard, J., Santer, R., Crepon, M., \& Thiria, S. (2012). Atmospheric correction of MERIS data for case-2 waters using a neuro-variational inversion. Remote Sensing of Environment, 126, 51-61

Brewin, R.J., Sathyendranath, S., Müller, D., Brockmann, C., Deschamps, P.-Y., Devred, E., Doerffer, R., Fomferra, N., Franz, B., \& Grant, M. (2013). The Ocean Colour Climate Change Initiative: III. A round-robin comparison on in-water bio-optical algorithms. Remote Sensing of Environment

Bricaud, A., Morel, A., \& Prieur, L. (1981). Absorption by Dissolved OrganicMatter of the Sea (Yellow Substance) in the Uv and Visible Domains. Limnology and Oceanography, 26, 43-53

Buckton, D., O'Mongain, E., \& Danaher, S. (1999). The use of Neural Networks for the estimation of oceanic constituents based on the MERIS instrument. International Journal of Remote Sensing, 20, 1841-1851 
Bunt, J.A., Larcombe, P., \& Jago, C.F. (1999). Quantifying the response of optical backscatter devices and transmissometers to variations in suspended particulate matter. Continental Shelf Research, 19, 1199-1220

Canadell, J.G., \& Dickinson, R. (2006). Global Carbon Project. Science Framework and Implementation. Global Carbon Project. Science Framework and Implementation. Earth System Science Partnership, 80

Cao, F., Tzortziou, M., Hu, C., Mannino, A., Fichot, C.G., Del Vecchio, R., Najjar, R.G., \& Novak, M. (2018). Remote sensing retrievals of colored dissolved organic matter and dissolved organic carbon dynamics in North American estuaries and their margins. Remote Sensing of Environment, 205, 151-165

Carder, K.L., Chen, F.R., Lee, Z.P., Hawes, S.K., \& Kamykowski, D. (1999). Semianalytic Moderate-Resolution Imaging Spectrometer algorithms for chlorophyll a and absorption with bio-optical domains based on nitratedepletion temperatures. Journal of Geophysical Research-Oceans, 104, 5403

Carder, K.L., Steward, R.G., Harvey, G.R., \& Ortner, P.B. (1989). Marine Humic and Fulvic-Acids - Their Effects on Remote-Sensing of Ocean Chlorophyll. Limnology and Oceanography, 34, 68-81

Cauwet, G., \& Mackenzie, F.T. (1993). Carbon inputs and distribution in estuaries of turbid rivers: the Yang Tze and Yellow rivers (China). Marine Chemistry, 43, 235-246

Chen, J., Cui, T.W., Tang, J.W., \& Song, Q.J. (2014). Remote sensing of diffuse attenuation coefficient using MODIS imagery of turbid coastal waters: A case study in Bohai Sea. Remote Sensing of Environment, 140, 78-93

Chen, J., D'Sa, E., Cui, T., \& Zhang, X. (2013). A semi-analytical total suspended sediment retrieval model in turbid coastal waters: A case study in Changjiang River Estuary. Optics Express, 21, 13018-13031

Chen, R.F., \& Gardner, G.B. (2004). High-resolution measurements of chromophoric dissolved organic matter in the Mississippi and Atchafalaya River plume regions. Marine Chemistry, 89, 103-125

Chen, S.-L., Zhang, G.-A., Yang, S.-L., \& Shi, J.Z. (2006). Temporal variations of fine suspended sediment concentration in the Changjiang River estuary and adjacent coastal waters, China. Journal of Hydrology, 331, 137-145

Chen, S., Zhang, G., \& Yang, S. (2003). Temporal and spatial changes of suspended sediment concentration and resuspension in the Yangtze River estuary. Journal of Geographical Sciences, 13, 498-506 
Chen, Z., Li, J., Shen, H., \& Zhanghua, W. (2001). Yangtze River of China: historical analysis of discharge variability and sediment flux. Geomorphology, 41, 77-91

Chen, Z.Q., Li, Y., \& Pan, J.M. (2004). Distributions of colored dissolved organic matter and dissolved organic carbon in the Pearl River Estuary, China. Continental Shelf Research, 24, 1845-1856

Cloern, J.E. (1987). Turbidity as a control on phytoplankton biomass and productivity in estuaries. Continental Shelf Research, 7, 1367-1381

D'Sa, E.J., Miller, R.L., \& McKee, B.A. (2007). Suspended particulate matter dynamics in coastal waters from ocean color: Application to the northern Gulf of Mexico. Geophysical Research Letters, 34

Dall'Olmo, G., Gitelson, A.A., \& Rundquist, D.C. (2003). Towards a unified approach for remote estimation of chlorophyll-a in both terrestrial vegetation and turbid productive waters. Geophysical Research Letters, 30, 1938

Darecki, M., \& Stramski, D. (2004). An evaluation of MODIS and SeaWiFS biooptical algorithms in the Baltic Sea. Remote Sensing of Environment, 89, 326350

Del Castillo, C.E., Coble, P.G., Morell, J.M., L O Pez, J.M., \& Corredor, J.E. (1999). Analysis of the optical properties of the Orinoco River plume by absorption and fluorescence spectroscopy. Marine Chemistry, 66, 35--51

Del Castillo, C.E., \& Miller, R.L. (2011). Horizontal and vertical distributions of colored dissolved organic matter during the Southern Ocean Gas Exchange Experiment. Journal of Geophysical Research, 116, C00F07

Del Vecchio, R., \& Blough, N.V. (2002). Photobleaching of chromophoric dissolved organic matter in natural waters: kinetics and modeling. Marine Chemistry, 78, 231-253

Del Vecchio, R., \& Blough, N.V. (2004). On the origin of the optical properties of humic substances. Environmental Science \& Technology, 38, 3885-3891

Doerffer, R., \& Fischer, J. (1994). Concentrations of Chlorophyll, Suspended Matter, and Gelbstoff in Case-Ii Waters Derived from Satellite Coastal Zone Color Scanner Data with Inverse Modeling Methods. Journal of Geophysical Research-Oceans, 99, 7457-7466

Doerffer, R., \& Schiller, H. (2007). The MERIS Case 2 water algorithm. International Journal of Remote Sensing, 28, 517-535

Dogliotti, A., Ruddick, K.G., Nechad, B., Doxaran, D., \& Knaeps, E. (2015). A single algorithm to retrieve turbidity from remotely-sensed data in all coastal and estuarine waters. Remote Sensing of Environment, 156, 157-168 
Dong, Q., Shang, S., \& Lee, Z.J.R.S.o.E. (2013). An algorithm to retrieve absorption coefficient of chromophoric dissolved organic matter from ocean color, 128, 259-267

Doron, M., Babin, M., Mangin, A., \& Hembise, O. (2007). Estimation of light penetration, and horizontal and vertical visibility in oceanic and coastal waters from surface reflectance. Journal of Geophysical Research-Oceans, 112

Doxaran, D., Cherukuru, N., \& Lavender, S.J. (2006). Apparent and inherent optical properties of turbid estuarine waters: measurements, empirical quantification relationships, and modeling. Applied Optics, 45, 2310-2324

Doxaran, D., Froidefond, J.-M., Lavender, S., \& Castaing, P. (2002a). Spectral signature of highly turbid waters: Application with SPOT data to quantify suspended particulate matter concentrations. Remote Sensing of Environment, $81,149-161$

Doxaran, D., Froidefond, J.M., \& Castaing, P. (2002b). A reflectance band ratio used to estimate suspended matter concentrations in sediment-dominated coastal waters. International Journal of Remote Sensing, 23, 5079-5085

Doxaran, D., Froidefond, J.M., \& Castaing, P. (2003). Remote-sensing reflectance of turbid sediment-dominated waters. Reduction of sediment type variations and changing illumination conditions effects by use of reflectance ratios. Applied Optics, 42, 2623--2634

Doxaran, D., Froidefond, J.M., Castaing, P., \& Babin, M. (2009). Dynamics of the turbidity maximum zone in a macrotidal estuary (the Gironde, France): Observations from field and MODIS satellite data. Estuarine, Coastal and Shelf Science, 81, 321-332

Doxaran, D., Lamquin, N., Park, Y.J., Mazeran, C., Ryu, J.H., Wang, M.H., \& Poteau, A. (2014). Retrieval of the seawater reflectance for suspended solids monitoring in the East China Sea using MODIS, MERIS and GOCI satellite data. Remote Sensing of Environment, 146, 36-48

Doxaran, D., Leymarie, E., Nechad, B., Dogliotti, A., Ruddick, K., Gernez, P., \& Knaeps, E. (2016). Improved correction methods for field measurements of particulate light backscattering in turbid waters. Optics Express, 24, 36153637

Droppo, I., \& Ongley, E. (1994). Flocculation of suspended sediment in rivers of southeastern Canada. water research, 28, 1799-1809

Duntley, S.Q. (1942). The optical properties of diffusing materials. Journal of the Optical Society of America, 32, 61--61 
Duntley, S.Q. (1963). Light in the sea. Journal of the Optical Society of America, $53,214--233$

Fargion, G.S., \& Mueller, J.L. (2000). Ocean optics protocols for satellite ocean color sensor validation, Revision 2. National Aeronautics and Space Administration, Goddard Space Flight Center

Ferrari, G.M. (2000). The relationship between chromophoric dissolved organic matter and dissolved organic carbon in the European Atlantic coastal area and in the West Mediterranean Sea (Gulf of Lions). Marine Chemistry, 70, 339-357

Fichot, C.G., \& Benner, R. (2011). A novel method to estimate DOC concentrations from CDOM absorption coefficients in coastal waters. Geophysical Research Letters, 38, L03610

Fichot, C.G., \& Benner, R. (2012). The spectral slope coefficient of chromophoric dissolved organic matter (S275-295) as a tracer of terrigenous dissolved organic carbon in river-influenced ocean margins. Limnology and Oceanography, 57, 1453-1466

Forget, P., Ouillon, S., Lahet, F., \& Broche, P. (1999). Inversion of reflectance spectra of nonchlorophyllous turbid coastal waters. Remote Sensing of Environment, 68, 264-272

Gardner, G.B., Chen, R.F., \& Berry, A. (2005). High-resolution measurements of chromophoric dissolved organic matter $(\mathrm{CDOM})$ in the Neponset River Estuary, Boston Harbor, MA. Marine Chemistry, 96, 137-154

Garver, S.A., \& Siegel, D.A. (1997). Inherent optical property inversion of ocean color spectra and its biogeochemical interpretation.1. Time series from the Sargasso Sea. Journal of Geophysical Research-Oceans, 102, 18607-18625

Gitelson, A. (1992). The peak near $700 \mathrm{~nm}$ on radiance spectra of algae and water: relationships of its magnitude and position with chlorophyll concentration. International Journal of Remote Sensing, 13, 3367--3373

Gitelson, A.A., Schalles, J.F., \& Hladik, C.M. (2007). Remote chlorophyll-a retrieval in turbid, productive estuaries: Chesapeake Bay case study. Remote Sensing of Environment, 109, 464-472

Gons, H.J. (1999). Optical teledetection of chlorophyll a in turbid inland waters. Environmental Science \& Technology, 33, 1127-1132

Gordon, H.R. (1973). Simple calculation of the diffuse reflectance of the ocean. Applied Optics, 12, 2803-2804

Gordon, H.R., Brown, O.B., Evans, R.H., Brown, J.W., Smith, R.C., Baker, K.S., \& Clark, D.K. (1988). A Semianalytic Radiance Model of Ocean Color. Journal of Geophysical Research-Atmospheres, 93, 10909-10924 
Gordon, H.R., Clark, D.K., Brown, J.W., Brown, O.B., Evans, R.H., \& Broenkow, W.W. (1983). Phytoplankton pigment concentrations in the Middle Atlantic Bight: comparison of ship determinations and CZCS estimates. Applied Optics, 22, 20-36

Gordon, H.R., \& Morel, A.Y. (1983). Remote assessment of ocean color for interpretation of satellite visible imagery: A review.

Gordon, H.R., \& Wang, M. (1994a). Influence of oceanic whitecaps on atmospheric correction of ocean-color sensors. Applied Optics, 33, 77547763

Gordon, H.R., \& Wang, M. (1994b). Retrieval of water-leaving radiance and aerosol optical thickness over the oceans with SeaWiFS: a preliminary algorithm. Applied Optics, 33, 443-452

Goyens, C., Jamet, C., \& Schroeder, T. (2013). Evaluation of four atmospheric correction algorithms for MODIS-Aqua images over contrasted coastal waters. Remote Sensing of Environment, 131, 63-75

Granskog, M.A. (2012). Changes in spectral slopes of colored dissolved organic matter absorption with mixing and removal in a terrestrially dominated marine system (Hudson Bay, Canada). Marine Chemistry, 134-135, 10-17

Green, S.A., \& Blough, N.V. (1994). Optical-Absorption and Fluorescence Properties of Chromophoric Dissolved Organic-Matter in Natural-Waters. Limnology and Oceanography, 39, 1903-1916

Gregg, W.W., Rousseaux, C.S., \& Franz, B.A. (2017). Global trends in ocean phytoplankton: a new assessment using revised ocean colour data. Remote Sensing Letters, 8, 1102-1111

Guo, L., \& He, Q. (2011). Freshwater flocculation of suspended sediments in the Yangtze River, China. Ocean Dynamics, 61, 371-386

Guo, W.D., Stedmon, C.A., Han, Y.C., Wu, F., Yu, X.X., \& Hu, M.H. (2007). The conservative and non-conservative behavior of chromophoric dissolved organic matter in Chinese estuarine waters. Marine Chemistry, 107, 357-366

Hansell, D.A., \& Carlson, C.A. (1998). Deep-ocean gradients in the concentration of dissolved organic carbon. Nature, 395, 263-266

He, X., Bai, Y., Pan, D., Huang, N., Dong, X., Chen, J., Chen, C.-T.A., \& Cui, Q. (2013). Using geostationary satellite ocean color data to map the diurnal dynamics of suspended particulate matter in coastal waters. Remote Sensing of Environment, 133, 225-239

He, X., Bai, Y., Pan, D., Tang, J., \& Wang, D. (2012). Atmospheric correction of satellite ocean color imagery using the ultraviolet wavelength for highly turbid waters. Optics Express, 20, 20754-20770 
Helms, J.R., Stubbins, A., Ritchie, J.D., Minor, E.C., Kieber, D.J., \& Mopper, K. (2008). Absorption spectral slopes and slope ratios as indicators of molecular weight, source, and photobleaching of chromophoric dissolved organic matter. Limnology and Oceanography, 53, 955-969

Hoge, F.E., \& Lyon, P.E. (1996). Satellite retrieval of inherent optical properties by linear matrix inversion of oceanic radiance models: an analysis of model and radiance measurement errors. Journal of Geophysical Research: Oceans, $101,16631-16648$

Hong, H.S., Wu, J.Y., Shang, S.L., \& Hu, C.M. (2005). Absorption and fluorescence of chromophoric dissolved organic matter in the Pearl River Estuary, South China. Marine Chemistry, 97, 78-89

Hooker, S.B., Lazin, G., Zibordi, G., \& McLean, S. (2002). An evaluation of above- and in-water methods for determining water-leaving radiances. Journal of Atmospheric and Oceanic Technology, 19, 486-515

Hu, C., Chen, Z., Clayton, T.D., Swarzenski, P., Brock, J.C., \& Muller-Karger, F.E. (2004). Assessment of estuarine water-quality indicators using MODIS medium-resolution bands: Initial results from Tampa Bay, FL. Remote Sensing of Environment, 93, 423-441

Hu, C., Feng, L., \& Lee, Z. (2012). Evaluation of GOCI sensitivity for at-sensor radiance and GDPS-retrieved chlorophyll-a products. Ocean Science Journal, 47, 279-285

Hu, C.M., Carder, K.L., \& Muller-Karger, F.E. (2000). Atmospheric correction of SeaWiFS imagery over turbid coastal waters: A practical method. Remote Sensing of Environment, 74, 195-206

Huang, S. (1992). Management of Chinese Estuaries. Beijing: China Ocean Press, 156pp (in Chinese)

Huot, J.P., Tait, H., Rast, M., Delwart, S., Bezy, J.L., \& Levrini, G. (2001). The optical imaging instruments and their applications: AATSR and MERIS. Esa Bulletin-European Space Agency, 56-66

IOCCG (2000). Remote Sensing of Ocean Colour in Coastal, and Other Optically-Complex, Waters. Sathyendranath, S. (ed.), Reports of the International Ocean-Colour Coordinating Group, No.3, IOCCG, Dartmouth, Canada

IOCCG (2006). Remote Sensing of Inherent Optical Properties: Fundamentals, Tests of Algorithms, and Applications. Lee, Z. P. (ed.), Reports of the International Ocean-Colour Coordinating Group, No. 5 
Jamet, C., Loisel, H., \& Dessailly, D. (2012). Retrieval of the spectral diffuse attenuation coefficient $\mathrm{K}_{\mathrm{d}}(\lambda)$ in open and coastal ocean waters using a neural network inversion. Journal of Geophysical Research, 117

Joshi, I.D., D'Sa, E.J., Osburn, C.L., Bianchi, T.S., Ko, D.S., Oviedo-Vargas, D., Arellano, A.R., \& Ward, N.D. (2017). Assessing chromophoric dissolved organic matter (CDOM) distribution, stocks, and fluxes in Apalachicola Bay using combined field, VIIRS ocean color, and model observations. Remote Sensing of Environment, 191, 359-372

Keith, D.J., Yoder, J.A., \& Freeman, S.A. (2002). Spatial and temporal distribution of coloured dissolved organic matter (CDOM) in Narragansett Bay, Rhode Island: Implications for phytoplankton in coastal waters. Estuarine, Coastal and Shelf Science, 55, 705-717

Kirk, J.T. (1994). Light and photosynthesis in aquatic ecosystems. Cambridge university press

Kirk, J.T.O. (1984). Dependence of Relationship between Inherent and Apparent Optical-Properties of Water on Solar Altitude. Limnology and Oceanography, $29,350-356$

Kirk, J.T.O. (1991). Volume Scattering Function, Average Cosines, and the Underwater Light-Field. Limnology and Oceanography, 36, 455-467

Knaeps, E., Dogliotti, A., Raymaekers, D., Ruddick, K., \& Sterckx, S.J.R.S.o.E. (2012). In situ evidence of non-zero reflectance in the OLCI $1020 \mathrm{~nm}$ band for a turbid estuary, 120, 133-144

Knaeps, E., Doxaran, D., Dogliotti, A., Nechad, B., Ruddick, K., Raymaekers, D., \& Sterckx, S. (2018). The SeaSWIR dataset. Earth System Science Data, 10, 1439-1449

Knaeps, E., Ruddick, K., Doxaran, D., Dogliotti, A., Nechad, B., Raymaekers, D., \& Sterckx, S. (2015). A SWIR based algorithm to retrieve total suspended matter in extremely turbid waters. Remote Sensing of Environment, 168, 6679

Kubelka, P., \& Munk, F. (1931). A contribution to the optics of pigments. Z. Tech. Phys, 12, 593-599

Kuchinke, C.P., Gordon, H.R., \& Franz, B.A. (2009). Spectral optimization for constituent retrieval in Case 2 waters I: Implementation and performance. Remote Sensing of Environment, 113, 571-587

Kuliński, K., \& Pempkowiak, J. (2008). Dissolved organic carbon in the southern Baltic Sea: Quantification of factors affecting its distribution. Estuarine, Coastal and Shelf Science, 78, 38-44 
Lagerloef, G.S., Swift, C.T., \& Le Vine, D.M. (1995). Sea surface salinity: The next remote sensing challenge. National Aeronautics and Space Administration

Laws, E.A. (1997). Mathematical methods for oceanographers: An introduction. John Wiley \& Sons

Le, C.F., Hu, C.M., Cannizzaro, J., English, D., Muller-Karger, F., \& Lee, Z. (2013). Evaluation of chlorophyll-a remote sensing algorithms for an optically complex estuary. Remote Sensing of Environment, 129, 75-89

Le, C.F., Li, Y.M., Zha, Y., Sun, D.Y., Huang, C.C., \& Lu, H. (2009). A fourband semi-analytical model for estimating chlorophyll a in highly turbid lakes: The case of Taihu Lake, China. Remote Sensing of Environment, 113, $1175-1182$

Lee, Z., Carder, K.L., Mobley, C.D., Steward, R.G., \& Patch, J.S. (1998). Hyperspectral remote sensing for shallow waters. I. A semianalytical model. Applied Optics, 37, 6329--6338

Lee, Z., Carder, K.L., Mobley, C.D., Steward, R.G., \& Patch, J.S. (1999). Hyperspectral remote sensing for shallow waters. 2. Deriving bottom depths and water properties by optimization. Applied Optics, 38, 3831--3843

Lee, Z., Hu, C., Shang, S., Du, K., Lewis, M., Arnone, R., \& Brewin, R. (2013). Penetration of UV-visible solar radiation in the global oceans: Insights from ocean color remote sensing. Journal of Geophysical Research: Oceans, 118, 4241-4255

Lee, Z., Lance, V.P., Shang, S.L., Vaillancourt, R., Freeman, S., Lubac, B., Hargreaves, B.R., Del Castillo, C., Miller, R., Twardowski, M., \& Wei, G.M. (2011). An assessment of optical properties and primary production derived from remote sensing in the Southern Ocean (SO GasEx). Journal of Geophysical Research-Oceans, 116

Lee, Z., Shang, S., Lin, G., Chen, J., \& Doxaran, D. (2016). On the modeling of hyperspectral remote-sensing reflectance of high-sediment-load waters in the visible to shortwave-infrared domain. Applied Optics, 55, 1738-1750

Lee, Z., Weidemann, A., Kindle, J., Arnone, R., Carder, K.L., \& Davis, C. (2007). Euphotic zone depth: Its derivation and implication to ocean-color remote sensing. Journal of Geophysical Research-Oceans, 112, C03009

Lee, Z.P., Carder, K.L., \& Arnone, R.A. (2002). Deriving inherent optical properties from water color: a multiband quasi-analytical algorithm for optically deep waters. Applied Optics, 41, 5755--5772

Lee, Z.P., Darecki, M., Carder, K.L., Davis, C.O., Stramski, D., \& Rhea, W.J. (2005a). Diffuse attenuation coefficient of downwelling irradiance: An 
Bibliography

evaluation of remote sensing methods. Journal of Geophysical ResearchOceans, 110

Lee, Z.P., Du, K.P., \& Arnone, R. (2005b). A model for the diffuse attenuation coefficient of downwelling irradiance. Journal of Geophysical ResearchOceans, 110

Lee, Z.P., Lubac, B., Werdell, J., \& Arnone, R. (2009). An update of the quasianalytical algorithm (QAA_v5). International Ocean Color Group Software Report

Lei, H., Pan, D.L., Bai, Y., Tao, B.Y., Sun, J., Zhang, L., \& Zhang, X. (2012). The proportions and variations of the light absorption coefficients of major ocean color components in the East China Sea. ACTA Oceanologica Sinica, $31,45-61$

Liu, H., He, Q., Wang, Z., Weltje, G.J., \& Zhang, J. (2010). Dynamics and spatial variability of near-bottom sediment exchange in the Yangtze Estuary, China. Estuarine, Coastal and Shelf Science, 86, 322-330

Liu, J., Xu, K., Li, A.e.a., Milliman, J., Velozzi, D., Xiao, S., \& Yang, Z. (2007). Flux and fate of Yangtze River sediment delivered to the East China Sea. Geomorphology, 85, 208-224

Liu, Q., Pan, D., Bai, Y., Wu, K., Chen, C.-T.A., Sun, J., \& Zhang, L. (2013). The satellite reversion of dissolved organic carbon (DOC) based on the analysis of the mixing behavior of DOC and colored dissolved organic matter: the East China Sea as an example. ACTA Oceanologica Sinica, 32, 1-11

Liu, Q., Pan, D.L., Bai, Y., Wu, K., Chen, C.T.A., Liu, Z.L., \& Zhang, L. (2014). Estimating dissolved organic carbon inventories in the East China Sea using remote-sensing data. Journal of Geophysical Research-Oceans, 119, 65576574

Loisel, H., Vantrepotte, V., Dessailly, D., \& Meriaux, X. (2014). Assessment of the colored dissolved organic matter in coastal waters from ocean color remote sensing. Optics Express, 22, 13109-13124

Loiselle, S.A., Bracchini, L., Cozar, A., Dattilo, A.M., Tognazzi, A., \& Rossi, C. (2009). Variability in photobleaching yields and their related impacts on optical conditions in subtropical lakes. Journal of Photochemistry and Photobiology B: Biology, 95, 129-137

Longhurst, A.R., \& Harrison, W.G. (1989). The Biological Pump - Profiles of Plankton Production and Consumption in the Upper Ocean. Progress in Oceanography, 22, 47-123

Luo, Y., Doxaran, D., Ruddick, K., Shen, F., Gentili, B., Yan, L., \& Huang, H. (2018). Saturation of water reflectance in extremely turbid media based on 
field measurements, satellite data and bio-optical modelling. Optics Express, 26, 10435-10451

Majozi, N.P., Salama, M.S., Bernard, S., Harper, D.M., \& Habte, M.G. (2014). Remote sensing of euphotic depth in shallow tropical inland waters of Lake Naivasha using MERIS data. Remote Sensing of Environment, 148, 178-189

Mannino, A., Russ, M.E., \& Hooker, S.B. (2008). Algorithm development and validation for satellite-derived distributions of DOC and CDOM in the US Middle Atlantic Bight. Journal of Geophysical Research-Oceans, 113, C07051

Mao, Z., Chen, J., Pan, D., Tao, B., \& Zhu, Q. (2012). A regional remote sensing algorithm for total suspended matter in the East China Sea. Remote Sensing of Environment, 124, 819-831

Maritorena, S., Siegel, D.A., \& Peterson, A.R. (2002). Optimization of a semianalytical ocean color model for global-scale applications. Applied Optics, 41, 2705--2714

Matsuoka, A., Bricaud, A., Benner, R., Para, J., Sempere, R., Prieur, L., Belanger, S., \& Babin, M. (2012a). Tracing the transport of colored dissolved organic matter in water masses of the Southern Beaufort Sea: relationship with hydrographic characteristics. Biogeosciences, 9, 925-940

Matsuoka, A., Hooker, S.B., Bricaud, A., Gentili, B., \& Babin, M. (2012b). Estimating absorption coefficients of colored dissolved organic matter (CDOM) using a semi-analytical algorithm for Southern Beaufort Sea (Canadian Arctic) waters: application to deriving concentrations of dissolved organic carbon from space. Biogeosciences Discussions, 9, 13743--13771

McClain, C.R., Arrigo, K., Tai, K.S., \& Turk, D. (1996). Observations and simulations of physical and biological processes at ocean weather station $\mathrm{P}$, 1951-1980. Journal of Geophysical Research: Oceans (1978-2012), 101, 3697-3713

Mikkelsen, O.A. (2002). Variation in the projected surface area of suspended particles: Implications for remote sensing assessment of TSM. Remote Sensing of Environment, 79, 23-29

Mitchell, C., Cunningham, A., \& McKee, D. (2014). Remote sensing of shelf sea optical properties: Evaluation of a quasi-analytical approach for the Irish Sea. Remote Sensing of Environment, 143, 142-153

Mobley, C.D. (1994). Light and water: radiative transfer in natural waters. Academic press

Mobley, C.D. (1999). Estimation of the remote-sensing reflectance from abovesurface measurements. Applied Optics, 38, 7442-7455 
Morel, A. (1974). Optical properties of pure water and pure sea water. Optical aspects of Oceanography, 1-24

Morel, A., \& Loisel, H. (1998). Apparent optical properties of oceanic water: dependence on the molecular scattering contribution. Applied Optics, 37, 4765-4776

Morel, A., \& Prieur, L. (1977). Analysis of Variations in Ocean Color. Limnology and Oceanography, 22, 709-722

Morel, A.E. (1980). In-water and remote measurements of ocean color. Boundary-Layer Meteorology, 18, 177--201

Mueller, J.L. (2000). SeaWiFS algorithm for the diffuse attenuation coefficient, K (490), using water-leaving radiances at 490 and $555 \mathrm{~nm}$. SeaWiFS postlaunch calibration and validation analyses, part (p. 24)

Mueller, L.J., \& Fargion, S.G. (2002). Ocean Optics Protocols for Satellite Ocean Color Sensor Validation. NASA/TM

Nechad, B., Ruddick, K., \& Park, Y. (2010). Calibration and validation of a generic multisensor algorithm for mapping of total suspended matter in turbid waters. Remote Sensing of Environment, 114, 854-866

Neil, C., Cunningham, A., \& McKee, D. (2011). Relationships between suspended mineral concentrations and red-waveband reflectances in moderately turbid shelf seas. Remote Sensing of Environment, 115, 37193730

Neukermans, G., Loisel, H., Mériaux, X., Astoreca, R., \& McKee, D. (2012). In situ variability of mass-specific beam attenuation and backscattering of marine particles with respect to particle size, density, and composition. Limnology and Oceanography, 57, 124-144

Nieke, B., Reuter, R., Heuermann, R., Wang, H., Babin, M., \& Therriault, J.C. (1997). Light absorption and fluorescence properties of chromophoric dissolved organic matter (CDOM), in the St Lawrence Estuary (Case 2 waters). Continental Shelf Research, 17, 235-252

Nordkvist, K., Loisel, H., \& Gaurier, L.D. (2009). Cloud masking of SeaWiFS images over coastal waters using spectral variability. Optics Express, 17, 12246-12258

O'Reilly, J.E., Maritorena, S., Mitchell, B.G., Siegel, D.A., Carder, K.L., Garver, S.A., Kahru, M., \& McClain, C. (1998). Ocean color chlorophyll algorithms for SeaWiFS. Journal of Geophysical Research-Oceans, 103, 24937-24953

Pan, D., Liu, Q., \& Bai, Y. (2012). Progress in remote sensing of DOC: based on the analysis of conservative behaviors of DOC and CDOM in global rivers estuaries. ACTA Oceanologica Sinica, 34, 1-11 
Pan, Y., Shen, F., \& Verhoef, W. (2017). An improved spectral optimization algorithm for atmospheric correction over turbid coastal waters: A case study from the Changjiang (Yangtze) estuary and the adjacent coast. Remote Sensing of Environment, 191, 197-214

Pegau, W.S., Gray, D., \& Zaneveld, J.R.V. (1997). Absorption and attenuation of visible and near-infrared light in water: dependence on temperature and salinity. Applied Optics, 36, 6035-6046

Petzold, T.J. (1972). Volume scattering functions for selected ocean waters. In: DTIC Document

Pope, R.M., \& Fry, E.S. (1997). Absorption spectrum (380 -700 nm)of pure water. II. Integrating cavity measurements. Applied Optics, 36, 8710-8723

Qiu, Z., Wu, T., \& Su, Y. (2013). Retrieval of diffuse attenuation coefficient in the China seas from surface reflectance. Optics Express, 21, 15287-15297

Redalje, D.G., \& Fahnenstiel, G.L. (1994). The relationship between primary production and the vertical export of particulate organic matter in a riverimpacted coastal ecosystem. Estuaries and Coasts, 17, 829-838

Retamal, L., Vincent, W.F., Martineau, C., \& Osburn, C.L. (2007). Comparison of the optical properties of dissolved organic matter in two river-influenced coastal regions of the Canadian Arctic. Estuarine Coastal and Shelf Science, $72,261-272$

Rochelle-Newall, E., Hulot, F.D., Janeau, J.L., \& Merroune, A. (2014). CDOM fluorescence as a proxy of DOC concentration in natural waters: a comparison of four contrasting tropical systems. Environmental Monitoring and Assessment, 186, 589-596

Rochelle-Newall, E.J., \& Fisher, T.R. (2002). Chromophoric dissolved organic matter and dissolved organic carbon in Chesapeake Bay. Marine Chemistry, 77, 23-41

Röttgers, R., \& Gehnke, S. (2011). Measurement of light absorption by aquatic particles: improvement of the quantitative filter technique by use of an integrating sphere approach. Applied Optics, 51, 1336-1351

Röttgers, R., McKee, D., \& Woźniak, S.B. (2013). Evaluation of scatter corrections for ac-9 absorption measurements in coastal waters. Methods in Oceanography, 7, 21-39

Ruddick, K.G., De Cauwer, V., Park, Y.-J., \& Moore, G. (2006). Seaborne measurements of near infrared water-leaving reflectance: The similarity spectrum for turbid waters. Limnology and Oceanography, 51, 1167-1179 
Ruddick, K.G., Ovidio, F., \& Rijkeboer, M. (2000). Atmospheric correction of SeaWiFS imagery for turbid coastal and inland waters. Applied Optics, 39, 897-912

Ryu, J.H., Han, H.J., Cho, S., Park, Y.J., \& Ahn, Y.H. (2012). Overview of Geostationary Ocean Color Imager (GOCI) and GOCI Data Processing System (GDPS). Ocean Science Journal, 47, 223-233

Salama, M.S., Dekker, A., Su, Z., Mannaerts, C.M., \& Verhoef, W. (2009). Deriving inherent optical properties and associated inversion-uncertainties in the Dutch Lakes. Hydrology and Earth System Sciences, 13, 1113-1121

Salama, M.S., Melin, F., \& Van der Velde, R. (2011). Ensemble uncertainty of inherent optical properties. Optics Express, 19, 16772-16783

Salama, M.S., Monbaliu, J., \& Coppin, P. (2004). Atmospheric correction of Advanced Very High Resolution Radiometer imagery. International Journal of Remote Sensing, 25, 1349-1355

Salama, M.S., \& Shen, F. (2010a). Simultaneous atmospheric correction and quantification of suspended particulate matters from orbital and geostationary earth observation sensors. Estuarine Coastal and Shelf Science, $86,499-511$

Salama, M.S., \& Shen, F. (2010b). Stochastic inversion of ocean color data using the cross-entropy method. Optics Express, 18, 479-499

Salama, M.S., \& Stein, A. (2009). Error decomposition and estimation of inherent optical properties. Applied Optics, 48, 4947-4962

Salama, M.S., Van der Velde, R., van der Woerd, H.J., Kromkamp, J.C., Philippart, C.J.M., Joseph, A.T., O'Neill, P.E., Lang, R.H., Gish, T., Werdell, P.J., \& Su, Z. (2012). Technical Note: Calibration and validation of geophysical observation models. Biogeosciences, 9, 2195-2201

Salama, M.S., \& Verhoef, W. (2015). Two-stream remote sensing model for water quality mapping: 2SeaColor. Remote Sensing of Environment, 157, 111-122

Salinas, S.V., Chang, C.W., \& Liew, S.C. (2007). Multiparameter retrieval of water optical properties from above-water remote-sensing reflectance using the simulated annealing algorithm. Applied Optics, 46, 2727-2742

Sathyendranath, S., Cota, G., Stuart, V., Maass, H., \& Platt, T. (2001). Remote sensing of phytoplankton pigments: a comparison of empirical and theoretical approaches. International Journal of Remote Sensing, 22, 249-273

Sathyendranath, S., Platt, T., Caverhill, C.M., Warnock, R.E., \& Lewis, M.R. (1989). Remote-Sensing of Oceanic Primary Production - Computations 
Using a Spectral Model. Deep-Sea Research Part A-Oceanographic Research Papers, 36, 431-453

Schiller, H., \& Doerffer, R. (1999). Neural network for emulation of an inverse model operational derivation of Case II water properties from MERIS data. International Journal of Remote Sensing, 20, 1735-1746

Schroeder, T., Behnert, I., Schaale, M., Fischer, J., \& Doerffer, R. (2007). Atmospheric correction algorithm for MERIS above case-2 waters. International Journal of Remote Sensing, 28, 1469-1486

Shen, F., Salama, M.S., Zhou, Y.X., Li, J.F., Su, Z.B., \& Kuang, D.B. (2010a). Remote-sensing reflectance characteristics of highly turbid estuarine waters - a comparative experiment of the Yangtze River and the Yellow River. International Journal of Remote Sensing, 31, 2639-2654

Shen, F., \& Verhoef, W. (2010). Suppression of local haze variations in MERIS images over turbid coastal waters for retrieval of suspended sediment concentration. Optics Express, 18, 12653-12662

Shen, F., Verhoef, W., Zhou, Y.X., Salama, M.S., \& Liu, X.L. (2010b). Satellite Estimates of Wide-Range Suspended Sediment Concentrations in Changjiang (Yangtze) Estuary Using MERIS Data. Estuaries and Coasts, 33, 1420-1429

Shen, F., Zhou, Y.X., Li, D.J., Zhu, W.J., \& Salama, M.S. (2010c). Medium resolution imaging spectrometer (MERIS) estimation of chlorophyll-a concentration in the turbid sediment-laden waters of the Changjiang (Yangtze) Estuary. International Journal of Remote Sensing, 31, 4635-4650

Shen, F., Zhou, Y.X., Li, J.F., He, Q., \& Verhoef, W. (2013). Remotely sensed variability of the suspended sediment concentration and its response to decreased river discharge in the Yangtze estuary and adjacent coast. Continental Shelf Research, 69, 52-61

Shen, F., Zhou, Y.X., Peng, X.Y., \& Chen, Y.L. (2014). Satellite multi-sensor mapping of suspended particulate matter in turbid estuarine and coastal ocean, China. International Journal of Remote Sensing, 35, 4173-4192

Shi, J.Z. (2010). Tidal resuspension and transport processes of fine sediment within the river plume in the partially-mixed Changjiang River estuary, China: a personal perspective. Geomorphology, 121, 133-151

Shi, W., \& Wang, M. (2010). Satellite observations of the seasonal sediment plume in central East China Sea. Journal of Marine Systems, 82, 280-285

Shi, W., Wang, M.H., \& Jiang, L.D. (2011). Spring-neap tidal effects on satellite ocean color observations in the Bohai Sea, Yellow Sea, and East China Sea. Journal of Geophysical Research-Oceans, 116 
Siegel, D.A., Wang, M., Maritorena, S., \& Robinson, W. (2000). Atmospheric correction of satellite ocean color imagery: the black pixel assumption. Applied Optics, 39, 3582-3591

Siswanto, E., Tang, J.W., Yamaguchi, H., Ahn, Y.H., Ishizaka, J., Yoo, S., Kim, S.W., Kiyomoto, Y., Yamada, K., Chiang, C., \& Kawamura, H. (2011). Empirical ocean-color algorithms to retrieve chlorophyll-a, total suspended matter, and colored dissolved organic matter absorption coefficient in the Yellow and East China Seas. Journal of Oceanography, 67, 627-650

Smith, R.C., \& Baker, K.S. (1978). Optical classification of natural waters. Limnology and Oceanography, 23, 260-267

Smith, R.C., \& Baker, K.S. (1981). Optical properties of the clearest natural waters (200-800 nm). Applied Optics, 20, 177-184

Sokoletsky, L., Yang, X., \& Shen, F. (2014). MODIS-based retrieval of suspended sediment concentration and diffuse attenuation coefficient in Chinese estuarine and coastal waters. In, SPIE Asia Pacific Remote Sensing (pp. 926119-926119-926125): International Society for Optics and Photonics

Sokoletsky, L.G., \& Shen, F. (2014). Optical closure for remote-sensing reflectance based on accurate radiative transfer approximations: the case of the Changjiang (Yangtze) River Estuary and its adjacent coastal area, China. International Journal of Remote Sensing, 35, 4193-4224

Spencer, R.G.M., Ahad, J.M.E., Baker, A., Cowie, G.L., Ganeshram, R., UpstillGoddard, R.C., \& Uher, G. (2007). The estuarine mixing behaviour of peatland derived dissolved organic carbon and its relationship to chromophoric dissolved organic matter in two North Sea estuaries (UK). Estuarine Coastal and Shelf Science, 74, 131-144

Spencer, R.G.M., Aiken, G.R., Butler, K.D., Dornblaser, M.M., Striegl, R.G., \& Hernes, P.J. (2009a). Utilizing chromophoric dissolved organic matter measurements to derive export and reactivity of dissolved organic carbon exported to the Arctic Ocean: A case study of the Yukon River, Alaska. Geophysical Research Letters, 36, L06401

Spencer, R.G.M., Stubbins, A., Hernes, P.J., Baker, A., Mopper, K., Aufdenkampe, A.K., Dyda, R.Y., Mwamba, V.L., Mangangu, A.M., Wabakanghanzi, J.N., \& Six, J. (2009b). Photochemical degradation of dissolved organic matter and dissolved lignin phenols from the Congo River. Journal of Geophysical Research-Biogeosciences, 114, G03010

Spitzy, A., \& Ittekkot, V. (1986). Gelbstoff: an uncharacterized fraction of dissolved organic carbon. The Influence of Yellow Substances on Remote Sensing of Sea-Water Constituent From Space 
Stramska, M., \& Zuzewicz, A. (2013). Influence of the parametrization of water optical properties on the modelled sea surface temperature in the Baltic Sea. Oceanologia, 55, 53-76

Stumpf, R., Arnone, R., Gould, R., Martinolich, P., \& Ransibrahmanakul, V. (2003). A partially coupled ocean-atmosphere model for retrieval of waterleaving radiance from SeaWiFS in coastal waters. NASA Tech. Memo, 206892, 51-59

Su, Z., Roebeling, R.A., Schulz, J., Holleman, I., Levizzani, V., Timmermans, W.J., Rott, H., Mognard-Campbell, N., de Jeu, R., Wagner, W., Rodell, M., Salama, M.S., Parodi, G.N. and Wang, L. (2011) Observation of hydrological processes using remote sensing. In: Treatise on water science/ed. by P. Wilderer. - : Elsevier, 2011. ISBN 978-0-444-53199-5. pp. 351-399

Sun, D.Y., Qiu, Z.F., Li, Y.M., Shi, K., Huang, C.C., \& Gong, S.Q. (2014a). New strategy to improve estimation of diffuse attenuation coefficient for highly turbid inland waters. International Journal of Remote Sensing, 35, 3350-3371

Sun, Q., Wang, C., Wang, P., Hou, J., \& Ao, Y. (2014b). Absorption and fluorescence characteristics of chromophoric dissolved organic matter in the Yangtze Estuary. Environmental Science and Pollution Research, 21, 34603473

Sutherland, T., Lane, P., Amos, C., \& Downing, J. (2000). The calibration of optical backscatter sensors for suspended sediment of varying darkness levels. Marine Geology, 162, 587-597

Verhoef, W., \& Bach, H. (2003). Simulation of hyperspectral and directional radiance images using coupled biophysical and atmospheric radiative transfer models. Remote Sensing of Environment, 87, 23-41

Vodacek, A., Blough, N.V., DeGrandpre, M.D., Peltzer, E.T., \& Nelson, R.K. (1997). Seasonal variation of CDOM and DOC in the Middle Atlantic Bight: Terrestrial inputs and photooxidation. Limnology and Oceanography, 42, 674-686

Volpe, V., Silvestri, S., \& Marani, M. (2011). Remote sensing retrieval of suspended sediment concentration in shallow waters. Remote Sensing of Environment, 115, 44-54

Wang, M. (2007). Remote sensing of the ocean contributions from ultraviolet to near-infrared using the shortwave infrared bands: simulations. Applied Optics, 46, 1535-1547

Wang, M., \& Shi, W. (2007). The NIR-SWIR combined atmospheric correction approach for MODIS ocean color data processing. Optics Express, 15, 15722-15733 
Wang, M.H., \& Shi, W. (2005). Estimation of ocean contribution at the MODIS near-infrared wavelengths along the east coast of the US: Two case studies. Geophysical Research Letters, 32, L13606

Wang, M.H., \& Shi, W. (2006). Cloud masking for ocean color data processing in the coastal regions. Ieee Transactions on Geoscience and Remote Sensing, 44, 3196-3205

Wang, M.H., Shi, W., \& Jiang, L.D. (2012). Atmospheric correction using nearinfrared bands for satellite ocean color data processing in the turbid western Pacific region. Optics Express, 20, 741-753

Wang, M.H., Son, S., \& Harding, L.W. (2009a). Retrieval of diffuse attenuation coefficient in the Chesapeake Bay and turbid ocean regions for satellite ocean color applications. Journal of Geophysical Research-Oceans, 114

Wang, M.H., Son, S., \& Shi, W. (2009b). Evaluation of MODIS SWIR and NIRSWIR atmospheric correction algorithms using SeaBASS data. Remote Sensing of Environment, 113, 635-644

Wang, M.H., Tang, J.W., \& Shi, W. (2007). MODIS-derived ocean color products along the China east coastal region. Geophysical Research Letters, 34

Wang, Y., Shen, F., Sokoletsky, L., \& Sun, X. (2017). Validation and Calibration of QAA Algorithm for CDOM Absorption Retrieval in the Changjiang (Yangtze) Estuarine and Coastal Waters. Remote Sensing, 9, 1192

Ward, N.D., Krusche, A.V., Sawakuchi, H.O., Brito, D.C., Cunha, A.C., Moura, J.M.S., da Silva, R., Yager, P.L., Keil, R.G., \& Richey, J.E. (2015). The compositional evolution of dissolved and particulate organic matter along the lower Amazon River - Óbidos to the ocean. Marine Chemistry, 177, 244-256

Warnock, R.E., Gieskes, W.W.C., \& van Laar, S. (1999). Regional and seasonal differences in light absorption by yellow substance in the Southern Bight of the North Sea. Journal of Sea Research, 42, 169-178

Werdell, P.J., \& Bailey, S.W. (2005). An improved in-situ bio-optical data set for ocean color algorithm development and satellite data product validation. Remote Sensing of Environment, 98, 122-140

Werdell, P.J., Franz, B.A., Bailey, S.W., Feldman, G.C., Boss, E., Brando, V.E., Dowell, M., Hirata, T., Lavender, S.J., \& Lee, Z. (2013). Generalized ocean color inversion model for retrieving marine inherent optical properties. Applied Optics, 52, 2019-2037

Woźniak, S.B., Stramski, D., Stramska, M., Reynolds, R.A., Wright, V.M., Miksic, E.Y., Cichocka, M., \& Cieplak, A.M. (2010). Optical variability of seawater in relation to particle concentration, composition, and size 
distribution in the nearshore marine environment at Imperial Beach, California. Journal of Geophysical Research: Oceans, 115

Wu, Y., Tang, C.C.L., Sathyendranath, S., \& Platt, T. (2007). The impact of biooptical heating on the properties of the upper ocean: A sensitivity study using a 3-D circulation model for the Labrador Sea. Deep Sea Research Part II: Topical Studies in Oceanography, 54, 2630-2642

Xie, H.X., Aubry, C., Belanger, S., \& Song, G.S. (2012). The dynamics of absorption coefficients of CDOM and particles in the St. Lawrence estuarine system: Biogeochemical and physical implications. Marine Chemistry, 128, 44-56

Yang, S., Zhang, J., \& Zhu, J. (2004). Response of suspended sediment concentration to tidal dynamics at a site inside the mouth of an inlet: Jiaozhou Bay (China). Hydrology and Earth System Sciences Discussions, 8, 170-182

Yang, W., Matsushita, B., Chen, J., Yoshimura, K., \& Fukushima, T. (2013). Retrieval of Inherent Optical Properties for Turbid Inland Waters From Remote-Sensing Reflectance. Ieee Transactions on Geoscience and Remote Sensing, 51, 3761-3773

Yu, X., Salama, M.S., Shen, F., \& Verhoef, W. (2016). Retrieval of the diffuse attenuation coefficient from GOCI images using the 2SeaColor model: A case study in the Yangtze Estuary. Remote Sensing of Environment, 175, 109119

Zhang, E., Chen, S., Gu, G., Yang, H., \& Wang, R. (2015). Temporal and spatial variations in suspended sediment concentration and transport in the North Branch of the Yangtze estuary. Acta Oceanologica Sinica (Chinese version), $37,138-151$

Zhang, M., Tang, J., Dong, Q., Song, Q., \& Ding, J. (2010). Retrieval of total suspended matter concentration in the Yellow and East China Seas from MODIS imagery. Remote Sensing of Environment, 114, 392-403

Zhang, T., \& Fell, F. (2007). An empirical algorithm for determining the diffuse attenuation coefficient K-d in clear and turbid waters from spectral remote sensing reflectance. Limnology and Oceanography-Methods, 5, 457-462

Zhang, X.Y., Chen, X., Deng, H., Du, Y., \& Jin, H.Y. (2013). Absorption features of chromophoric dissolved organic matter (CDOM) and tracing implication for dissolved organic carbon (DOC) in Changjiang Estuary, China. Biogeosciences Discussions, 10, 12217--12250

Zhang, Y.L., Qin, B.Q., Zhu, G.W., Gao, G., Luo, L.C., \& Chen, W.M. (2006). Effect of sediment resuspension on underwater light field in shallow lakes in the middle and lower reaches of the Yangtze River: A case study in Longgan 
Lake and Taihu Lake. Science in China Series D-Earth Sciences, 49, 114125

Zhao, Y., \& Song, K. (2018). Relationships between DOC and CDOM based on the total carbon-specific fluorescence intensities for river waters across China. Journal of Geophysical Research: Biogeosciences

Zibordi, G., Mélin, F., Berthon, J.-F., Holben, B., Slutsker, I., Giles, D., D'Alimonte, D., Vandemark, D., Feng, H., \& Schuster, G. (2009). AERONET-OC: a network for the validation of ocean color primary products. Journal of Atmospheric and Oceanic Technology, 26, 1634-1651 


\section{Biography}

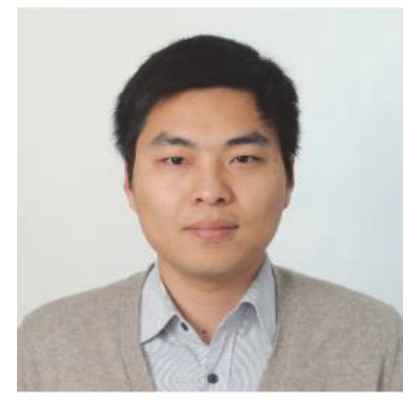

Xiaolong Yu (余小龙, in Chinese), was born on Jan 2, 1990, in Lu'an, Anhui, China. He received his BSc degree of Engineering at the School of Ocean and Earth Science, Tongji University in 2010. He was granted an MSc degree of Science at the State Key Laboratory of Estuarine and Coastal Research (SKLEC), East China Normal University in 2013. He started as Ph.D. candidate in September 2013 at the Faculty of Geo-Information Science and Earth Observation (ITC), University of Twente. His research focused on retrieving water optical properties in turbid coastal water from remote sensing based on radiative transfer approaches.

\section{Peer-reviewed journal papers:}

Yu, X., Salama, M.S., Shen, F., \& Verhoef, W. (2016). Retrieval of the diffuse attenuation coefficient from GOCI images using the 2SeaColor model: A case study in the Yangtze Estuary. Remote Sensing of Environment, 175, 109-119

Yu, X., Shen, F., \& Liu, Y. (2016). Light absorption properties of CDOM in the Changjiang (Yangtze) estuarine and coastal waters: An alternative approach for DOC estimation. Estuarine, Coastal and Shelf Science, 181, 302-311

Yu, X., Salama, M.S., Shen, F., \& Verhoef, W. Retrieval of wide-range suspended particulate matter concentration from remotely sensed particulate backscattering coefficients in the Yangtze estuary. Submitted to Remote Sensing of Environment.

\section{Conference papers:}

Yu, X., Salama, S., Shen, F., Doxaran, D., \& Zhou, Y. (2016). Multi-Mission Remote Sensing of Suspended Particulate Matter and Diffuse Attenuation Coefficient in the Yangtze Estuarine and Coastal Waters. In, Dragon 3 Final Results and Dragon 4 Kick-Off (p. 32)

Doxaran, D., Salama, S., Yu, X., Shen, F., \& Zhou, Y. (2014). Variations of Estuarine Turbid Plumes and Mudflats in Response to Human Activities and Climate Change. In, Dragon 3Mid Term Results (p. 40) 